Supplement of Geosci. Model Dev., 10, 2169-2199, 2017

https://doi.org/10.5194/gmd-10-2169-2017-supplement

(C) Author(s) 2017. This work is distributed under

the Creative Commons Attribution 3.0 License.

(c) (1)

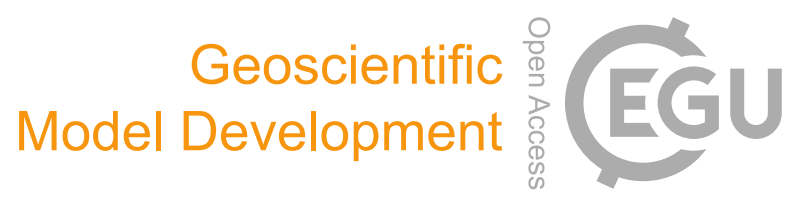

Supplement of

\title{
Biogeochemical protocols and diagnostics for the CMIP6 Ocean Model Intercomparison Project (OMIP)
}

James C. Orr et al.

Correspondence to: James C. Orr (james.orr@1sce.ipsl.fr)

The copyright of individual parts of the supplement might differ from the CC BY 3.0 License. 


\section{CFC HOWTO}

J. Orr, J.-Cl. Dutay, R. Najjar, J. Bullister, and P. Brockmann

Revision : 1.6, Date : 1999/04/2922: $31: 29$

So you want to simulate CFC-11 and CFC-12 in your ocean model according to standard OCMIP-2 protocols? This document provides step-by-step information to do just that.

\section{Contents}

1 Recuperation of OCMIP-2 files by ftp: 2

2 Model runs 2

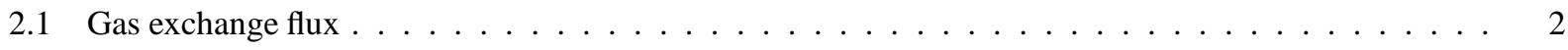

2.2 The Piston Velocity $\mathrm{Kw} \ldots \ldots \ldots \ldots \ldots \ldots$

2.3 Oceanic and Atmospheric Components . . . . . . . . . . . . . . . . . . . . 4

3 Duration of simulation $\quad 5$

4 Output type and frequency $\quad 5$

5 Output Format $\quad 6$

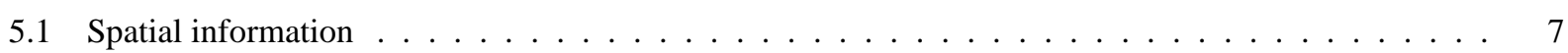

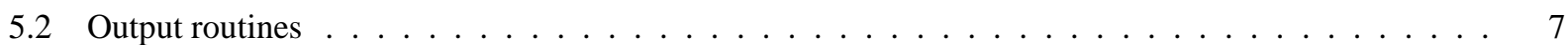

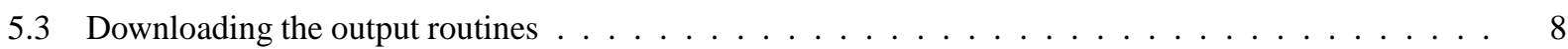

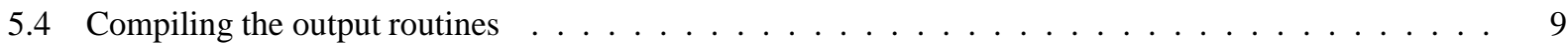

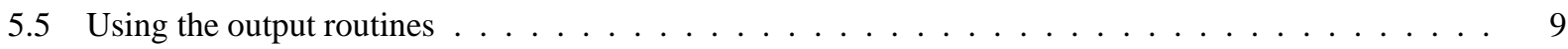

5.6 Need more details? . . . . . . . . . . . . . . . . . . . . . . . . . . . . 10

$\begin{array}{llr}6 & \text { Transfer of output } & 10\end{array}$

7 Who has submitted what? 11

8 References $\quad 11$

9 Contacts $\quad 11$

10 Same document, another format? 


\section{Recuperation of OCMIP-2 files by ftp:}

To comply with OCMIP-2 guidelines, all modelers must make simulations according to OCMIP-2 standard boundary conditions. To do so, one must first recuperate the following files via this Web page (you can save a file to disk by clicking a link while holding down the Shift key).

- rgasx_ocmip2.f

- gasx_ocmip2.nc.gz

- vgasx_ocmip2.jnl

- read_cfcatm.f

- cfc_interp.f

- $\operatorname{cfc} 1112 . \mathrm{atm}$

- $s c \_c f c . f$

- sol_cfc.f

After transferring the file gasx_ocmip2 . nc.gz (binary mode), one must then uncompress it:

gunzip gasx_ocmip2.nc

Other files are text and need no special treatment after transfer. Use of these files is described below.

\section{Model runs}

\subsection{Gas exchange flux}

For simulations of CFC-11 and CFC-12, we will directly model the finite air-sea flux $\mathbf{F}$. In other words, surface CFC concentrations will NOT be set equal to temperature-derived equilibrium values determined from the solubility. Modelers must use the formulation for the standard OCMIP-2 air-to-sea flux,

(1a) $\mathbf{F}=\mathbf{K w}$ (Csat - Csurf)

with

(1b) $\mathbf{C s a t}=$ alpha $* \mathbf{p C F C} * \mathbf{P} / \mathbf{P o}$

where

- Kw is the gas transfer (piston) velocity $[\mathrm{m} / \mathrm{s}]$;

- Csurf is the modeled surface ocean CFC-11 (or CFC-12) concentration [mol/m^3];

- alpha is the CFC solubility for water-vapor saturated air [mol/(m^3* picoatm)]; 
- pCFC is the partial pressure of CFC-11 (or CFC-12) in dry air at one atmosphere total pressure [in picoatm], which is the same as the dry air mixing ratio of CFC-11 or (CFC-12) multiplied by $10^{\wedge} 12$;

- $\mathbf{P}$ is the total air pressure at sea level [atm], locally;

- Po is 1 atm.

All right hand terms, except $\mathrm{P}$ and Po, in equations (1a) and (1b) are different for CFC-11 and CFC-12, as well as other tracers.

\subsection{The Piston Velocity Kw}

For simulations of CFC-11 and CFC-12, modelers must use the standard OCMIP-2 formulation for the piston velocity $\mathbf{K w}$. The monthly climatology of $\mathbf{K w}$, to be interpolated linearly in time by each modeling group, is computed with the following equation adapted from Wanninkhof (1992, eq. 3):

(2) $\mathrm{Kw}=(1-$ Fice $)[\mathrm{Xconv} * \mathrm{a} *(\mathbf{u} 2+\mathrm{v})](\mathrm{Sc} / 660) * *-1 / 2$

where

- Fice is the fraction of the sea surface covered with ice, which varies from 0.0 to 1.0 , and is given as monthly averages from the Walsh (1978) and Zwally et al. (1983) climatology (OCMIP-2 modelers must resest Fice values less than 0.2 to zero, after interpolation to their model grid)

- $\mathbf{u 2}$ is the instantaneous SSMI wind speed, averaged for each month, then squared, and subsequently averaged over th e same month of all years to give the monthly climatology. (see the OCMIP-1 README.satdat for further details);

- $\mathbf{v}$ is the variance of the instantaneous SSMI wind speed computed over one month temporal resolution And 2.5 degree spatial resolution, and subsequently averaged over the same month of all years to give the monthly climatology. Again, see the OCMIP-1 README.satdat for further details.

- $\mathbf{a}$ is the coefficient of 0.337 , consistent with a piston velocity in $\mathrm{cm} / \mathrm{hr}$. We adjusted the coefficient $\mathbf{a}$ for OCMIP-2, in order to obtain Broecker et al.'s (1986) radiocarbon-calibrated, global CO2 gas exchange of $0.061 \mathrm{~mol} \mathrm{CO} 2 /\left(\mathrm{m}^{\wedge} 2 * \mathrm{yr} *\right.$ uatm $)$, when using the satellite SSMI wind information $(\mathbf{u} 2+\mathbf{v})$ from Boutin and Etcheto (pers. comm.). Our computed value for $\mathbf{a}$ is similar to that determined by Wanninkhof $(\mathbf{a}=0.31)$, who used a different wind speed data set and assumptions about wind speed variance; we use the observed variance.

- Xconv $=1 / 3.6 \mathrm{e}+05$, is a constant factor to convert the piston velocity from $[\mathrm{cm} / \mathrm{hr}]$ to $[\mathrm{m} / \mathrm{s}]$. This conversion factor is already included in the forcing field $\mathbf{x K w}$, provided below.

- Sc is the Schmidt number which is to be computed using modeled SST, using the formulation from Zheng et al (1998). The function sc_cfc.f computes the Sc's (unit-less) for both CFC-11 and CFC-12.

Practically speaking, to use equation (2) each group will interpolate the OCMIP-2 standard information to their own model grid. The standard information is provided by IPSL/LSCE as a monthly climatology on the $1 \mathrm{x} 1$ degree grid of Levitus (1982) in netCDF format (in file gasx_ocmip2.nc). Gridded variables in that file include 
- the variable Fice,

- the second term, $[\mathbf{X c o n v} * \mathbf{a} *(\mathbf{u} \mathbf{2}+\mathbf{v})]$, denoted as $\mathbf{x K w}[\mathrm{m} / \mathrm{s}]$

- the mask Tmask (1 if ocean; 0 if land),

- the total atmospheric pressure at sea level $\mathbf{P}$ [atm]

- the longitude Lon at the center of each 1 x 1 degree grid box,

- the latitude Lat at the center of each 1 x 1 degree grid box.

For the variables Fice and $\mathbf{x K w}$, continents on the 1 x 1 degree standard grid have been flooded with adjacent ocean values. Such an approach avoids discontinuities at land-sea boundaries during interpolation. See the Fortran program rgasx_ocmip2.f for an example of how to read the information in cfc1112.atm into your interpolation routines. After compilation, to link and use rgasx_ocmip2.f, one must have already installed netCDF.

<http://www.unidata.ucar.edu/packages/netcdf/>

The file gasx_ocmip2 . nc may also be inspected with software that uses netCDF format, such as ncdump or Ferret. Ferret will be used for some of the analysis during OCMIP-2. We encourage participants to become familiar with Ferret now

<http://ferret.wrc.noaa.gov/Ferret/>

After installation, one can visualize maps of the standard information in gasx_ocmip2.nc, by using the Ferret script vgasx_ocmip2.jnl.

After launching Ferret, simply issue the following command (at Ferret's "yes?" prompt)

yes? go vgasx_ocmip2.jnl

\subsection{Oceanic and Atmospheric Components}

Apart from Kw, there are two other terms in equation (1a). The ocean component Csurf [in mol/m^3] is computed by the model each timestep; the atmospheric component Csat is specified a priori via the three remaining terms:

1. alpha: The CFC solubility alpha is to be computed using modeled SST and SSS, both of which vary in time at each grid point. For OCMIP-2 we use the solubility formulation determined by Warner and Weiss (1985, Table 5 for solubility in $\left.\left[\mathrm{mol} /\left(1^{*} \mathrm{~atm}\right)\right]\right)$. The function sol_cfc.f determines alpha accordingly, for both CFC-11 and $\mathrm{CFC}-12$, but changes the units to $\left[\mathrm{mol} /\left(\mathrm{m}^{\wedge} 3 *\right.\right.$ picoatm $\left.)\right]$ so that model $\mathrm{CFC}$ concentrations can then be carried in SI units [mol/m^3].

2. pCFC: Extrapolated records for observed CFC-11 and CFC-12 [in picoatm] constructed at $41 \mathrm{~S}$ and $45 \mathrm{~N}$ (Walker et al., pers. comm.). For OCMIP-2, each station will be treated as representative of its own hemisphere, except between $10 \mathrm{~S}$ and $10 \mathrm{~N}$ where those station values will be interpolated linearly as a function of latitude. Thus there are 3 zones:

- 90S-10S, where CFC's are held to same value as at the station at 41S; 
- 10S-10N, a buffer zone where values are interpolated linearly; and

- $10 \mathrm{~N}-90 \mathrm{~N}$ where values are held to the same value as at the measuring station at $45 \mathrm{~N}$.

3. P: Is the total atmospheric pressure [atm] from the monthly mean climatology of Esbensen and Kushnir (1981). The latter, given originally on a $4 \times 5$ degree grid (latitude $\mathrm{x}$ longitude) in bars, is converted to atm by multiplying by (1/1.101325). Land and sea ice values in the original data set were filled with average values from adjacent ocean points. These monthly mean arrays were then linearly interpolated to the $1 \mathrm{x} 1$ degree grid of Levitus (see netCDF file gasx_ocmip2.nc).

Technical notes:

1. The Fortran subroutine cfc_interp.f interpolates $\mathbf{~ P C F C}$ spatially following the above algorithm. The code allows, in one pass, to spatially interpolate atmospheric pCFC-11 and pCFC-12, at a given timestep, to all grid points as a function of latitude.

2. The ASCII file cfc1112.atm provides mid-year values of atmospheric pCFC-11 and pCFC-12 [in picoatm] at both stations for the period from 1931 to 1997. See the program read_cfcatm.f.

3. Temporal interpolation of atmospheric pCFC-11 and pCFC-12 is to be made linearly for each time step, based on mid-year values (file cfc1112.atm).

\section{Duration of simulation}

Following the atmospheric record, the standard OCMIP-2 simulation for CFC-11 and CFC-12 will begin at the beginning of 1931 with zero concentrations in the atmosphere and ocean. CFC simulations will stop at the end of 1997.

\section{Output type and frequency}

1. Early Output: prior to 1982 (no oceanic CFC data are available).

- Frequency: monthly averages every 10 years $(1940,1950,1960,1970,1980)$

- Type:

- 3-D Fields:

* CFC-11 and CFC-12 tracer distributions [mol/m^3]

- 2-D Fields:

* Monthly mean flux of CFC-11 and CFC-12 [mol/(m^2*s)]

* Cumulative flux of CFC-11 and CFC-12 [mol/m^2]

* Model SST (online models every year; offline models year 1940 only) [C]

* Model SSS (online models every year; offline models year 1940 only) [psu]

2. Late Output: from 1982 to 1997 
- Frequency: monthly averages every year

- Type: same as above

3. Transport Output: in 1990 (just one year)

- Frequency: monthly averages

- Type:

- The rate of change of each tracer $\left(\left[\mathrm{mol} / \mathrm{m}^{\wedge} 3 * \mathrm{~s}\right]\right.$ at tracer grid points) due to advection, diffusion, and convection,

\section{Split according to process and direction}

* Total rate of change $\mathrm{dC} / \mathrm{dt}$

* Rate of change due to advection (from $\mathrm{x}, \mathrm{y}$, and $\mathrm{z}$ directions, separately),

* Rate of change due to diffusion (from $\mathrm{x}, \mathrm{y}$, and $\mathrm{z}$ directions, separately), and

* Rate of change due to convection (from $\mathrm{z}$ direction), if modeled

- Tracer fluxes (3-D) $\left[\mathrm{mol} / \mathrm{m}^{\wedge} 2 * \mathrm{~s}\right]$

Split according to process and direction

* advective fluxes (from $\mathrm{x}, \mathrm{y}$, and $\mathrm{z}$, separately) at advection grid points,

* diffusive fluxes (from $\mathrm{x}, \mathrm{y}$, and $\mathrm{z}$, separately) at diffusion grid points, and

* convective fluxes (z), if modeled, at "convection" grid points

\section{Conventions for the direction of fluxes:}

* rectangular grid: positive from the west, from the south, and from below

* curvilinear grid: postive from $\mathrm{i}, \mathrm{j}, \mathrm{k}$ directions

* other grids (e.g., AWI, MPI, and ULG): contact orr@cea.fr

4. Equilibrium Output: All models provide first output year (1940); Online models also provide output for the year 1990

- Frequency: monthly averages

- Type:

- Active tracers (T and S) in 3-D

- Advection field $(\mathrm{u}, \mathrm{v}, \mathrm{w})[\mathrm{m} / \mathrm{s}]$ as separate scalar values at advection grid points $(\mathrm{u}, \mathrm{v}, \mathrm{w})$, which usually do not coincide

- Tracer diffusion coefficient $\left[\mathrm{m}^{\wedge} 2 / \mathrm{s}\right]$ as separate values at diffusion grid points

\section{Output Format}

Each modeling group must provide their output in the standard OCMIP-2 format. Model output that does not follow these formatting conventions cannot be included for analysis during OCMIP-2. Model groups must use the standard routines that we have developed specifically for writing output in standard form for OCMIP-2. 


\subsection{Spatial information}

Some of the models participating in OCMIP-2 are Irregular, which means that one 1-D array in latitude and one 1-D array in longitude are insufficient to describe the position of all grid points. Models with an irregular grid require a 2-D array in latitude and a 2-D array in longitude to describe the horizontal positioning of grid points. During OCMIP-2, regularly spaced models (those for which 1-D arrays in latitude and longitude are sufficient), will still write their output in the same irregular format. This will allow consistency between models for analysis, although at the price of somewhat larger output files.

Following the GDT conventions, all OCMIP-2 models will provide latitude and longitude information at the center of each tracer grid box and on all four corners (lower left, lower right, upper left and upper right) that are associated with each tracer grid point. Here is an example of a 2-D array in longitude and its corresponding boundary array (both with indices at their maximum values):

lon (imt, jmt)

bounds_lon (imt, jmt, 2, 2)

where

- bounds_lon $(i, j, 1,1)$ is the longitude of the lower left corner of the grid box $i, j$, where the meanings of lower and left are obvious for rectangular grids; for curvilinear grids, those terms correspond to the direction from grid boxes with smaller $j$ and smaller $i$, respectively;

- bounds_lon $(i, j, 2,1)$ is the lower right corner;

- bounds_lon $(i, j, 1,2)$ is the upper left corner; and

- bounds_lon $(i, j, 2,2)$ is the upper right corner.

Analogous arrays are needed for latitude.

\subsection{Output routines}

For 1 and 2 each modeling group must use the three routines listed in the following table. Input to these routines consists of your model's output and characteristics. The first routine write_nc_MaskAreaBathy. f must be called only once (for the 1st output year-1940). The second routine write_nc_CFC_year.f must be called for every output year (see previous section 4). The third routine write_nc_SurfTS_year. $f$ must also be called for every output year for online models, but only once (the first output year) for offline models.

$\begin{array}{lll}\text { Routine } & \text { Input } & \text { Units } \\ & & \\ \text { write_nc_MaskAreaBathy.f } & \text { Tracer Mask } & \text { Land=0/Ocean=1 } \\ & \text { Surface Area } & \mathrm{m}^{\wedge} 2 \\ & \text { Bathymetry } & \mathrm{m}\end{array}$




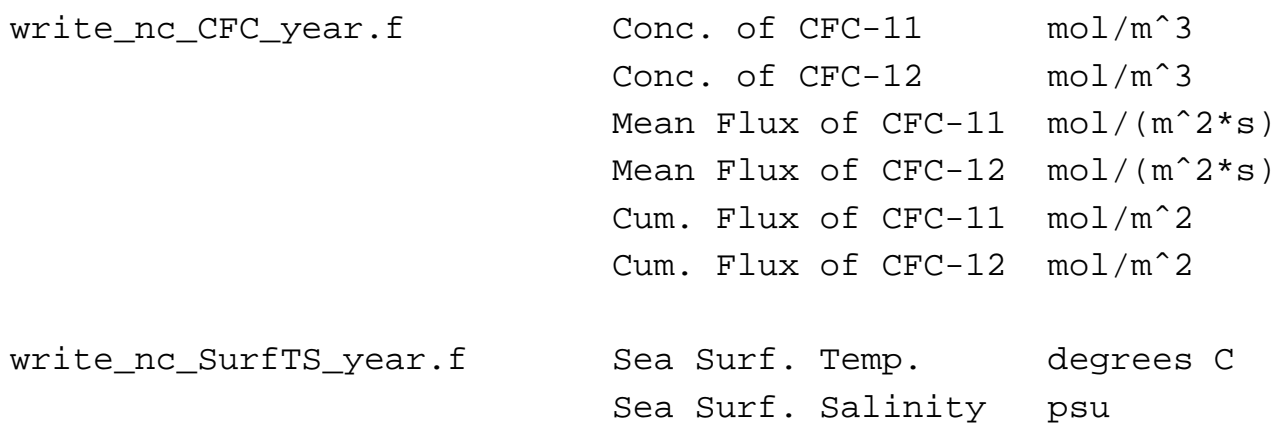

(1) Also includes other input arguments, as necessary to define position of grid boxes (latitude, longitude, and depth specifications)

(2) For online models, monthly SST and SSS should be saved each year

for which other output is written (with write_nc_CFC_year.f);

for offline models, monthly SST and SSS may be saved for just one year, since there is no year-to-year variation.

Please send e-mail now (orr@cea.fr) concerning whether you have an offline or online model.

\section{Conventions}

1. Longitudes must be expressed in degrees as eastward positive (e.g., $120 \mathrm{~W}$ is to be expressed as $-120 ; 120 \mathrm{E}$ is to be expressed as +120$)$.

2. Latitudes must be expressed in degrees as northward positive. (e.g., $90 \mathrm{~S}$ is to be expressed as -90 ; $90 \mathrm{~N}$ is to be expressed as +90).

3. Depth must be expressed in meters as positive downward (e.g., the depth of $1000 \mathrm{~m}$ is to be expressed as 1000).

4. For irregular model grids which must be stored as a 1-D vector instead of a 2-D array (e.g., model AWI), you must set $\mathrm{jmt}=1$, and not imt $=1$.

5. You must provide model output on a grid without overlapping boxes. For example, if for longitudes of your model

- $\mathrm{i}=1$ is the same as $\mathrm{i}=\mathrm{imt}-1$ and

- $\mathrm{i}=2$ is the same as $\mathrm{i}=\mathrm{imt}$,

then you must only provide model output for values from $\mathrm{i}=2$ to $\mathrm{i}=\mathrm{imt}-1$. Future reference to i during OCMIP-2 analysis will thus be shifted by one, relative to that used in your model.

\subsection{Downloading the output routines}

The output routines for your model class can be found in <http://www.ipsl.jussieu.fr/OCMIP/phase2/simulations/CFC/distrib/> or, in the HTML version of this document, by clicking on the three links below, while holding down the Shift key. 
- write_nc_MaskAreaBathy.f

- write_nc_CFC_year.f

- write_nc_SurfTS_year.f

Routines for writing out results for 3 and 4 will be made available soon.

You will also need to transfer the subroutine handle_errors.f to properly deal with errors while you are writing your netCDF files.

\subsection{Compiling the output routines}

Here is a an example of how you would compile one of the output routines:

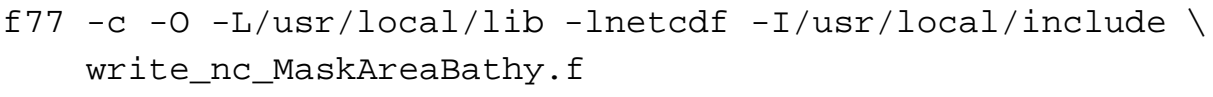

Because we have made these routines F77 compatible, you may need a function len_trim.f (from F90), which we also provide and which returns the length of a character string (after neglecting trailing blanks).

\subsection{Using the output routines}

These routines write out your model results following the naming and output conventions (netCDF, COARDS, GDT) chosen for OCMIP-2. The output filename is constructed automatically within each routine from three of the arguments: the tracer name, the year, and the standard model code <http: / / www.ipsl.jussieu.fr/OCMIP/phase2/\#modgroups> used during OCMIP-2 to identify your group.

For example, after compiling and linking the OCMIP-2 output routines, we add the following code to the IPSL routines to store output in standard OCMIP-2 form

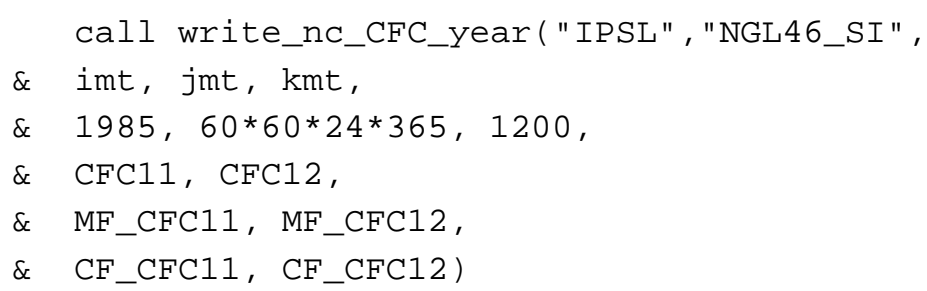

By line, the arguments include

1. the OCMIP-2 model code AND your own model version indicator (in GDT 1.2 terminology, these 2 variables refer to the institution and production, respectively);

2. dimensions; 
3. the year, the number of seconds per year (in your model), and the number of timesteps per year;

4. the 12 monthly means for the 3-D tracer arrays for CFC-11 and CFC-12;

5. the 12 monthly means for the 2-D air-sea flux for CFC-11 and CFC-12; and

6. the end-of-year 2-D cumulative flux (from $\mathrm{t}=0$ ) for CFC-11 and CFC-12.

All arguments are input. The only output is the final netCDF file, ("IPSL_CFC_1985.nC"), which contains the information for analyzing the IPSL results for 1985. This file along with all others from the 3 routines above should be 6. Filenames should NOT be changed. At IPSL, files will subsequently be (1) tested for consistency, (2) included in the OCMIP-2 data base, and (3) processed for base analysis.

\subsection{Need more details?}

See <http://www.ipsl.jussieu.fr/OCMIP/tech>. for additional information about the format netCDF and other conventions (COARDS, GDT) chosen for storing OCMIP-2 model output.

If you have other questions, please contact Patrick.Brockmann@ipsl.jussieu.fr, or orr@cea.fr

\section{Transfer of output}

All files written by the OCMIP-2 output routines should be grouped according to type of analysis ( $1,2,3$, and 4). To do so, just recuperate the shell script stocmip2.sh, copy it to the directory where you have stored your standard OCMIP-2 output, cd to that same directory, and issue the following two commands:

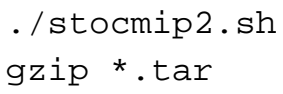

If gzip is not available on your machine, the alternative is to use compress.

Given the requested fields and frequencies specified in section (4) above, model output could be quite large, depending upon model resolution. If output is larger than $200 \mathrm{Mb}$ per simulation, we request that it be written to tape (DDS, DDS2, Exabyte, or DLT) and mailed to

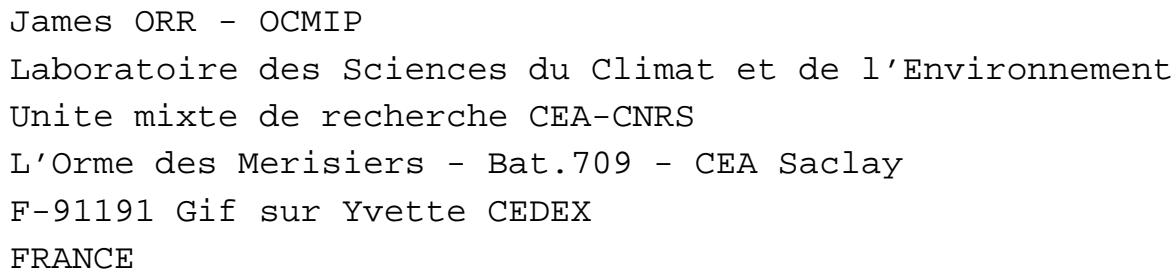

If smaller than $200 \mathrm{Mb}$, an attempt can be made to send this output via ftp (contact orr@cea.fr for details). The first analysis will be undertaken at IPSL (France) and at Penn. State (U.S.A.). 


\section{Who has submitted what?}

For a record of who has submitted what model output, see

<http://www.ipsl.jussieu.fr/OCMIP/phase2/progress/>.

\section{References}

Broecker, W.S., J. R. Ledwell, T. Takahashi, R. Weiss, L. Merlivat, L. Memery, T.-H. Peng, B. Jahne, and K. O. Munnich, 1986. Isotopic versus micrometeorlogic ocean CO2 fluxes, J. Geophys. Res., 91, 10517-10527.

Levitus, S., 1982. Climatological atlas of the World Ocean, NOAA Prof. Pap. 13, U.S. GPO., Washington, D.C., 173 pp.

Walsh, J. 1978. A data set on northern hemisphere sea ice extent, 1953-1976. Glaciological Data, World Data Center for Glaciology (Snow and Ice), Report GD-2, 49-51.

Wanninkhof, R., 1992. Relationship between wind speed and gas exchange over the ocean, J. Geophys. Res., 97, 7373-7382.

Warner, M. J. and R. F. Weiss (1985) Solubilities of chlorofluorocarbons 11 and 12 in water and seawater, Deep-Sea Res., 32, 1485-1497.

Zheng M., W. J. DeBruyn, and E. S. Saltzman, 1998. Measurements of the diffusion coefficients of CFC-11 and CFC-12 in pure water and seawater, J. Geophys. Res., 103, 1375-1379.

Zwally, H. J., J. Comiso, C. Parkinson, W. Campbell, F. Carsey, and P. Gloerson, 1983. Antarctic Sea Ice, 1973-1976: Satellite Passive Microwave Observations, NASA, 206 pp.

\section{Contacts}

orr@cea.fr,brock@1sce.saclay.cea.fr

\section{Same document, another format?}

This document is available in other formats:

- $\operatorname{HTML}(<$ HOWTO-CFC.html $>$ )

- Postscript (<HOWTO-CFC.ps>)

- $\operatorname{ASCII}(<$ HOWTO-CFC.txt $>)$

- $\operatorname{LaTeX}(<$ HOWTO-CFC.tex $>)$

- DVI ( <HOWTO-CFC.dvi $>$ )

- RTF - as 2 files 
1. Table of Contents $<\mathrm{HOWTO}-\mathrm{CFC}$. rt f $>$

2. Body $<\mathrm{HOWTO}-\mathrm{CFC}-0 . \mathrm{rtf}>$ 


\section{Abiotic-HOWTO}

J. Orr, R. Najjar, C. Sabine, and F. Joos

Revision: 1.16, Date: 2000/01/08 18:46:21

This document provides step-by-step guidelines to make the so-called solubility pump runs for CO2 and C-14 according to the standard OCMIP-2 protocols. No biological effects are included. The ocean model carries only DIC and DIC14. We describe five types of abiotic simulations: (1) Equilibrium run, (2) Historical run for 1765-2000, (3) Future runs (IPCC S650 and CIS92A) for DIC only, (4) a 1000-yr Pulse Input run for DIC only, and (5) three Control runs needed for drift correction for the Abiotic transient runs (i.e., the Historical, Future, and Pulse simulations).

\section{Contents}

1 Recuperation of OCMIP-2 files by ftp: $\quad 3$

2 Model runs $\quad 4$

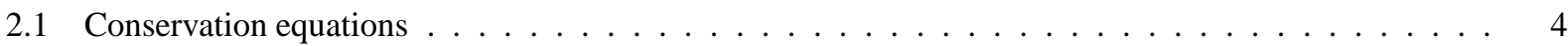

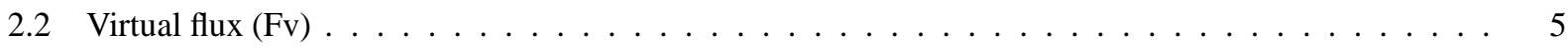

2.3 Air-sea gas exchange fluxes $(\mathrm{F}$ and $\mathrm{F} 14) \ldots \ldots \ldots \ldots \ldots \ldots \ldots \ldots$

2.4 The Piston Velocity $\mathrm{Kw} \ldots \ldots \ldots \ldots \ldots \ldots \ldots \ldots \ldots$

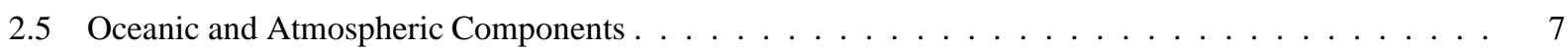

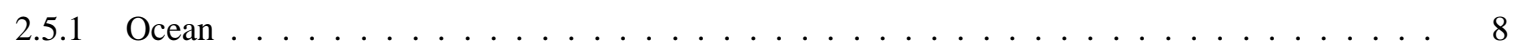

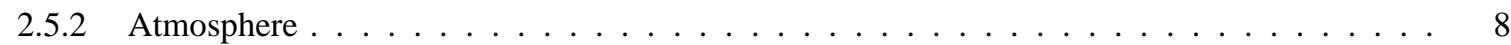

3 Initialization and duration of simulations $\quad 9$

4 Output type and frequency 11

5 Output Format $\quad 14$

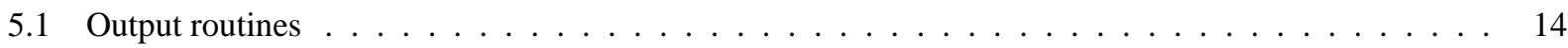

5.2 Downloading the output routines $\ldots \ldots \ldots \ldots \ldots \ldots \ldots \ldots \ldots \ldots \ldots$

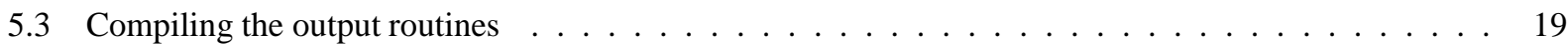

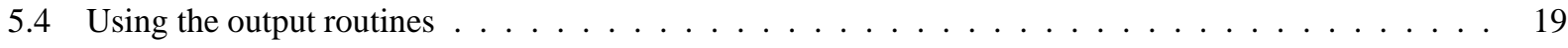

5.4 .1 Equilibrium Output . . . . . . . . . . . . . . . . . . . . . . . 19

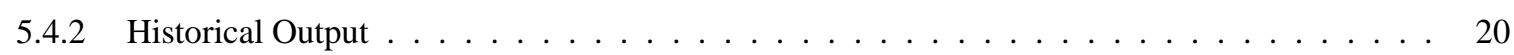

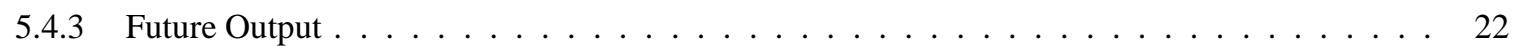

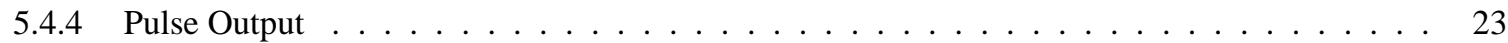




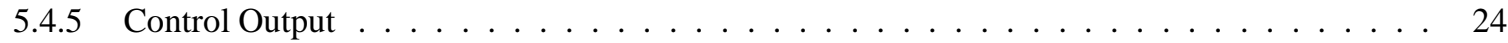

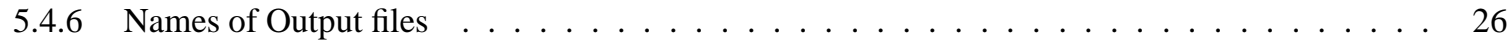

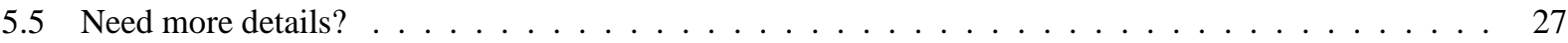

6 Transfer of output $\quad 27$

7 References $\quad 28$

8 Contacts $\quad 29$

9 Same document, another format? 


\section{Recuperation of OCMIP-2 files by ftp:}

To comply with OCMIP-2 guidelines, all modelers must make simulations according to OCMIP-2 standard boundary conditions. To do so, one must first recuperate the following files via this Web page. (you can save a file to disk by clicking on its link while holding down the Shift key)

- Files concerning gas exchange (same for all OCMIP-2 runs)

- rgasx_ocmip2.f

- gasx_ocmip2.nc.gz

- vgasx_ocmip2.jnl

- Files concerning atmospheric $\mathrm{CO} 2$ and $\mathrm{C}-14$, for transient simulations

- splco2.dat

- stab.dat

- cis92a.dat

- c14nth.dat

- c14equ.dat

- c14sth.dat

- read_co2atm.f

- read_c14atm.f

- c_interp.f

- try_c_interp.f

- locate.f

- Files concerning abiotic model

- scco2.f

- co2flux.f

- Files concerning standard carbonate chemistry (same for all OCMIP-2 carbon runs)

- README.Cchem

- Makefile

- co2calc.f

- drtsafe.f

- ta_iter_1.f

- test.r

- test.out.gz 
After transferring these files (in binary mode), modelers must then uncompress (gunzip) the file containing the gas exchange boundary conditions (gasx_ocmip2.nc.gz):

gunzip gasx_ocmip2.nc

Other files are text and need no special treatment after transfer. Use of these files is described below.

\section{Model runs}

\subsection{Conservation equations}

For the inorganic carbon and radiocarbon, both passive tracers, the conservation equations carried in the model are

(1a) $\mathbf{d}[\mathbf{D I C}] / \mathbf{d t}=\mathbf{L}([\mathrm{DIC}])+\mathbf{J v}+\mathbf{J}$

and

(1b) $\mathbf{d}[$ DIC14]/dt = L([DIC14]) - Lambda $*[$ DIC14] + Jv14 + J14

where

- [DIC] is the model's concentration (moles/m^3) of total dissolved inorganic carbon;

- [DIC14] is the model's DIC-normalized concentration (also in moles/m^3) of total dissolved inorganic C-14 (see below);

- $\mathbf{L}$ is the 3-D transport operator, which represents effects due to advection, diffusion, and convection;

- Lambda is the radioactive decay constant for C-14 $(\ln (2) / 5730$ year $=1.2097 \mathrm{e}-04$ year $\hat{\wedge}-1)$, converted to $\hat{s}-1$ using the number of seconds/year in your particular model;

- Jv is the "virtual" source-sink term representing the changes in surface [DIC] due to evaporation and precipitation, which must be accounted for because of the relatively high background concentration of [DIC];

- Jv14 is the "virtual" source-sink term for changes in surface [DIC14]due to evaporation and precipitation (E-P changes in background concentrations are of the same order as observed variability);

- $\mathbf{J}$ is the the source-sink term due to air-sea exchange of $\mathrm{CO} 2$; and

- J14 is the source-sink term due to air-sea exchange of 14CO2.

The source-sink terms $\mathbf{J v}, \mathbf{J v 1 4}$, J, and $\mathbf{J 1 4}$ are added only as surface boundary conditions. That is they are equal to zero in all subsurface layers. These source-sink terms are equivalent to the fluxes, described below, divided by the surface layer thickness dz1.

$\mathbf{J v}=\mathbf{F v} / \mathbf{d z 1}$

Jv14 = Fv14/dz1

$\mathbf{J}=\mathbf{F} / \mathbf{d z 1}$

$\mathbf{J 1 4}=\mathbf{F 1 4} / \mathrm{dz1}$ 


\subsection{Virtual flux (Fv)}

In models where surface salinity is restored to observed values, this results in a surface flux of salt, not a surface flux of water as in the real world. Such surface salt fluxes are typically found in models with a rigid lid, and even in some models with a free surface (e.g., the OGCM from Louvain-la-Neuve). For simplicity, we categorize both classes of models as "rigid-lid-like". Conversely, non-rigid-lid-like models have a free surface and restore surface salinity by an equivalent flux of water leading to dilution or concentration (e.g., the MPI LSG model). Salinity in the latter type of free-surface model is conserved; E-P fluxes are taken into account by the velocity fields and thus do not need to be explicitly formulated in the transport model.

Yet for all rigid-lid-like models, we must explicitly take into account the concentration-dilution effect of E-P (Evaporation minus Precipitation), which changes surface [DIC] and [Alk]. Thus we add the virtual flux to the surface layer, each time step according to

(2a) $\mathbf{F v}=\mathbf{D I C g} *(\mathbf{E}-\mathbf{P})$

(2b) Fv14 = DIC14g * (E-P)

where DICg and DIC14g are the model's globally averaged surface concentrations of DIC and DIC14, respectively. Both global averages must be computed at least once per year. For rigid-lid-like models with only salinity restoring, we suggest that $(\mathrm{P}-\mathrm{E})$ be computed as

(3) $\mathbf{P}-\mathbf{E}=\left(S-S^{\prime}\right) / S g * \mathbf{d z 1} / \mathbf{T a u}$

where $\mathbf{S}$ ' is the observed local salinity to which modeled local salinity $\mathbf{S}$ is being restored, $\mathbf{S g}$ is the model's globally averaged surface salinity, $\mathbf{d z 1}$ is the top layer thickness, and Tau is the restoring time scale for salinity. For rigid-lid-like models which in addition include explicit $\mathrm{P}$ - E water fluxes, that term must of course also be added to eq (3).

\subsection{Air-sea gas exchange fluxes (F and F14)}

For simulations of DIC and DIC14, OCMIP-2 simulations will directly model the finite air-sea fluxes F and F14, respectively. Modelers must use the formulation for the standard OCMIP-2 air-to-sea flux,

(4a) $\mathbf{F}=\mathbf{K w}$ (Csat - Csurf)

(4b) F14 = Kw (14Csat - 14Csurf)

with

(5a) $\quad$ Csat $=$ alphaC $*$ pCO2atm $*$ P/Po

(5b) 14 Csat $=$ Csat $*$ Ratm

where

- $\mathbf{K w}$ is the $\mathrm{CO} 2$ gas transfer (piston) velocity $[\mathrm{m} / \mathrm{s}]$;

- Csurf is the surface aqueous [CO2] concentration [mol/m^3], which is computed from the model's surface [DIC], T, S, and [Alk] (see section 2.5);

- 14Csurf is the surface ocean [14CO2] (see section 2.5); 
- alphaC is the $\mathrm{C}$ solubility for water-vapor saturated air $\left[\mathrm{mol} /\left(\mathrm{m}^{\wedge} 3 * \mathrm{uatm}\right)\right]$;

- pCO2atm is the partial pressure of $\mathrm{CO} 2$ in dry air at one atmosphere total pressure [in microatm], which is the same as the dry air mixing ratio of $\mathrm{CO} 2$ multiplied by $10^{\wedge} 6$;

- $\mathbf{P}$ is the total air pressure at sea level [atm], locally;

- Po is 1 atm; and

- Ratm is the normalized atmospheric ratio of C-14/C-12, which for our purposes we divide by the analogous ratio for the standard Rstd

(6) Ratm $=(1+$ D14Catm/1000)

where D14Catm is the atmospheric Delta C-14, the fractionation corrected ratio of C-14/C-12, given in permil (see below).

Those familiar with C-14, may be surprised that in equation (6) we define Ratm, without multiplying the right hand term by Rstd (1.176e-12). Instead, we prefer to be able to compare [DIC14] to [DIC], directly, in order to simplify early interpretation and code verification. With the above formulation for the OCMIP equilibrium runs (where pCO2atm $=278 \mathrm{ppm}$ and D14Catm $=0 \%$ ), if both tracers are initialized identically, the only difference between units for the [DIC] and [DIC14] tracers will be due to radioactive decay. For the anthropogenic runs, there will also be contributions due to differences between atmospheric records for pCO2atm and D14Catm.

\subsection{The Piston Velocity Kw}

For simulations of DIC and DIC14, modelers must use the standard OCMIP-2 formulation for the piston velocity $\mathbf{K w}$ for $\mathrm{CO}$. The monthly climatology of $\mathbf{K w}$, to be interpolated linearly in time by each modeling group, is computed with the following equation adapted from Wanninkhof (1992, eq. 3):

(7) $\mathrm{Kw}=(1-$ Fice $)[\mathrm{Xconv} * \mathbf{a} *(\mathbf{u} 2+\mathrm{v})](\mathrm{Sc} / 660) * *-1 / 2$

where

- Fice is the fraction of the sea surface covered with ice, which varies from 0.0 to 1.0 , and is given as monthly averages from the Walsh (1978) and Zwally et al. (1983) climatology (OCMIP-2 modelers must reset Fice values less than 0.2 to zero, after interpolation to their model grid)

- $\mathbf{u 2}$ is the instantaneous SSMI wind speed, averaged for each month, then squared, and subsequently averaged over th e same month of all years to give the monthly climatology. (see the OCMIP-1 README.satdat for further details);

- $\mathbf{v}$ is the variance of the instantaneous SSMI wind speed computed over one month temporal resolution And 2.5 degree spatial resolution, and subsequently averaged over the same month of all years to give the monthly climatology. Again, see the OCMIP-1 README.satdat for further details.

- $\mathbf{a}$ is the coefficient of 0.337 , consistent with a piston velocity in $\mathrm{cm} / \mathrm{hr}$. We adjusted the coefficient $\mathbf{a}$ for OCMIP-2, in order to obtain Broecker et al.'s (1986) radiocarbon-calibrated, global CO2 gas exchange of $0.061 \mathrm{~mol} \mathrm{CO} 2 /\left(\mathrm{m}^{\wedge} 2 * \mathrm{yr} *\right.$ uatm $)$, when using the satellite SSMI wind information $(\mathbf{u} \mathbf{2}+\mathbf{v})$ from Boutin and 
Etcheto (pers. comm.). Our computed value for $\mathbf{a}$ is similar to that determined by Wanninkhof $(\mathbf{a}=0.31)$, who used a different wind speed data set and assumptions about wind speed variance; we use the observed variance.

- $\mathbf{X c o n v}=1 / 3.6 \mathrm{e}+05$, is a constant factor to convert the piston velocity from $[\mathrm{cm} / \mathrm{hr}]$ to $[\mathrm{m} / \mathrm{s}]$. This conversion factor is already included in the forcing field $\mathbf{x K w}$, provided below.

- Sc is the Schmidt number which is to be computed using modeled SST, using the formulation from Wanninkhof (1992). The function scco2.f computes the Sc (unit-less) for CO2.

Practically speaking, to use equation (2) each group will interpolate the OCMIP-2 standard information to their own model grid. The standard information is provided by IPSL/LSCE as a monthly climatology on the $1 \mathrm{x} 1$ degree grid of Levitus (1982) in netCDF format (in file gasx_ocmip2.nc). Gridded variables in that file include

- the variable Fice,

- the second term, $[\mathbf{X c o n v} * \mathbf{a} *(\mathbf{u} \mathbf{2}+\mathbf{v})]$, denoted as $\mathbf{x K w}[\mathrm{m} / \mathrm{s}]$

- the mask Tmask (1 if ocean; 0 if land),

- the total atmospheric pressure at sea level $\mathbf{P}$ [atm]

- the longitude Lon at the center of each 1 x 1 degree grid box,

- the latitude Lat at the center of each 1 x 1 degree grid box.

For the variables Fice and $\mathbf{x K w}$, continents on the 1 x 1 degree standard grid have been flooded with adjacent ocean values. Such an approach avoids discontinuities at land-sea boundaries during interpolation. See the Fortran program rgasx_ocmip2.f for an example of how to read the information in gasx_ocmip2.nc.gz into your interpolation routines. After compilation, to link and use rgasx_ocmip2.f, one must have already installed netCDF.

<http://www.unidata.ucar.edu/packages/netcdf/>

The file gasx_ocmip2. nc may also be inspected with software that uses netCDF format, such as ncdump or Ferret. Ferret will be used for some of the analysis during OCMIP-2. We encourage participants to become familiar with Ferret now

<http://ferret.wrc.noaa.gov/Ferret/>

After installation, one can visualize maps of the standard information in gasx_ocmip2.nc, by using the Ferret script vgasx_ocmip2.jnl.

After launching Ferret, simply issue the following command (at Ferret's "yes?" prompt)

yes? go vgasx_ocmip2.jnl

\subsection{Oceanic and Atmospheric Components}

Apart from Kw, there are a total of four other terms in equation (4a) and (4b) which require further development. 


\subsubsection{Ocean}

The oceanic terms Csurf and 14Csurf [in mol/m^3] are not carried as tracers, so they must be computed each timestep to determine gas exchange

Csurf is the surface [CO2] concentration [mol/m^3], which is computed from the model's surface [DIC], T, S, and [Alk] through the equations and constants found in the subroutine co2calc.f. As input, we must provide alkalinity, which we determine as a normalized linear function of salinity.

(8) $[$ Alk $]=$ Alkbar $*$ S/Sbar

where [Alkbar] is $2310 \mathrm{microeq} / \mathrm{kg}$ and Sbar is the model's annual mean surface salinity, integrated globally (horizontally). Two other input arguments, both nutrient concentrations, are needed as input. Although accounting for both of their equilibria makes a difference, neither nutrient is included in the solubility pump run. Hence we take concentrations of both as being constant, equal to the global mean of surface observations: $0.5 \mathrm{micromol} / \mathrm{kg}$ for phosphate and $7.5 \mathrm{micromol} / \mathrm{kg}$ for silicate. Note that for the later OCMIP-2 run which includes the biological pump, we will use observed seasonal distributions of surface phosphate.

IMPORTANT: The carbonate chemistry subroutine co2calc.f was originally designed to require tracer input ([DIC], [Alk], [PO4], and [SiO2]) on a per mass basis (umol/kg); however, for OCMIP-2 co2calc.f has been modified to pass tracer concentrations on a per volume basis $\left(\mathrm{mol} / \mathrm{m}^{\wedge} 3\right)$, as carried in ocean models. To do so, we use the mean surface density of the ocean $\left(1024.5 \mathrm{~kg} / \mathrm{m}^{\wedge} 3\right)$ as a constant conversion factor; we do NOT use model-predicted densities. For example, OCMIP-2 modelers should used $\mathrm{SiO} 2=7.7 \mathrm{e}-03 \mathrm{~mol} / \mathrm{m} \wedge 3$ and $\mathrm{PO} 4=5.1 \mathrm{e}-04 \mathrm{~mol} / \mathrm{m} 3$ as input arguments; again both are constant for the abiotic simulation. The output arguments co2star (Csurf) and dco2star (Csat - Csurf) are also returned in $\mathrm{mol} / \mathrm{m}^{\wedge} 3$.

14Csurf is the surface ocean [14CO2], defined as

\section{(9) 14Csurf = Csurf * Rocn,}

where

(10) $\operatorname{Rocn}=[$ DIC14 $] /[$ DIC $]$.

Furthermore, for comparison to ocean measurements, we compute

(11) D14Cocn $=1000 *($ Rocn -1$)$.

Following equation (4), we do not include Rstd when calculating D14Cocn in the model.

\subsubsection{Atmosphere}

The atmospheric components Csat and 14Csat in equations (4a) and (4b) are specified a priori via four remaining terms:

1. alphaC: The CO2 solubility alphaC is to be computed using modeled SST and SSS, both of which vary in time at each grid point. For OCMIP-2 we use the solubility formulation of Weiss (1974), corrected for the contribution of water vapor to the total pressure (Weiss and Price, 1980, Table IV for solubility in [mol/(1* atm)]). The solubility alphaC is calculated within the routine co2calc.f.

2. pCO2atm: For the Equilibrium run, pCO2atm is held constant at $278 \mathrm{ppm}$. For the anthropogenic perturbation, we define the equilibrium state as year 1765.0. Then for the Historical run, the model must be 
integrated until the end of 1999, following the observed record until 1990.5 (splco2.dat) and IPCC scenario S650 (stab.dat) until 2000.0 (Enting, 1994). That same scenario, Future run S650, will be continued from 2000.0 to 2300.0. Similarly, a second Future run CIS92A (see also cis92a.dat) will be run from 1990.0 to 2100.0, after initializing with model output from the Historical run in 1990.0. Additionally a Pulse run will be made, where preindustrial atmospheric $\mathrm{CO} 2$ is doubled and allowed to decline for 1000 years. Finally to eliminate effects due to model drift, we will make essentially two Control runs: (1) the first will be held to the same atmospheric boundary conditions as the Equilibrium run , carrying both DIC and DIC14 during 1765-2000 but only DIC from 2000-2300; (2) the second will be analogous to the Pulse run, made in forward mode for 1000 years, except that atmospheric $\mathrm{CO} 2$ will not be doubled on the first time step.

3. D14Catm: is atmospheric Delta C-14 [in permil]. For the Equilibrium run, D14Catm is held constant at 0\%. For the Historical run, we define the equilibrium state as year 1765.0. Then the model must be integrated until the end of year 1999 following the observed record (Enting, 1994). The observed atmospheric C-14 record is given for three latitudinal bands:

- $90 \mathrm{~S}-20 \mathrm{~S}$

- $20 \mathrm{~S}-20 \mathrm{~N}$

- $20 \mathrm{~N}-90 \mathrm{~N}$

There will be NO future or pulse simulations for C-14.

4. P: Is the total atmospheric pressure [atm] from the monthly mean climatology of Esbensen and Kushnir (1981). The latter, given originally on a 4 x 5 degree grid (latitude $\mathrm{x}$ longitude) in bars, is converted to atm by multiplying by (1/1.101325). Land and sea ice values in the original data set were filled with average values from adjacent ocean points. These monthly mean arrays were then linearly interpolated to the $1 \mathrm{x} 1$ degree grid of Levitus (see netCDF file gasx_ocmip2.nc).

Technical notes:

1. The ASCII file splco2.dat provides values of atmospheric pCO2 [in microatm], every half year, for the period from 1765.0 to 1990.5. Thereafter, there are two files used for future scenarios: for scenario S650, the ASCII file stab.dat provides half-year values of atmospheric pCO2 [in microatm] for the period from 1990.5 to 2300.5; for scenario CIS92A, the ASCII file cis92a.dat provides yearly values of atmospheric pCO2 for the period from 1990.5 to 2100.5. The subroutine read_co2atm.f reads atmospheric CO2 information from all three files.

2. The ASCII files c14nth.dat, c14equ.dat, and c14sth.dat provide mid-year values of atmospheric D14Catm [in permil] for the period from 1764.5 to 2000.0 . See the subroutine read_c14atm.f

3. The Fortran subroutine c_interp.f temporally interpolates (linearly) both pCO2atm and D14Catm at a given timestep. That routine is called by the demonstration program try_c_interp.f, which spatially assigns D14Catm to the three latitudinal bands for C-14 (see above). Thus both routines together effect (1) temporal interpolation for both pCO2atm and D14Catm and (2) spatial "interpolation" for D14Catm as a function of latitude.

\section{Initialization and duration of simulations}

\section{Equilibrium run:}


- Initial Conditions: These don't really matter for the Abiotic Equilibrium run. That is, the final steady-state distributions for DIC and DIC14 do not depend on the initial conditions because exchange with the atmosphere will ultimately determine their final steady-state inventories. However, a judicious choice of initial conditions can reduce the integration time required to reach steady-state. Unfortunately, initial conditions must be quite close indeed to the steady-state solution if there is to be a significant reduction in computing time. The choice of initial conditions is left to the discretion of each of the modeling groups. For initial debugging, groups may prefer to initialize DIC14 to the same 3-D field as used for DIC. That way the only difference between the two tracers is driven by radioactive decay.

- Duration: The Equilibrium run for abiotic DIC and DIC14 should be continued until at least both the following criteria are reached:

- For DIC, we recommend that the globally integrated air-sea flux should be less than $0.01 \mathrm{Pg} \mathrm{C} / \mathrm{yr}$

- For C-14, we recommend that $98 \%$ of the ocean volume should have a drift of less than $0.001 \%$ ofyear (Aumont et al., 1998, p. 105). In terms of C-14 age, this drift is equivalent to a change of $8.27 \mathrm{yr}$ per 1000 years of simulation.

For most models, these criteria can be reached only after integrations of at least few thousand model years.

\section{Historical run:}

- Initial Conditions: The historical abiotic simulation for both DIC and DIC14 will be initialized with final output (on Dec. 31) from the Equilibrium run or "steady-state" simulation.

- Duration: The historical simulation will begin at the beginning of 1765 (Jan 1, i.e., 1765.0). The anthropogenic simulation will be continued until the year 2000.0.

- CO2: Until 1990.5, pCO2atm will follow the splco2.dat; then from 1990.5 to 2000.0, the atmosphere will follow IPCC scenario S650 in stab.dat.

- C-14: Atmospheric D14Catm will follow values in c14nth.dat, c14equ.dat, and c14sth.dat (for 90S-20S, 20S-20N, and 20N-90N, respectively) until 2000.0. For lack of data, atmospheric C-14 between 1995.5 and 2000.0 is held constant at $107 \%$.

\section{Future runs (DIC only):}

- Future run CIS92A:

- Initial Conditions: 3-D DIC field, 2-D Cumulative Fluxes and 2-D Cumulative Virtual Flux fields to be initialized with output from the Historical run at 1990.0

- Duration: to be continued using atmospheric CO2 from IPCC Scenario CIS92A until the year 2100.0

- Future run S650:

- Initial Conditions: 3-D DIC field, 2-D Cumulative Fluxes and 2-D Cumulative Virtual Flux fields to be initialized with output from the Historical run at 1990.0

- Duration: to be continued using atmospheric CO2 from IPCC Scenario S650 until the year 2300.0

\section{Pulse input response function (DIC only):}

- Initial Conditions: Ocean DIC is to be initialized with final output from the Equilibrium run; Atmospheric $\mathrm{CO} 2$ is to be doubled (556 ppm, where $1 \mathrm{ppm}=2.123 \mathrm{Pg} \mathrm{C}$ ) at $\mathrm{t}=0$, and then be controlled only via air-sea fluxes. Thus the model is then to be run in forward mode (atmospheric CO2 is calculated). The Injection HOWTO describes other forward simulations in more detail. 
- Duration: The total integration will be for 1000 years (1765.0 - 2765.0).

\section{Control Runs}

- Historical Control (DIC and DIC14); and Future Control (DIC only)/:

- Initial Conditions: Ocean DIC is to be initialized with final output from the Equilibrium run; Atmospheric $\mathrm{CO} 2$ and $\mathrm{C}-14$ are to be held at preindustrial conditions (278 ppm, $0 \%$ ) throughout the duration of the simulation.

- Duration: The total integration for DIC will be for 535 years (1765.0 - 2300.0). However the integration including DIC14 is only necessary for the first 235 years (Historical Control run 1765.0 2000.0).

- Historical-Future transistion: If run separately, the Future Control run should be initialized with the 3-D DIC fields AND the 2-D Cumulative Fluxes (i.e., both air-sea gas cumulative flux and virtual cumulative flux) from the last time step of 1999 (end of Historical Control run).

- Pulse Control (DIC only):

- Initial Conditions: Ocean DIC is to be initialized with final output from the Equilibrium run; Atmospheric $\mathrm{CO} 2$ is to be initialized with the quantity of $\mathrm{CO} 2$ equivalent to $278 \mathrm{ppm}(1 \mathrm{ppm}=2.123$ $\mathrm{Pg} \mathrm{C}$ ) at $\mathrm{t}=0$, and then be controlled only via air-sea fluxes. Thus the model is to be run in forward mode (atmospheric $\mathrm{CO} 2$ is calculated). The Injection HOWTO describes other forward simulations in more detail.

- Duration: The total integration will be for 1000 years (the equivalent of 1765.0 - 2765.0).

There are no Future or Pulse simulations for DIC14.

\section{Output type and frequency}

1. Equilibrium Output: steady-state "natural" simulation

- Type: (N.B. Below, the terms 3-D, 2-D, and 0-D refer to spatial dimensions; another dimension must be added for time).

3-D fields:

(a) Concentrations for both passive tracers [DIC] and [DIC14] (both in $\mathrm{mol} / \mathrm{m}^{\wedge} 3$ ); and

(b) Alk (in eq $/ \mathrm{m}^{\wedge} 3$ ), as determined from equation (8);

2-D fields

(a) pCO2surf $=$ Csurf/alphaC (uatm);

(b) $\mathbf{d p C O 2}=($ Csurf - Csat*P/Po) (uatm);

(c) Air-sea DIC gas exchange flux $\mathbf{F}\left(\mathrm{mol} /\left(\mathrm{m}^{\wedge} 2 * \mathrm{~s}\right)\right)$;

(d) Air-sea DIC14 flux F14 (mol/(m^2*s));

(e) Virtual DIC flux $\mathbf{F v}\left(\mathrm{mol} /\left(\mathrm{m}^{\wedge} 2 * \mathrm{~s}\right)\right)$;

(f) Virtual DIC14 flux Fv14 (mol/(m^2* s));

- Frequency: Monthly means and annual mean for the final year of equilibrium simulation. 
2. Historical Output: for anthropogenic run for CO2 and C-14 (1765.0-2000.0)

- Type: Same as for the Equilibrium run (except Alk, which is the same), plus

2-D fields

(a) Surface DIC concentration ( $\left.\mathrm{mol} / \mathrm{m}^{\wedge} 3\right)$;

(b) Surface DC14ocn (permil), see equation (11);

(c) Vertical Inventory of DIC (mol/m^2), i.e., the vertical integral of its concentration with depth, throughout the water column.

(d) Vertical Inventory of DC14ocn (permil * m), i.e., the vertical integral of its level with depth, throughout the water column (permil*m are strange but useful units).

(e) End-of-the-year cumulative air-sea gas exchange fluxes $\mathbf{F}$ and $\mathbf{F 1 4}$, accumulated every time step since year=1765.0 $\left(\mathrm{mol} / \mathrm{m}^{\wedge} 2\right)$.

(f) End-of-the-year cumulative virtual fluxes Fv and Fv14, accumulated every time step since year $=1765.0\left(\mathrm{~mol} / \mathrm{m}^{\wedge} 2\right)$.

0-D fields

(a) Globally averaged atmospheric pCO2atm (uatm) and DC14atm (permil);

(b) Globally averaged air-sea fluxes F and F14 $\left(\mathrm{mol} /\left(\mathrm{m}^{\wedge} 2 * \mathrm{~s}\right)\right.$

(c) Globally averaged virtual fluxes Fv and Fv14 $\left(\mathrm{mol} /\left(\mathrm{m}^{\wedge} 2 * \mathrm{~s}\right)\right.$

(d) Globally averaged DIC and DIC14 (mol/m^3), i.e., a Volume integral

(e) Globally averaged surface DIC and DIC14 (mol/m^3), i.e., a Surface integral

(f) Globally averaged pCO2surf (uatm)

(g) Globally averaged dpCO2 (uatm)

(h) Globally averaged surface DC14ocn (permil), see equation (11);

(i) Globally averaged DC14ocn (permil), see equation (11);

(j) Globally averaged cumulative air-sea fluxes (end-of-month) for F and F14 ( $\left.\mathrm{mol} / \mathrm{m}^{\wedge} 2\right)$;

(k) Globally averaged cumulative virtual fluxes (end-of-month) for Fv and Fv14 (mol/m^2)

- Frequency:

0-D fields:

(a) Monthly means during every year (1765-1999, inclusive)

2-D fields:

(a) Monthly means for 1838, 1839, 1900, and every year from 1948-1999 (inclusive).

3-D fields:

(a) Monthly means for 1838, 1953, 1954, 1957, 1965, 1972, 1973, 1974, 1977, 1978, 1981, 1982, 1983, 1985, 1986, 1987, 1988, 1989, 1991, 1993, 1995, 1997, 1999.

(b) Annual means for 1838, 1839, 1900, and every year from 1953-1999 (inclusive).

3. Future Output: for future runs CIS92A and S650

- Type: Same as the Historical run, but only for the DIC component, not DIC14

- Frequency:

0-D fields: 
(a) CIS92A: Monthly means during every year (1990-2099, inclusive)

(b) S650: Monthly means during every year (1990-2299, inclusive)

2-D and [3-D] fields:

* CIS92A

(a) Monthly means for 2000 and 2099.

(b) Annual means for 2000, 2010, every 20 years for 2020-2080, and 2099.

\section{* S650}

(a) Monthly means for 2000, 2100, 2200, and 2299.

(b) Annual means for 2000, 2010, every 20 years for 2020-2280, and 2299.

4. Pulse Output: for OCMIP models to be included in next IPCC analysis

- Type: Same as the Future run for 0-D and 2-D fields; No 3-D fields!

- Frequency:

0 -D fields

* 0.0-10.0 years: monthly means $(12 \times 10=120$ records $)$

* 10.0-100.0 years: annual means (i.e., 90 records)

* 100.0-1000.0 years: annual means every 10 years (i.e., 90 records)

* Final year (999.0-1000.0): annual mean (i.e., 1 record)

2-D fields

* 0.0-10.0 years: annual means each year (11 records)

* 10.0-100.0 years: annual means every 10 years (90 records)

* 100.0-1000.0 years: annual means every 100 years (90 records)

* Final year (999.0-1000.0): annual mean (1 record)

\section{Control Output:}

- Type:

- Historical Control (1765.0 - 2000.0) - ¿ Just like Historical run

- Future Control (2000.0 - 2300.0) - ¿ Just like Future run-only DIC component, not DIC14.

- Pulse Control (0.0 - 1000.0) - ¿ Just like Pulse run-only DIC component.

- Frequency:

0-D fields:

(a) Historical Control: Monthly means during every year (1765-1999, inclusive)

(b) Future Control: Monthly means during every year (2000-2300, inclusive)

(c) Pulse Control: just like Pulse run

* 0.0-10.0 years: monthly means $(12$ x $10=120$ records $)$

* 10.0-100.0 years: annual means (i.e., 90 records)

* 100.0-1000.0 years: annual means every 10 years (i.e., 90 records)

* Final year (999.0-1000.0): annual mean (i.e., 1 record)

2-D fields: 
(a) Historical Control: Annual means for 1838, 1839, 1900, and every year from 1948-1999 (inclusive).

(b) Future Control: Annual means for 2000, 2010, every 20 years for 2020-2080, 2099, every 20 years for 2100-2280, and 2299.

(c) Pulse Control: just like Pulse run

* 0.0-10.0 years: annual means each year (11 records)

* 10.0-100.0 years: annual means every 10 years (90 records)

* 100.0-1000.0 years: annual means every 100 years (90 records)

* Final year (999.0-1000.0): annual mean (1 record)

3-D fields:

(a) Historical Control: Annual means for 1838, 1839, and every year from 1953-1999 (inclusive)

(b) Future Control: Annual means for 2000, 2010, every 20 years for 2020-2080, 2099, every 20 years for 2100-2280, and 2299.

(c) Pulse Control: None!

\section{Output Format}

Each modeling group must provide their output in the standard OCMIP-2 format. Model output that does not follow these formatting conventions cannot be included for analysis during OCMIP-2. Model groups must use the standard routines that we have developed specifically for writing output in standard form for OCMIP-2.

If this is the first OCMIP-2 simulation you have made, you will need to recuperate the routine write_nc_MaskAreaBathy.f to write out characteristics of your model grid, mask, and bathymetry using the standard OCMIP-2 format. Use of this routine is detailed in the CFC HOWTO (section 5.1).

Otherwise if you have submitted OCMIP-2 model output previously, you will only need to resubmit the output file produced by write_nc_MaskAreaBathy.f under two conditions:

1. either your model's grid, mask, or bathymetry have changed; or

2. you have been notified by the OCMIP-2 analysis center at IPSL that your output file from this subroutine did not pass the routine integrity tests.

\subsection{Output routines}

Each modeling group must use the routines listed in the following table to store results in standard OCMIP-2 format for the Equilibrium Output, Historical Output, Future Output, Pulse Output, and Control Output.

Input to these routines consists of your model's output and characteristics. The first routine write_nc_Abiotic_equil. f must be called ONLY once, at the end of model spin-up. We define the final output of that run to be the initial conditions (at 1765.0) for the transient runs. The Historical routines

(write_nc_Abiotic_hist_year_3D.f write_nc_Abiotic_hist_year_2D.f) must be called for the appropriate output years of the Historical run (see previous section Output type and frequency); conversely the 
Historical routine (write_nc_Abiotic_hist_year_OD.f is called only once, after builiding a 1-D time series of global mean information. The same strategy holds for the output routines for the other Abiotic transient runs:

- Future runs (write_nc_Abiotic_futr_year_3D.f, write_nc_Abiotic_futr_year_2D.f, and write_nc_Abiotic_futr_year_OD.f);

- Pulse run (write_nc_Abiotic_puls_year_2D.f, and write_nc_Abiotic_puls_year_0D.f); and

- Control runs

- Historical Control: write_nc_Abiotic_ctrlH_year_3D.f, write_nc_Abiotic_ctrlH_year_2D.f, and write_nc_Abiotic_ctrlH_year_0D.f;

- Future Control: write_nc_Abiotic_ctrlF_year_3D.f, write_nc_Abiotic_ctrlF_year_2D.f, and write_nc_Abiotic_ctrlF_year_0D.f; and

- Pulse Control: write_nc_Abiotic_ctrlP_year_2D.f, and write_nc_Abiotic_ctrlP_year_0D.f).

The routine write_nc_Abiotic_TS_year. $f$ should be called only once for offline models; for online models, it should also be called a second time, in the year 1990 .

\begin{tabular}{|c|c|c|c|c|c|}
\hline Routine & \multicolumn{3}{|c|}{ Input } & Units & Comments \\
\hline \multirow[t]{9}{*}{ write_nc_Abiotic_equil.f } & 1) & Conc. of DIC & & $\mathrm{mol} / \mathrm{m}^{\wedge} 3$ & $(*)$ \\
\hline & 2) & Conc. of DIC14 & & $\mathrm{mol} / \mathrm{m}^{\wedge} 3$ & \\
\hline & 3) & Alk from eq. (8) & & $\mathrm{eq} / \mathrm{m}^{\wedge} 3$ & \\
\hline & 4) & Surf. ocean pCO2 & & uatm & \\
\hline & 5) & Delta pCO2 (dpCO2) & & uatm & \\
\hline & 6) & Gas Exch. Flux of & DIC & $\mathrm{mol} /\left(\mathrm{m}^{\wedge} 2 * \mathrm{~s}\right)$ & \\
\hline & 7) & Gas Exch. Flux of & DIC14 & $\mathrm{mol} /\left(\mathrm{m}^{\wedge} 2 * \mathrm{~s}\right)$ & \\
\hline & 8) & Virtual Flux of & DIC & $\mathrm{mol} /\left(\mathrm{m}^{\wedge} 2 * \mathrm{~s}\right)$ & \\
\hline & 9) & Virtual Flux of & DIC14 & $\operatorname{mol} /\left(m^{\wedge} 2 * s\right)$ & \\
\hline \multirow[t]{2}{*}{ write_nc_Abiotic_hist_year_3D.f } & 1) & Conc. of DIC & & $\mathrm{mol} / \mathrm{m} \wedge 3$ & \\
\hline & 2) & Conc. of DIC14 & & $\mathrm{mol} / \mathrm{m}^{\wedge} 3$ & \\
\hline \multirow[t]{8}{*}{ write_nc_Abiotic_hist_year_2D.f } & 1) & Surf. ocean pCO2 & & uatm & \\
\hline & 2) & Delta pCO2 (dpCO2) & & uatm & \\
\hline & 3) & Gas Exch. Flux of & $=\mathrm{DIC}$ & $\mathrm{mol} /\left(\mathrm{m}^{\wedge} 2{ }^{\star} \mathrm{s}\right)$ & \\
\hline & 4) & Gas Exch. Flux of & $=\mathrm{DIC} 14$ & $\mathrm{~mol} /\left(\mathrm{m}^{\wedge} 2{ }^{\star} \mathrm{s}\right)$ & \\
\hline & 5) & Virtual & $=D I C$ & $\mathrm{~mol} /\left(\mathrm{m}^{\wedge} 2{ }^{*} \mathrm{~s}\right)$ & \\
\hline & 6) & Virtual Flux of & $=\operatorname{DIC} 14$ & $\mathrm{~mol} /\left(\mathrm{m}^{\wedge} 2 * \mathrm{~s}\right)$ & \\
\hline & 7) & Surface DIC & & $\mathrm{mol} / \mathrm{m}^{\wedge} 3$ & \\
\hline & 8) & Surface Delta C-14 & & permil & \\
\hline
\end{tabular}




\begin{tabular}{|c|c|c|c|c|}
\hline & 9) & Vert. Integral of DIC & $\mathrm{mol} / \mathrm{m}^{\wedge} 2$ & \\
\hline & $10)$ & Vert. Integral of DC-14ocn & permil*m & \\
\hline & 11) & Cum. Gas Flux of DIC $n$ & $\mathrm{~mol} / \mathrm{m}^{\wedge} 2$ & $1765->$ \\
\hline & 12) & Cum. Gas Flux of DIC14 & $\mathrm{mol} / \mathrm{m}^{\wedge} 2$ & $1765->$ \\
\hline & 13) & Cum. Virt. Flux of DIC & $\mathrm{mol} / \mathrm{m}^{\wedge} 2$ & $1765->$ \\
\hline & 14) & Cum. Virt. Flux of DIC14 & $\mathrm{mol} / \mathrm{m}^{\wedge} 2$ & $1765->$ \\
\hline write_nc_Abiotic_hist_year_0D.f & 1) & Glob_mean (Gm) pco2atm & uatm & \\
\hline & 2) & Gm Delta $\mathrm{C}-14$ atm & permil & \\
\hline & 3) & Gm Gas Ex. Flux of DIC & $\mathrm{mol} /\left(\mathrm{m}^{\wedge} 2 \star \mathrm{s}\right)$ & \\
\hline & 4) & Gm Gas Ex. Flux of DIC14 & $\mathrm{mol} /\left(\mathrm{m}^{\wedge} 2 * \mathrm{~s}\right)$ & \\
\hline & 5) & Gm Virtual Flux of DIC & $\mathrm{mol} /\left(\mathrm{m}^{\wedge} 2 * \mathrm{~s}\right)$ & \\
\hline & 6) & Gm Virtual Flux of DIC14 & $\mathrm{mol} /\left(\mathrm{m}^{\wedge} 2 * \mathrm{~s}\right)$ & \\
\hline & 7) & Gm DIC & $\mathrm{mol} / \mathrm{m}^{\wedge} 3$ & \\
\hline & 8) & Gm DIC14 & $\mathrm{mol} / \mathrm{m}^{\wedge} 3$ & \\
\hline & 9) & Gm Surface DIC & $\mathrm{mol} / \mathrm{m}^{\wedge} 3$ & \\
\hline & 10) & Gm Surface DIC-14 & $\mathrm{mol} / \mathrm{m}^{\wedge} 3$ & \\
\hline & 11) & Gm pCo2surf & uatm & \\
\hline & 12) & Gm Delta pCO2 (dpCO2) & uatm & \\
\hline & 13) & Gm Surface Delta C-14 & permil & \\
\hline & 14) & Gm Delta $\mathrm{C}-14$ & permil & \\
\hline & 15) & Gm Cum. Gas Flux of DIC & $\mathrm{mol} / \mathrm{m}^{\wedge} 2$ & $1765->$ \\
\hline & 16) & Gm Cum. Gas Flux of DIC14 & $\mathrm{mol} / \mathrm{m}^{\wedge} 2$ & $1765->$ \\
\hline & 17) & Gm Cum. Virt. Flux of DIC & $\mathrm{mol} / \mathrm{m}^{\wedge} 2$ & $1765->$ \\
\hline & 18) & Gm Cum. Virt. Flux of DIC14 & $4 \mathrm{~mol} / \mathrm{m}^{\wedge} 2$ & $1765->$ \\
\hline write_nc_Abiotic_futr_year_3D.f & 1) & Conc. of DIC & $\mathrm{mol} / \mathrm{m}^{\wedge} 3$ & \\
\hline write_nc_Abiotic_futr_year_2D.f & 1) & Surf. ocean pCO2 & uatm & \\
\hline & 2) & Delta pCO2 (dpCO2) & uatm & \\
\hline & 3) & Gas Exch. Flux of DIC & $\mathrm{mol} /\left(\mathrm{m}^{\wedge} 2 * \mathrm{~s}\right)$ & \\
\hline & 4) & Virtual Flux of DIC & $\mathrm{mol} /\left(\mathrm{m}^{\wedge} 2 * \mathrm{~s}\right)$ & \\
\hline & 5) & Surface DIC & $\mathrm{mol} / \mathrm{m}^{\wedge} 3$ & \\
\hline & 6) & Vert. Integral of DIC & $\mathrm{mol} / \mathrm{m}^{\wedge} 2$ & \\
\hline & 7) & Cum. Gas Flux of DIC & $\mathrm{mol} / \mathrm{m}^{\wedge} 2$ & $1765->$ \\
\hline & 8) & Cum. Virt. Flux of DIC & $\mathrm{mol} / \mathrm{m}^{\wedge} 2$ & $1765->$ \\
\hline write_nc_Abiotic_futr_year_od.f & 1) & Glob_mean (Gm) pco2atm & uatm & \\
\hline & 2) & Gm Gas Ex. Flux of DIC & $\mathrm{mol} /\left(\mathrm{m}^{\wedge} 2{ }^{\star} \mathrm{s}\right)$ & \\
\hline & 3) & Gm Virtual Flux of DIC & $\mathrm{mol} /\left(\mathrm{m}^{\wedge} 2{ }^{\star} \mathrm{s}\right)$ & \\
\hline & 4) & $\mathrm{Gm}$ DIC & $\mathrm{mol} / \mathrm{m}^{\wedge} 3$ & \\
\hline & 5) & Gm Surface DIC & $\mathrm{mol} / \mathrm{m}^{\wedge} 3$ & \\
\hline & 6) & Gm pCo2surf & uatm & \\
\hline & 7) & Gm Delta pCO2 (dpCO2) & uatm & \\
\hline
\end{tabular}


8) Gm Cum. Gas Flux of DIC mol/m^2 1765->

9) Gm Cum. Virt. Flux of DIC mol/m^2 1765->

\begin{tabular}{|c|c|c|c|c|}
\hline \multirow{8}{*}{ write_nc_Abiotic_puls_year_2D.f } & 1) & Surf. ocean pCO2 & uatm & \\
\hline & 2) & Delta pCO2 (dpCO2) & uatm & \\
\hline & 3) & Gas Exch. Flux of DIC & $\mathrm{mol} /\left(\mathrm{m}^{\wedge} 2{ }^{\star} \mathrm{s}\right)$ & \\
\hline & 4) & Virtual Flux of DIC & $\mathrm{mol} /\left(\mathrm{m}^{\wedge} 2{ }^{\star} \mathrm{s}\right)$ & \\
\hline & 5) & Surface DIC & $\mathrm{mol} / \mathrm{m}^{\wedge} 3$ & \\
\hline & 6) & Vert. Integral of DIC & $\mathrm{mol} / \mathrm{m}^{\wedge} 2$ & \\
\hline & 7) & Cum. Gas Flux of DIC & $\mathrm{mol} / \mathrm{m}^{\wedge} 2$ & $1765->$ \\
\hline & $8)$ & Cum. Virt. Flux of DIC & $\mathrm{mol} / \mathrm{m}^{\wedge} 2$ & $1765->$ \\
\hline \multirow[t]{9}{*}{ write_nc_Abiotic_puls_year_od.f } & 1) & Glob_mean (Gm) pCO2atm & uatm & \\
\hline & 2) & Gm Gas Ex. Flux of DIC & $\mathrm{mol} /\left(\mathrm{m}^{\wedge} 2 * \mathrm{~s}\right)$ & \\
\hline & 3) & Gm Virtual Flux of DIC & $\mathrm{mol} /\left(\mathrm{m}^{\wedge} 2^{\star} \mathrm{s}\right)$ & \\
\hline & 4) & Gm DIC & $\mathrm{mol} / \mathrm{m}^{\wedge} 3$ & \\
\hline & 5) & Gm Surface DIC & $\mathrm{mol} / \mathrm{m}^{\wedge} 3$ & \\
\hline & 6) & Gm pCO2surf & uatm & \\
\hline & 7) & Gm Delta pCO2 (dpCO2) & uatm & \\
\hline & 8) & Gm Cum. Gas Flux of DIC & $\mathrm{mol} / \mathrm{m}^{\wedge} 2$ & $1765->$ \\
\hline & 9) & Gm Cum. Virt. Flux of DIC & $\mathrm{mol} / \mathrm{m}^{\wedge} 2$ & $1765->$ \\
\hline \multirow[t]{2}{*}{ write_nc_Abiotic_TS_year.f } & 1) & Potential temperature & degrees $\mathrm{C}$ & $(*)$ \\
\hline & 2) & Salinity & psu & \\
\hline
\end{tabular}

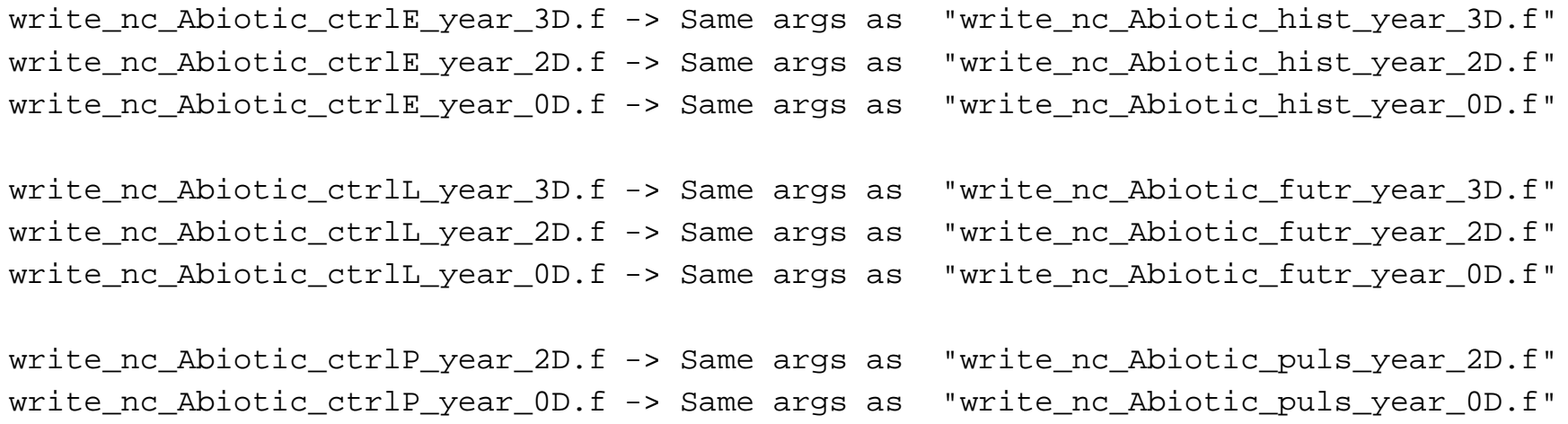

(*) For the equilibrium run: for online models, all 2- and 3-D fields should be averaged for each month over the last year of the simulation. 


\subsection{Downloading the output routines}

The output routines can be transferred to your machine by clicking on the links below, while holding down the Shift key.

- write_nc_MaskAreaBathy.f (This routine is the same as linked to the CFC HOWTO; thus, there is no need to recuperate it if you have already contributed OCMIP-2 CFC results).

- write_nc_Abiotic_equil.f

- write_nc_Abiotic_hist_year_3D.f

- write_nc_Abiotic_hist_year_2D.f

- write_nc_Abiotic_hist_year_0D.f

- write_nc_Abiotic_futr_year_3D.f

- write_nc_Abiotic_futr_year_2D.f

- write_nc_Abiotic_futr_year_0D.f

- write_nc_Abiotic_puls_year_2D.f

- write_nc_Abiotic_puls_year_0D.f

- write_nc_Abiotic_TS_year.f

- write_nc_Abiotic_ctrlH_year_3D.f

- write_nc_Abiotic_ctrlH_year_2D.f

- write_nc_Abiotic_ctrlH_year_0D.f

- write_nc_Abiotic_ctrlF_year_3D.f

- write_nc_Abiotic_ctrlF_year_2D.f

- write_nc_Abiotic_ctrlF_year_0D.f

- write_nc_Abiotic_ctrlP_year_2D.f

- write_nc_Abiotic_ctrlP_year_0D.f

You will also need to transfer the subroutine handle_errors.f to properly deal with possible errors while you are writing your netCDF files. 


\subsection{Compiling the output routines}

Here is a an example of how you would compile one of the output routines:

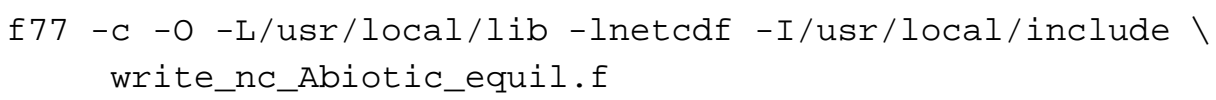

Because we have made these routines F77 compatible, you may need a function len_trim.f (from F90), which we also provide and which returns the length of a character string (after neglecting trailing blanks).

\subsection{Using the output routines}

\subsubsection{Equilibrium Output}

The Abiotic-run output routines store your model results following the naming and output conventions (netCDF, GDT version 1.2) chosen for OCMIP-2. The output filename is constructed automatically within each routine from three of the arguments: the tracer name, the year, and the standard model code <http: / / www.ipsl.jussieu.fr/OCMIP/phase2/\#modgroups> used during OCMIP-2 to identify your group.

For example, after compiling and linking the OCMIP-2 output routines, we add the following code to the IPSL routines to store output in standard OCMIP-2 form

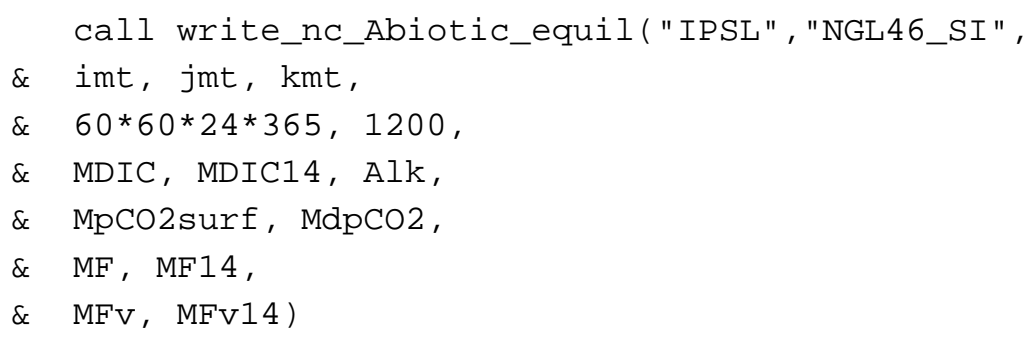

By line, the arguments include

1. the OCMIP-2 model code AND your own model version indicator (in GDT 1.2 terminology, these 2 variables refer to the institution and production, respectively);

2. dimensions;

3. the number of seconds per year (in your model), and the number of timesteps per year;

4. the 12 monthly means for the 3-D tracer arrays for DIC (mol/m^3) and DIC14 (mol/m^3) and for the Alk computed from eq. (8) (eq/m^3).

5. the 12 monthly means for the 2-D arrays for surface ocean pCO2 (pCO2surf, in uatm) and the sea-air pCO2 difference (dpCO2, in uatm).

6. the 12 monthly means for the 2-D air-sea flux for F and F14 (both in $\mathrm{mol} /\left(\mathrm{m}^{\wedge} 2 * \mathrm{~s}\right)$ ); and 
7. the 12 monthly means for the 2-D arrays for the surface "virtual" fluxes Fv and Fv14 (both in mol/(m^2*s));

When do I call the above Equilibrium output routine? It should be called only once, at the end of the simulation after building monthly arrays (12 members) for each of the 2-D and 3-D spatial fields given as arguments.

\subsubsection{Historical Output}

We need to use a slightly different routines for saving transient results from the Historical run. Unlike the equilibrium run, we separately store 3-D, 2-D, and 0-D data. The reason is that we store the higher dimensional data less often, to save space.

For your 3-D model output for the Abiotic Historical run, use

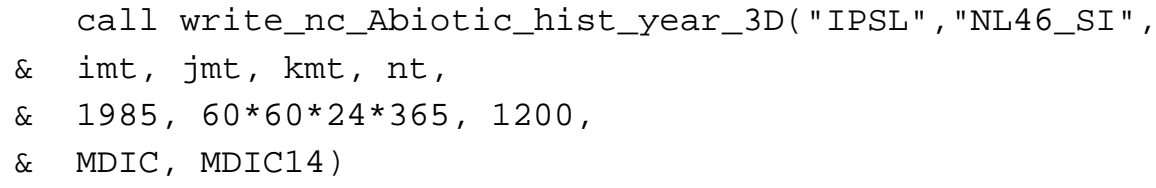

Note that we have also added the dimension $n t$ on line 2. You must use nt to signal if you are passing annual means $(n t=1)$ or monthly means $(n t=12)$. The argument $n t$ is used in the same fashion for routines that follow. The 3-D input arrays MDIC and MDIC14 are as described for the Equilibrium run.

When do I call the above 3-D Historical output routine? It should be called for each of the following times:

- with $n t=12$ (monthly means, 12 records per year) for each of the years $1838,1953,1954,1957,1965,1972$, 1973, 1974, 1977, 1978, 1981, 1982, 1983, 1985, 1986, 1987, 1988, 1989, 1991, 1993, 1995, 1997, 1999.

- with $n t=1$ (annual means, 1 record per year) for each of the years $1838,1839,1900$, and every year for 1953-1999 (inclusive).

For your 2-D Historical output, use

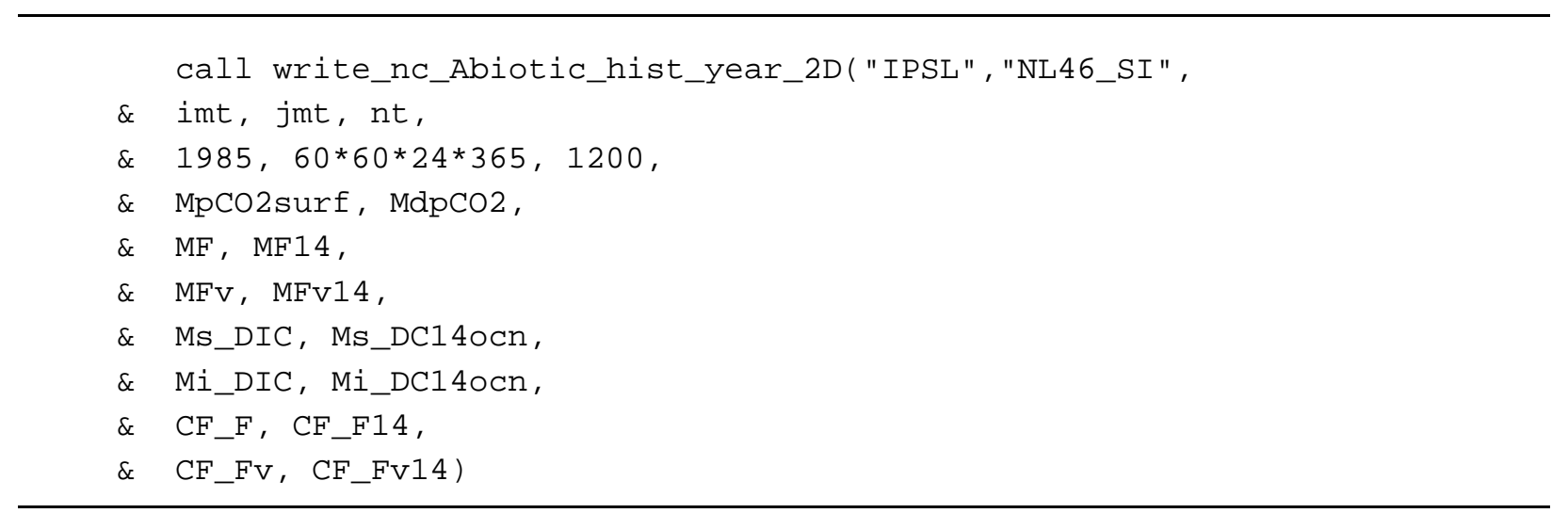

For 2-D output, we no longer need the dimension kmt, formerly in line 2. Conversely, we need supplemental 2-D model output for the Historical run which was not included in the equilibrium output. This supplemental 2-D output is needed to due to the Historical run's transient nature and our asynchronous saving of its 2-D and 3-D output. Supplemental 2-D Historical output includes 
- line 7: the mean surface DIC (mol/m^3) and DC14ocn (permil), see eq. (11);

- line 8: the mean vertical inventory of DIC (mol/m^2) and DC14ocn (permil * m);

- line 9: the end-of-year 2-D cumulative flux for F (mol/m^2) and F14 (mol/m^2);

- line 10: the end-of-year 2-D cumulative flux for Fv and Fv14 (both in mol/m^2)

Cumulative fluxes (lines 9 and 10 above) must be initialized to zero and integrated with respect to time (i.e., each time step) from year=1765.0. Note that these values should be output only at the end of each year, regardless of whether $n t=12$ or $n t=1$.

When do I call the above 2-D Historical output routine? It should be called with $n t=12$ for each of the following years: 1838, 1839, 1900, and every year for 1948-1999 (inclusive).

For 0-D (1-D with time) Historical output, use

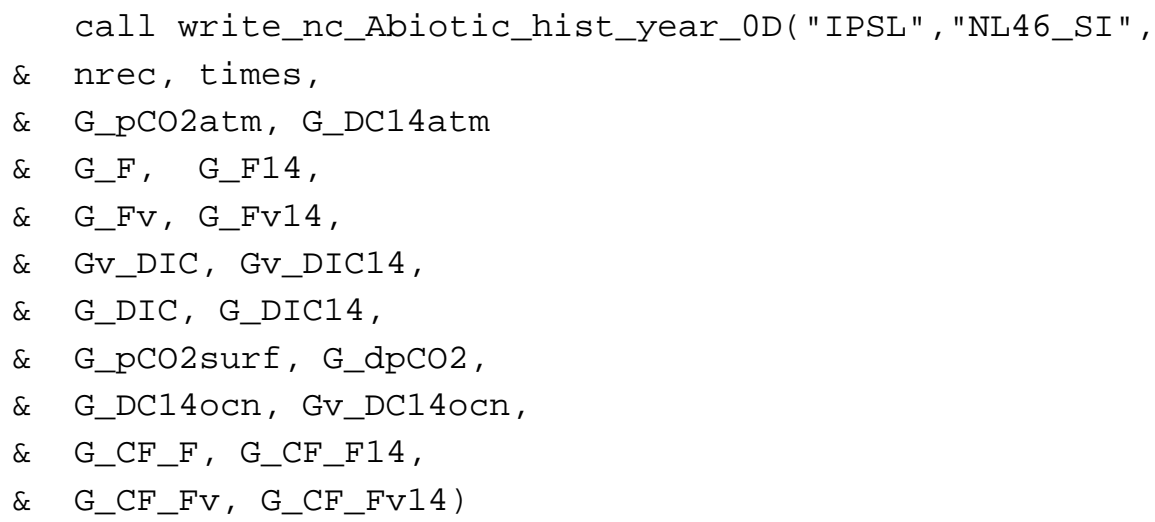

By line, the arguments include

1. the OCMIP-2 model code AND your own model version indicator (in GDT 1.2 terminology, these 2 variables refer to the institution and production, respectively);

2. the number of records saved and the array of the times (in decimal years) at which they were saved-for monthly means, times should be set to the corresponding time at mid-month (see below for exact values).

3. the corresponding arrays of the history of the global mean atmospheric CO2 (model input, in uatm) and global mean atmospheric C-14 (in permil, calculated from model input as an area weighted mean of your ocean grid boxes that you have identified as being in the $90 \mathrm{~S}-20 \mathrm{~S}, 20 \mathrm{~S}-20 \mathrm{~N}$, and $20 \mathrm{~N}-90 \mathrm{~N}$ latitudinal bands);

4. the corresponding array of the history of the global mean air-sea flux F (mol/m^2*s) and F14 (mol/m^2*s);

5. the history of the global mean virtual fluxes Fv (mol/m^2*s) and Fv14 (mol/m^2*s);

6. the history of the global mean concentrations of DIC (mol/m^3) and DIC14 (mol/m^3);

7. the history of the global mean surface concentrations of DIC (mol/m^3) and DIC14 (mol/m^3); 


\section{- For CIS92A}

- with $n t=12$ for both of the following years: 2000 and 2099

- with $n t=1$ for each of the following years: 2000, 2010, 2020, 2040, 2060, 2080, and 2099.

\section{- For $\mathbf{S 6 5 0}$}

- with $n t=12$ for each of the following years: 2000, 2100, 2200, 2299

- with $n t=1$ for each of the following years: 2000, 2010, 2020, 2040, 2060, 2080, 2100, 2120, 2140, 2160, 2180, 2200, 2220, 2240, 2260, 2280, 2299.

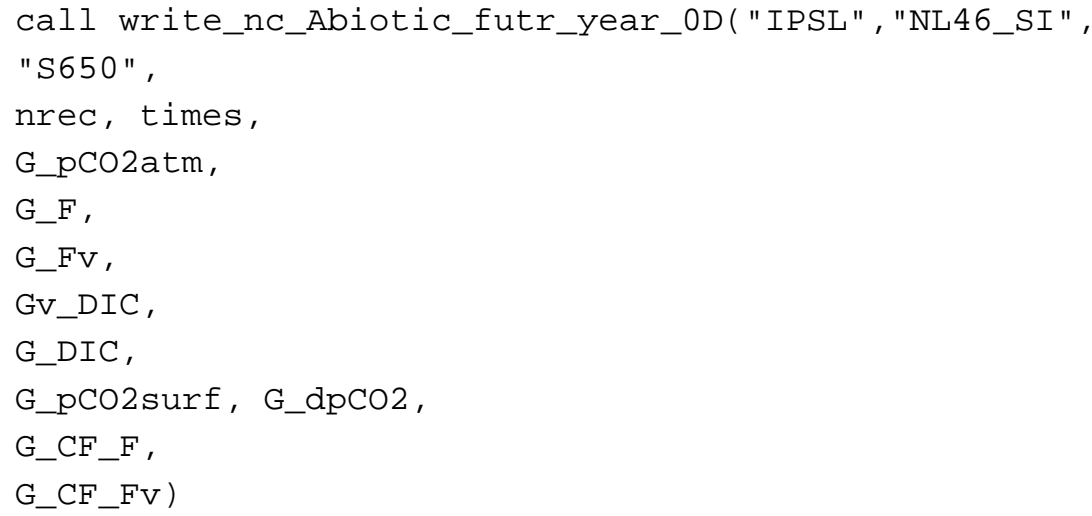

When do I call the above 0-D Future output routine? It should be called only once, after constructing 1-D (in time) arrays from all of your model output. The time storage frequency is regular: every month throughout the entire run (i.e., all years 1990-2299, inclusive). Thus modelers must use $n r e c=3720$, and they must fill the 1-D temporal array times) with appropriate corresponding values (i.e., 1990.04167, 1990.125, 1990.2083, 1990.29167, 1990.375, ..., 2299.875, 2299.9583).

\subsubsection{Pulse Output}

Another set of 2 routines is needed for storing the 2-D and 0-D results from the Pulse run; for that run there is NO 3-D output. Differences relative to the Pulse output routines are

- the scenario specification has been removed (only 1 pulse run is to be made); and

- the $n t$ term has been removed from the 2-D routine since 2-D output is to be saved only for annual means, not monthly means.

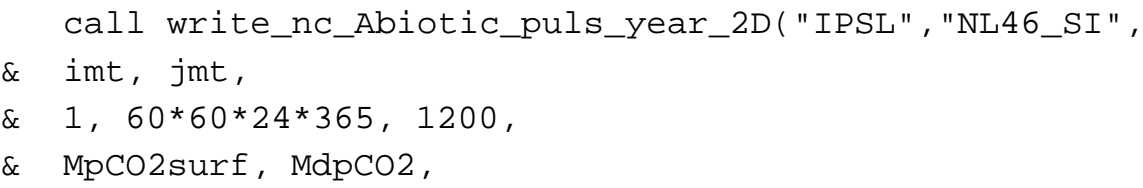




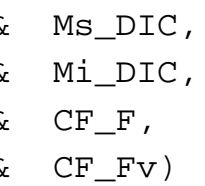

When do I call the above 2-D Pulse output routine? It should be called using annual means, for each of the following years: $0,1,2,3,4,5,6,7,8,9,10,20,30,40,50,60,70,80,90,100,200,300,400,500,600,700,800$, 900, and 999. These details are given in a structured way in the previous section (Output type and Frequency).

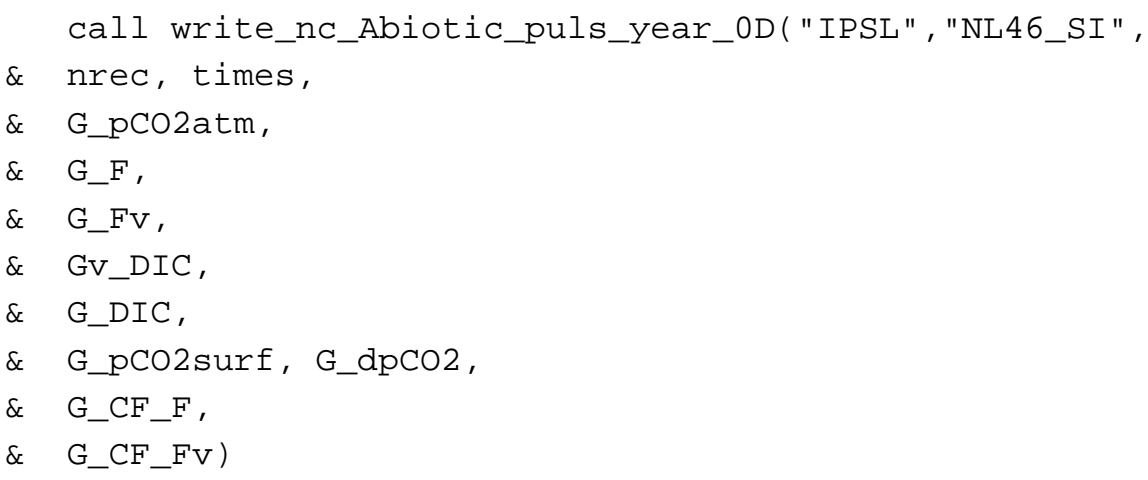

When do I call the above 0-D Pulse output routine? It should be called only once, after constructing 1-D (in time) arrays from all of your model output. The time storage frequency (spacing between individual members of the array times) is NOT regularly spaced in time. For the 0-D Pulse run, output as specified by times must be given for

- every month from years 0.0 to 10.0 (i.e., 12 x $10=120$ records), with corresponding monthly means provided at mid-month (i.e., for times $=0.04167,0.1250,0.2083,0.29167,0.3750, \ldots 9.875,9.9583$ );

- every year from years 10.0 to 100.0 (i.e., 90 records), with corresponding annual means provided at mid-year (i.e., for times $=10.5,11.5,12.5, \ldots 99.5)$;

- every 10 years from years 100.0-991.0 (i.e., 90 records), with corresponding annual means provided at mid-year (i.e., for times $=100.5,110.5,120.5,130.5, \ldots 990.5$ ); and

- the final year (i.e., 1 record), with its corresponding annual means provided at mid-year (i.e., for times $=999.5$ ).

Thus with this irregular spacing, models must use nrec $=301$ (i.e., $120+90+90+1$ ).

\subsubsection{Control Output}

Finally we need to store output for the control run. The control run is necessary because 3-D tracer fields and associated fluxes in our Equilibrium run never reach perfect equilibrium. The associated drift affects results for the transient runs. Correcting for drift may be important when comparing model differences, particularly integrated quantities, over long time periods. The control run is needed to drift-correct models, before comparison. It is desirable that all groups make all three control runs, but this may not be possible for some, due to CPU requirements. Below are a few guidelines to help you decide when the Control runs are necessary and what shortcuts can be taken: 
1. If you will make the Pulse run, you MUST also make the equivalent Pulse Control run.

2. If you have NOT respected the Equilibrium drift criteria you MUST make the Historical Control and Future Control runs.

3. If you have respected the recommended Equilibrium drift criteria, you may skip making the Historical Control and Future Control runs. However, we do HIGHLY RECOMMEND that you make these simulations, if you can afford them, i.e., if they do not represent a large proportion of your annual CPU budget. Having this output will simplify analysis and eliminate guess work.

4. If you have respected the Equilibrium drift criteria and choose not to submit Historical Control and Future Control output, you MUST still provide an indication of the drift of your model. In other words, you must use the three ${ }^{*} \mathrm{ctrlH}{ }^{*}$ routines (see below) to provide your output for another year. For instance, you could provide output from the $0-\mathrm{D}, 2-\mathrm{D}$, and $3-\mathrm{D} * \mathrm{ctrlH} *$ routines for the year 1775 . We would then compute your model drift and treat it as constant.

Those who will be making all the $\mathrm{CO} 2$ Injection simulations can economize a little. That is, with those runs, one automatically makes make both the Late Control and the Pulse Control runs, simultaneoulsy. The first of the ten Injection tracers is the control tracer. Unfortunately, the Injection runs do NOT offer an opportunity to skip the Historical Control run. For more details, see the final version of the Injection HOWTO.

Arguments of the Control output routines are the same as those used in the Historical, Future, and Pulse output routines, as described below.

1. Historical Control output (for 1765-1999, inclusive): We save both the DIC and DIC14 related components. We use 3 routines, with the same arguments as the 0-D, 2-D, and 3-D Historical output routines.

- When do I call the above 3-D Historical Control output routine (write_nc_Abiotic_ctrlH_3D.f)? It should be called with Annual means $(n t=1)$ for 1765, 1838, 1839, 1900, and every year from 1953-1999 (inclusive).

- When do I call the above 2-D Historical Control output routine (write_nc_Abiotic_ctrlH_2D.f)? It should be called with Annual means $(n t=1)$ for 1765, 1838, 1839, 1900, and every year from 1948-1999 (inclusive).

- When do I call the above 0-D Historical Control output routine (write_nc_Abiotic_ctrlH_0D.f)? It should be called only once, after constructing 1-D (in time) arrays from all of your model output. The time storage frequency is regular: every month throughout the entire run (i.e., all years 1765-1999, inclusive). Thus modelers must use $n r e c=2820$, and fill the the 1-D temporal array times with the appropriate values (i.e., 1765.04167, 1765.125, 1765.2083, 1765.29167, 1765.375, ... 1999.875, 1999.9583). The Historical Control Run uses the same nrec and times array as does the Historical run.

2. Future Control output (for 2000-2764, inclusive): We save only the DIC-related component. We use 3 routines with the same arguments as the $0-\mathrm{D}, 2-\mathrm{D}$, and 3-D Future output routines.

- When do I call the above 3-D Future Control output routine (write_nc_Abiotic_ctrlF_3D.f)? It should be called with Annual means ( $n t=1$ ) for years 2000, 2010, 2020, 2040, 2060, 2080, 2099, 2100, 2120 , 2140, 2160, 2180, 2200, 2220, 2240, 2260, 2280, 2299. 
- When do I call the above 2-D Future Control output routine (write_nc_Abiotic_ctrlF_2D.f)? It should be called with Annual means ( $n t=1$ ) for years 2000, 2010, 2020, 2040, 2060, 2065, 2080, 2099, 2100 , 2120, 2140, 2160, 2165, 2180, 2200, 2220, 2240, 2260, 2265, 2280, 2299.

- When do I call the above 0-D Future Control output routine (write_nc_Abiotic_ctrlF_0D.f)? It should be called only once, after constructing 1-D (in time) arrays from all of your model output. The time storage frequency is regular: every month throughout the entire run (i.e., all years 2000-2300, inclusive). Thus modelers must use $n r e c=3600$, and they must fill the 1-D temporal array times) with appropriate corresponding mid-month values (i.e., 2000.04167, 2000.125, 2000.2083, 2000.29167, 2000.375, ..., $2299.875,2299.9583)$. Note that nrec and times are NOT identical to those used when calling the analogous 0-D routine to save Future output (i.e., nrec is smaller; times starts 10 years later).

3. Pulse Control output (for 2000-2764, inclusive): We save only the DIC-related component. We use 2 routines with the same arguments as the 0-D and 2-D Pulse output routines.

- When do I call the above 2-D Pulse Control output routine (write_nc_Abiotic_ctrlP_2D.f)? It should be called with Annual means ( $n t=1)$ for years $0,1,2,3,4,5,6,7,8,9,10,20,30,40,50,60,70,80,90$, 100, 200, 300, 400, 500, 600, 700, 800, 900, and 999.

- When do I call the above 0-D Pulse Control output routine (write_nc_Abiotic_ctrlP_0D.f)? It should be called only once, after constructing 1-D (in time) arrays from all of your model output. The time storage frequency is NOT regularly spaced in time. For the 0-D Pulse Control run, output as specified by times must be given for

- every month from years 0.0 to 10.0 (i.e., 12 x $10=120$ records), with corresponding monthly means provided at mid-month (i.e., for times $=0.04167,0.1250,0.2083,0.29167,0.3750, \ldots 9.875,9.9583$ );

- every year from years 10.0 to 100.0 (i.e., 90 records), with corresponding annual means provided at mid-year (i.e., for times $=10.5,11.5,12.5, \ldots 99.5$ );

- every 10 years from years 100.0-991.0 (i.e., 90 records), with corresponding annual means provided at mid-year (i.e., for times $=100.5,110.5,120.5,130.5, \ldots 990.5$ ); and

- the final year (i.e., 1 record), with its corresponding annual means provided at mid-year (i.e., for times $=999.5)$.

Thus with this irregular spacing, models must use $n r e c=301$ (i.e., $120+90+90+1$ ).

\subsubsection{Names of Output files}

All arguments of the Abiotic routines are input; none are output. With the arguments as listed in the nine routines above, The corresponding output netCDF files are

- "IPSL_Abiotic_equil.nc";

- "IPSL_Abiotic_hist_1985_3D.nc", "IP SL_Abiotic_hist_1985_2D .nc",

"IPSL_Abiotic_hist_global_OD .nc";

- "IPSL_Abiotic_S650_2000_3D . nc", "IP SL_Abi ot i C_S650_2000_2D .nc",

"IPSL_Abiotic_S650_global_0D.nc";

- "IPSL_Abiotic_puls_0001_2D.nc", "IPSL_Abiotic_puls_global_0D.nc". 
- "IPSL_Abiotic_ctr1H_1985_3D.nc", "IPSL_Abiotic_ctrlH_1985_2D.nc",

"IPSL_Abiotic_ctrlH_global_oD.nc";

- "IPSL_Abiotic_ctrlF_2000_3D.nc", "IPSL_Abiotic_ctrlF_2000_2D.nc",

"IPSL_Abiotic_ctrlF_global_0D .nc";

- "IPSL_Abiotic_ctrlP_0001_2D.nc", "IPSL_Abiotic_ctrlP_global_0D.nc".

These files along with all others produced by the Abiotic routines should be trasferred to IPSL (see section Transfer of output). Filenames should NOT be changed. Subsequently, at IPSL, files will be (1) tested for consistency, (2) included in the OCMIP-2 data base, and (3) processed for base analysis.

\subsection{Need more details?}

See <http: / /www.ipsl.jussieu.fr/OCMIP/tech>. for additional information about the format netCDF and other conventions (COARDS, GDT) chosen for storing OCMIP-2 model output.

If you have other questions, please contact orr@cea.fr or Patrick.Brockmann@ipsl.jussieu.fr.

\section{Transfer of output}

We provide details only for transferring Equilibrium Output. Output from the other Abiotic simulations (Historical Output, Future Output, Pulse Output, and Control Output) should be transferred in an analogous fashion.

The Equilibrium Output files IPSL_Abiotic_equil.nc and IPSL_Abiotic_TS_year.nc should first be compressed.

gzip IPSL_Abiotic_equil.nc IPSL_Abiotic_TS_year.nc

If gzip is not available on your machine, the alternative is to use compress. After compression, you should ftp your files to LSCE for processing and analysis. Your model output could be quite large depending upon model resolution. Fear not though, because we have the disk space to accommodate output from all OCMIP models. Contact us if the ftp transfer rate is inadequate. In that case, you'll need to write your output to tape (DDS, DDS2, Exabyte, or DLT) and mail it to

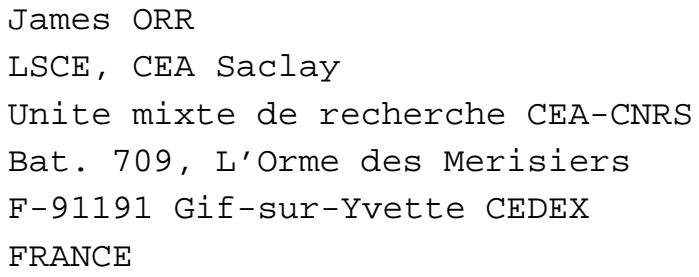

Here are the commands to transfer your output by ftp: 


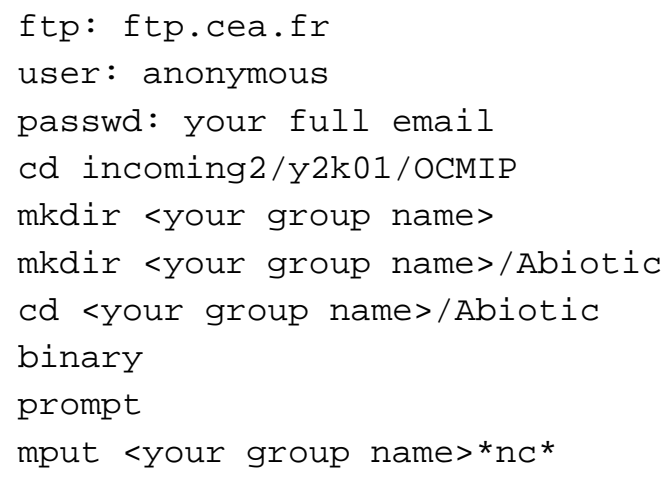

Then e-mail us (orr@cea.fr and Patrick.Brockmann@ipsl.jussieu.fr) that your transfer is complete.

To avoid confusion, you can create further subdirectories (Abiotic/equil, Abiotic/hist, Abiotic/futr, Abiotic/puls, and Abiotic/ctrl) to distinguish the five different types of runs. The ftp archive is erased automatically every 8 days, so be sure to contact us as soon as you have completed transfer, and save your output files at least until we have notified you that they have been transferred to the OCMIP-2 model output archive.

\section{References}

Aumont, O., J. C. Orr, D. Jamous, P. Monfray, O. Marti, and G. Madec, 1998. A degradation approach to accelerate simulations to steady-state in a 3-D tracer transport model of the global ocean. Climate Dynamics, 14, 101-116.

Broecker, W.S., J. R. Ledwell, T. Takahashi, R. Weiss, L. Merlivat, L. Memery, T.-H. Peng, B. Jahne, and K. O. Munnich, 1986. Isotopic versus micrometeorlogic ocean CO2 fluxes, J. Geophys. Res., 91, 10517-10527.

Enting, I.G., T. M. L. Wigley, M. Heimann, 1994. Future Emissions and concentrations of carbon dioxide: key ocean / atmosphere / land analyses, CSIRO Aust. Div. Atmos. Res. Tech. Pap. No. 31, 118 pp.

Joos, F., M. Bruno, R. Fink, T. F. Stocker, U. Siegenthaler, C. Le \{Quéré\}, and J. L. Sarmiento, 1996. An efficient and accurate representation of complex oceanic and biospheric models of anthropogenic carbon uptake, Tellus, Ser. B, 48, 397-417.

Levitus, S., 1982. Climatological atlas of the World Ocean, NOAA Prof. Pap. 13, U.S. GPO., Washington, D.C., 173 pp.

Maier-Reimer, E. and K. Hasselmann, 1987. Transport and storage of CO2 in the ocean-an inorganic ocean-circulation carbon cycle model, Clim. Dyn., 2, 63-90, 1987.

Sarmiento, J. L., J. C. Orr, and U. Siegenthaler, 1992. A perturbation simulation of CO2 uptake in an ocean general circulation model, J. Geophys. Res., 97, 3621-3645.

Walsh, J. 1978. A data set on northern hemisphere sea ice extent, 1953-1976. Glaciological Data, World Data Center for Glaciology (Snow and Ice), Report GD-2, 49-51.

Wanninkhof, R., 1992. Relationship between wind speed and gas exchange over the ocean, J. Geophys. Res., 97 , 7373-7382. 
Warner, M. J. and R. F. Weiss (1985) Solubilities of chlorofluorocarbons 11 and 12 in water and seawater, Deep-Sea Res., 32, 1485-1497.

Zheng M., W. J. DeBruyn, and E. S. Saltzman, 1998. Measurements of the diffusion coefficients of CFC-11 and CFC-12 in pure water and seawater, J. Geophys. Res., 103, 1375-1379.

Zwally, H. J., J. Comiso, C. Parkinson, W. Campbell, F. Carsey, and P. Gloerson, 1983. Antarctic Sea Ice, 1973-1976: Satellite Passive Microwave Observations, NASA, 206 pp.

\section{Contacts}

orr@cea.fr, brock@1sce.saclay.cea.fr

\section{Same document, another format?}

This document is available in other formats:

- HTML ( <HOWTO-Abiotic.html>)

- Postscript ( <HOWTO-Abiotic.ps>)

- ASCII ( <HOWTO-Abiotic.txt $>$ )

- $\operatorname{LaTeX}(<$ HOWTO-Abiotic.tex $>)$

- DVI ( <HOWTO-Abiotic.dvi>) 


\section{Biotic-HOWTO}

R. G. Najjar and J. C. Orr

Revision: 1.7, Date: 1999/10/05 16:42:16

This document provides step-by-step guidelines to make the so-called "nutrient-restoring" runs for phosphate, oxygen, dissolved organic phosphorus, dissolved inorganic carbon and alkalinity according to the standard OCMIP-2 protocols.

\section{Contents}

1 Recuperation of OCMIP-2 files by ftp: 3

2 Model runs $\quad 4$

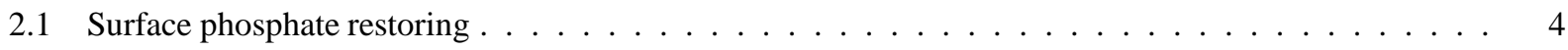

2.2 Conservation equations $\ldots \ldots \ldots \ldots \ldots \ldots \ldots \ldots$

2.3 Virtual fluxes $(\mathrm{FvDIC}$ and FvAlk $) \ldots \ldots \ldots \ldots \ldots \ldots$

2.4 Air-sea gas exchange fluxes $(\mathrm{FgDIC}$ and $\mathrm{FgO} 2) \ldots \ldots \ldots \ldots$

2.5 The Piston Velocities $\left(\mathrm{KwCO} 2\right.$ and $\left.\mathrm{KwO}_{2}\right) \ldots \ldots \ldots \ldots \ldots$

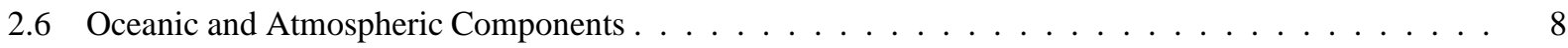

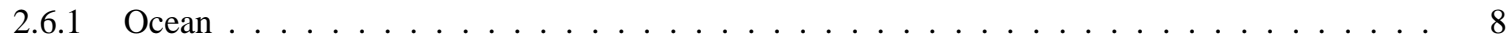

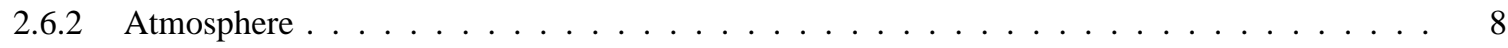

3 Initialization and duration of simulations $\quad 9$

4 Output type and frequency $\quad 9$

5 Output Format $\quad 10$

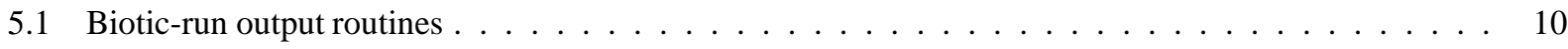

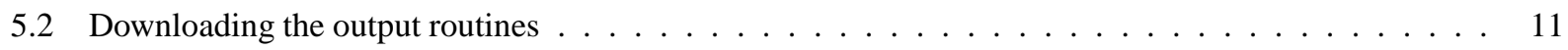

5.3 Compiling the output routines $\ldots \ldots \ldots \ldots \ldots \ldots \ldots \ldots$

5.4 Using the output routines . . . . . . . . . . . . . . . . . . . . . . . 12

5.5 Need more details? . . . . . . . . . . . . . . . . . . . . . . . . . . . 13

$\begin{array}{llr}6 & \text { Transfer of output } & 14\end{array}$

$\begin{array}{lll}7 & \text { Who has submitted what? } & 14\end{array}$

8 References $\quad 15$ 
9 Contacts

10 Same document, another format? 


\section{Recuperation of OCMIP-2 files by ftp:}

To comply with OCMIP-2 guidelines, all modelers must make simulations according to OCMIP-2 standard boundary conditions. To do so, one must first recuperate the following files via this Web page (you can save a file to disk by clicking a link while holding down the Shift key)

- Files concerning gas exchange (same for all OCMIP-2 runs)

- rgasx_ocmip2.f

- gasx_ocmip2.nc.gz

- vgasx_ocmip2.jnl

- Files concerning phosphate maps

- README.po4maps

- po4mapnew.dat.gz

- readmap.f

- nutrient-doc

- feb0m.ps

- aug0m.ps

- dif0m.ps

- Files concerning common biotic model

- bio.f

- bio.h

- jbio.f

- co2flux.f

- o2flux.f

- o2sato.f

- $\operatorname{scco} 2 . \mathrm{f}$

- sco2.f

- Files concerning standard carbonate chemistry (same for all OCMIP-2 carbon runs)

- README.Cchem

- Makefile

- co2calc.f

- drtsafe.f

- ta_iter_1.f

- test.r 
- test.out.gz

After transfer, the files containing the OCMIP-2 boundary conditions for gas exchange (gasx_ocmip2.nc.gz) and phosphate restoring po4map.dat.gz should be uncompressed as follows:

gunzip gasx_ocmip2.nc

gunzip po4mapnew.dat

Other files are text and need no special treatment after transfer. Use of these files is described below.

\section{Model runs}

\subsection{Surface phosphate restoring}

F. Louanchi has created a monthly climatology of phosphate in the upper ocean that is to be used to nudge the model towards observations in the upper $75 \mathrm{~m}$. These data are on a $2 \times 2$ degree grid for the six following depth levels: 0 , 10, 20, 30, 50 and $75 \mathrm{~m}$. The data are in the file po4mapnew.dat.gz. See the files README.po4maps, readmap.f, and nutrient-doc for further information. All modelers are required to linearly interpolate the phosphate maps spatially and temporally to their model grid. Units of the phosphate maps are mmol/m^3 and these will have to be converted by each group to model units of $\mathrm{mol} / \mathrm{m}^{\wedge} 3$.

\subsection{Conservation equations}

There are five tracers carried in this run: phosphate (PO4), dissolved organic phosphorus (DOP), oxygen (O2), dissolved inorganic carbon (DIC) and alkalinity (Alk). The corresponding conservation equations are

(1a) $\mathbf{d}[\mathbf{P O 4}] / \mathbf{d t}=\mathbf{L}([\mathbf{P O 4}])+\mathbf{J b P O 4}$

(1b) $\mathbf{d}[\mathrm{DOP}] / \mathbf{d t}=\mathbf{L}([\mathrm{DOP}])+\mathbf{J b D O P}$

(1c) $\mathbf{d}[\mathrm{O} 2] / \mathrm{dt}=\mathrm{L}([\mathrm{O2}])+\mathrm{JbO2}+\mathrm{JgO2}$

(1d) $\mathbf{d}[$ DIC $] / \mathbf{d t}=\mathbf{L}([\mathrm{DIC}])+\mathbf{J b D I C}+\mathbf{J g D I C}+\mathbf{J v D I C}$

(1e) $\mathbf{d}[\mathrm{Alk}] / \mathbf{d t}=\mathbf{L}([\mathrm{Alk}])+\mathbf{J b A l k}+\mathbf{J v A l k}$

where

- $\mathbf{L}$ is the 3-D transport operator, which represents effects due to advection, diffusion, and convection;

- [] or "square brackets" indicate concentrations in moles/m^3 (or eq/m^3 for Alk);

- JbX is the biological source sink term for X;

- JvDIC and JvAlk are the "virtual" source-sink terms for changes in surface $D I C$ and $A l k$, respectively, due to evaporation and precipitation; and

- JgDIC and JgO2 are the source-sink terms due to air-sea exchange of CO2 and O2, respectively. 
The source-sink terms JvDIC, JvAlk, JgDIC, and JgO2 are added only as surface boundary conditions. That is they are equal to zero in all subsurface layers. These source-sink terms are equivalent to the fluxes, described below, divided by the surface layer thickness dz1.

$$
\begin{aligned}
& \text { JvDIC= FvDIC/dz1 } \\
& \text { JvAlk }=\text { FvAlk } / \text { dz1 } \\
& \text { JgDIC }=\text { FgDIC/dz1 } \\
& \text { JgO2 }=\text { FgO2/dz1 }
\end{aligned}
$$

The Jb terms are rather detailed and are described in the OCMIP-2 simulation design document; they are not repeated here. We have supplied some Fortran code, found in the files bio.h, bio.f, and jbio.f. This code should be used to compute the $\mathrm{Jb}$ terms. However, this code serves only as a template, which must be modified by each group to suit their particular model.

\subsection{Virtual fluxes (FvDIC and FvAlk)}

In models where surface salinity is restored to observed values, this results in a surface flux of salt, not a surface flux of water as in the real world. Such surface salt fluxes are typically found in models with a rigid lid, and even in some models with a free surface (e.g., the OGCM from Louvain-la-Neuve). For simplicity, we categorize both classes of models as "rigid-lid-like". Conversely, non-rigid-lid-like models have a free surface and restore surface salinity by an equivalent flux of water leading to dilution or concentration (e.g., the MPI LSG model). Salinity in the latter type of free-surface model is conserved; E-P fluxes are taken into account by the velocity fields and thus do not need to be explicitly formulated in the transport model.

Yet for all rigid-lid-like models, we must explicitly take into account the concentration-dilution effect of E-P (Evaporation minus Precipitation), which changes surface [DIC] and [Alk]. Thus we add the virtual flux to the surface layer, each time step according to

(2a) $\quad$ FvDIC $=$ DICg $*(\mathbf{E}-\mathbf{P})$

(2b) FvAlk = Alkg * (E-P)

where DICg and Alkg are the model's globally averaged surface concentrations of DIC and Alk, respectively. Both global averages must be computed at least every five years. For rigid-lid-like models with only salinity restoring, we suggest that $(\mathrm{P}-\mathrm{E})$ be computed as

(3) $\mathbf{P}-\mathbf{E}=\left(S-S^{\prime}\right) / S g * \mathbf{d z 1} / \mathrm{Tau}$

where $\mathbf{S}$ ' is the observed local salinity to which modeled local salinity $\mathbf{S}$ is being restored, $\mathbf{S g}$ is the model's globally averaged surface salinity, $\mathbf{d z 1}$ is the top layer thickness, and Tau is the restoring time scale for salinity. For rigid-lid models (or free surface models) which in addition include explicit P - E water fluxes, that term must of course also be added to eq (3).

IMPORTANT: It is critical that the virtual fluxes do not result in a net flux of alkalinity to or from the model. There are at least two ways of getting around this. One possibility is to insure that the global mean of $\mathrm{E}-\mathrm{P}$ used in equations (2a) and (2b) is equal to zero. This could be achieved by subtracting off the global mean E - P before computing the virtual flux. A second possibility is to update the inventory of alkalinity periodically so that the inventory of alkalinity $+16^{*}$ phosphate is at its initial value. See also Section 3 . 


\subsection{Air-sea gas exchange fluxes (FgDIC and FgO2)}

For simulations of DIC and O2, OCMIP-2 simulations will directly model the finite air-sea fluxes FgDIC and FgO2, respectively. Modelers must use the formulation for the standard OCMIP-2 air-to-sea flux:

(4a) FgDIC $=$ KwCO2 (CO2sat - CO2surf)

(4b) $\mathrm{FgO2}=\mathrm{KwO2} \mathrm{(O2sat}-$ O2surf)

with

(5a) CO2sat $=$ alphaC $*$ pCO2atm $* \mathbf{P} / \mathbf{P o}$

(5b) O2sat $=\mathbf{O} 2$ sato $^{*} \mathbf{P} / \mathbf{P o}$

where

- KwCO2 and KwO2 are the $\mathrm{CO} 2$ and $\mathrm{O} 2$ gas transfer (piston) velocities [m/s], respectively;

- CO2surf is the surface aqueous $\mathrm{CO} 2$ concentration [mol/m^3], which is computed from the model's surface [DIC], T, S, [Alk], and [PO4]; (see section 2.6);

- O2surf is the surface $\mathrm{O} 2$ concentration [mol/m^3] computed by the model;

- alphaC is the $\mathrm{CO} 2$ solubility for water-vapor saturated air $\left[\mathrm{mol} /\left(\mathrm{m}^{\wedge} 3 * \mathrm{uatm}\right)\right]$;

- pCO2atm is the partial pressure of $\mathrm{CO} 2$ in dry air at one atmosphere total pressure [in uatm], which is the same as the dry air mixing ratio of $\mathrm{CO} 2$ multiplied by $10^{\wedge} 6$;

- O2sato is the $\mathrm{O} 2$ saturation concentration at one atmosphere total pressure for water saturated air [mol/m^3];

- $\mathbf{P}$ is the total air pressure at sea level [atm], locally; and

- Po is $1 \mathrm{~atm}$.

\subsection{The Piston Velocities ( $\mathrm{KwCO} 2$ and $\mathrm{KwO2}$ )}

For simulations of DIC and O2, modelers must use the standard OCMIP-2 formulation for the piston velocities of $\mathrm{CO} 2$ (KwCO2) and O2 (KwO2). The monthly climatologies of KwCO2 and KwO2 are to be interpolated linearly in time by each modeling group. They are computed with the following equations adapted from Wannikhof (1992, eq. 3):

(6a) $\mathrm{Kw}=(1-$ Fice $)[\mathrm{Xconv} * \mathrm{a} *(\mathbf{u} 2+\mathrm{v})](\mathrm{ScCO} / 660) * *-1 / 2$

(6b) $\mathrm{Kw}=(1-\mathrm{Fice})[\mathrm{Xconv} * \mathrm{a} *(\mathbf{u} 2+\mathrm{v})](\mathrm{ScO} 2 / 660) *-1 / 2$

where

- Fice is the fraction of the sea surface covered with ice, which varies from 0.0 to 1.0 , and is given as monthly averages from the Walsh (1978) and Zwally et al. (1983) climatology (OCMIP-2 modelers must reset Fice values less than 0.2 to zero, after interpolation to their model grid) 
- $\mathbf{u 2}$ is the instantaneous SSMI wind speed, averaged for each month, then squared, and subsequently averaged over the same month of all years to give the monthly climatology. (see the OCMIP-1 README.satdat for further details);

- $\mathbf{v}$ is the variance of the instantaneous SSMI wind speed computed over one month temporal resolution and 2.5 degree spatial resolution, and subsequently averaged over the same month of all years to give the monthly climatology. Again, see the OCMIP-1 README.satdat for further details.

- $\mathbf{a}$ is the coefficient of 0.337 , consistent with a piston velocity in $\mathrm{cm} / \mathrm{hr}$. We adjusted the coefficient $\mathbf{a}$ for OCMIP-2, in order to obtain Broecker et al.'s (1986) radiocarbon-calibrated, global CO2 gas exchange of $0.061 \mathrm{~mol} \mathrm{CO} 2 /\left(\mathrm{m}^{\wedge} 2 * \mathrm{yr} *\right.$ uatm $)$, when using the satellite SSMI wind information $(\mathbf{u} 2+\mathbf{v})$ from Boutin and Etcheto (pers. comm.). Our computed value for $\mathbf{a}$ is similar to that determined by Wanninkhof $(\mathbf{a}=0.31)$, who used a different wind speed data set and assumptions about wind speed variance; we use the observed variance.

- Xconv $=1 / 3.6 \mathrm{e}+05$, is a constant factor to convert the piston velocity from $[\mathrm{cm} / \mathrm{hr}]$ to $[\mathrm{m} / \mathrm{s}]$. This conversion factor is already included in the forcing field $\mathbf{x K w}$, provided below.

- ScCO2 and ScO2 are the Schmidt numbers for $\mathrm{CO} 2$ and O2, respectively. They are to be computed using the formulation of Wannikhof (1992) for CO2 and Keeling et al. (1998) for O2. The corresponding Fortran functions are scco2.f and sco2.f. Both ScCO2 and ScO2 are unitless.

Practically speaking, to use equations (4) and (6), each group will interpolate the OCMIP-2 standard information to their own model grid. The standard information is provided by IPSL/LSCE as a monthly climatology on the $1 \mathrm{x} 1$ degree grid of Levitus (1982) in netCDF format (in file gasx_ocmip2.nc). Gridded variables in that file include

- the variable Fice,

- the second term, $[\mathbf{X c o n v} * \mathbf{a} *(\mathbf{u} \mathbf{2}+\mathbf{v})]$, denoted as $\mathbf{x K w}[\mathrm{m} / \mathrm{s}]$

- the mask Tmask (1 if ocean; 0 if land),

- the total atmospheric pressure at sea level $\mathbf{P}$ [atm]

- the longitude Lon at the center of each 1 x 1 degree grid box,

- the latitude Lat at the center of each 1 x 1 degree grid box.

For the variables Fice and $\mathbf{x K w}$, continents on the $1 \times 1$ degree standard grid have been flooded with adjacent ocean values. Such an approach avoids discontinuities at land-sea boundaries during interpolation. See the Fortran program rgasx_ocmip2.f for an example of how to read the information in gasx_ocmip2 . nc into your interpolation routines. After compilation, to link and use rgasx_ocmip2.f, one must have already installed netCDF.

<http://www.unidata.ucar.edu/packages/netcdf/>

The file gasx_ocmip2 . nc may also be inspected with software that uses netCDF format, such as ncdump or Ferret. Ferret will be used for some of the analysis during OCMIP-2. We encourage participants to become familiar with Ferret now.

<http://ferret.wrc.noaa.gov/Ferret/> 
After installation, one can visualize maps of the standard information in gasx_ocmip2.nc, by using the Ferret script vgasx_ocmip2.jnl.

After launching Ferret, simply issue the following command (at Ferret's "yes?" prompt)

yes? go vgasx_ocmip2.jnl

\subsection{Oceanic and Atmospheric Components}

Apart from Kw, there are other terms that require further development to simulate air-sea gas exchange.

\subsubsection{Ocean}

The oceanic term CO2surf [in $\mathrm{mol} / \mathrm{m}^{\wedge} 3$ ] is not carried as a tracer, so it must be computed each timestep to determine gas exchange.

CO2surf is the surface [CO2] concentration, which is computed from the model's surface [DIC], [Alk], T, S, and [PO4] through the equations and constants found in the subroutine co2calc.f. Silicate is also needed as an input, as it affects the equilibria; for that, we use its global mean surface value of $7.5 \mathrm{umol} / \mathrm{kg}$.

IMPORTANT: The carbonate chemistry subroutine co2calc.f was originally designed to require tracer input ([DIC], [Alk], [PO4], and [SiO2]) on a per mass basis (umol/kg); however, for OCMIP-2 co2calc.f has been modified to pass tracer concentrations on a per volume basis $\left(\mathrm{mol} / \mathrm{m}^{\wedge} 3\right)$, as carried in ocean models. To do so, we use the mean surface density of the ocean $\left(1024.5 \mathrm{~kg} / \mathrm{m}^{\wedge} 3\right)$ as a constant conversion factor; we do NOT use model-predicted densities. Output arguments co2star (CO2surf) and dco2star (CO2sat - CO2surf) are also returned in mol/m^3.

\subsubsection{Atmosphere}

The atmospheric components CO2sat and O2sat in equations (4a) and (4b) are specified a priori via four remaining terms:

1. alphaC: The CO2 solubility alphaC is to be computed using modeled SST and SSS, both of which vary in time at each grid point. For OCMIP-2 we use the solubility formulation of Weiss (1974), corrected for the contribution of water vapor to the total pressure (Weiss and Price, 1980, Table IV for solubility in [mol/(1* atm)]). The solubility alphaC is calculated within the routine co2calc.f.

2. pCO2atm: This is held constant at $278 \mathrm{ppm}$. For the OCMIP-2 simulations, modelers should pass pCO2atm as one of the the input arguments (xco2) to co2flux.f in units of ppm. This in turn is passed to co2calc.f.

3. O2sato: This is computed from the model $\mathrm{T}$ and $\mathrm{S}$ in units of $\mathrm{mol} / \mathrm{m}^{\wedge} 3$, using the formulation of Garcia and Gordon (1992). The subroutine o2sato.f performs this function.

4. P: Is the total atmospheric pressure [atm] from the monthly mean climatology of Esbensen and Kushnir (1981). The latter, was given originally on a 4 x 5 degree grid (latitude $\mathrm{x}$ longitude) in bars. We converted $\mathbf{P}$ to atm by multiplying it by (1/1.101325). Land and sea ice values in the original data set were filled with average values from adjacent ocean points. These monthly mean arrays were then linearly interpolated to the $1 \mathrm{x} 1$ degree grid 
of Levitus (see netCDF file gasx_ocmip2.nc). The atmospheric pressure, is passed as an input argument, in atm, to both co2flux.f and o2flux.f.

\section{Initialization and duration of simulations}

It is up to the discretion of the modeler as to how to initialize their simulations, but the following criteria must be upheld:

1. The global mean inventory of alkalinity $+16 *$ phosphate must be initialized to $2370+16 * 2.17 \mathrm{ueq} / \mathrm{kg}=$ $2404.72 \mathrm{ueq} / \mathrm{kg}$ (or $2.4636 \mathrm{eq} / \mathrm{m}^{\wedge} 3$ ) and maintained at that level.

2. The global mean PO4 + DOP concentration must be set equal to $2.17+0.02=2.19 \mathrm{umol} / \mathrm{kg}$ (or 0.002245 $\mathrm{mol} / \mathrm{m} \wedge$ )

As for the duration of simulations, the biotic equilibrium simulation should be continued at least until the globally integrated air-sea CO2 flux is less than $0.01 \mathrm{Pg} \mathrm{C} / \mathrm{yr}$. For most models, this criterion can be reached only after an integration of at least a few thousand model years.

To approach equilibrium more rapidly, some modelers use the acceleration technique where the timestep increases in deeper layers (Bryan, 1984). When modelers use this technique, one complication is that the global inventory of certain biogeochemical tracers (those without external sources or sinks) cannot be conserved. As a fix, those at NCAR suggest that modelers who use such a technique should periodically adjust global tracer inventories to their initial values. In any case, some method must be used to avoid losing mass from the system. Furthermore, we strongly recommend that the deep acceleration method be switched off and that the model be run for at least an additional 500 years, before final "equilibrium" output is stored for later OCMIP-2 analysis.

\section{Output type and frequency}

The Biotic simulation represents only one equilibrium run per model. Therefore only time-averaged fields of the seasonal cycle of the final "steady-state" solution need be saved. Modelers must submit results based on an average of the last 10 years of the simulation. Below are listed the required fields. The spatial dimension is indicated in square brackets; another dimension must be added for time, i.e., 12 months per year):

3-D Monthly mean tracer concentrations for both active tracers: potential temperature $\mathrm{T}$ (degrees C) and salinity S (psu);

3-D Monthly mean tracer concentrations for all five passive tracers ( [PO4], [DOP], [O2], [DIC], and [Alk]) for the whole water column $(\mathrm{mol} / \mathrm{m} \wedge 3)$;

2-D Monthly mean pCO2surf = CO2surf/alphaC (uatm);

2-D Monthly mean dpCO2 $=($ CO2surf - CO2sat*P/Po $)($ uatm $)$;

2-D Monthly mean air-sea CO2 flux FgDIC (mol/m^2/s); 
2-D Monthly mean air-sea O2 flux FgO2 (mol/m^2/s);

2-D Monthly mean virtual DIC flux FvDIC (mol/m^2/s);

2-D Monthly mean virtual flux of total Alkalinity FvAlk (eq/m^2/s);

2-D Monthly mean downward flux of particulate organic phosphorus interpolated to the compensation depth (75 m) PnewPOP $\left(\mathrm{mol} / \mathrm{m}^{\wedge} 2 / \mathrm{s}\right)$;

2-D Monthly mean total downward flux of dissolved organic phosphorus (DOP) interpolated to the compensation depth (75 m) PnewDOP (mol/m^2/s);

2-D Monthly mean advective net downward flux of DOP interpolated to the compensation depth (75 m) PnewDOPa $\left(\mathrm{mol} / \mathrm{m}^{\wedge} 2 / \mathrm{s}\right)$;

2-D Monthly mean diffusive net downward flux of DOP interpolated to the compensation depth (75 m) PnewDOPd $\left(\mathrm{mol} / \mathrm{m}^{\wedge} 2 / \mathrm{s}\right)$; and

2-D Monthly mean convective net downward flux of DOP interpolated to the compensation depth (75 m) PnewDOPc $\left(\mathrm{mol} / \mathrm{m}^{\wedge} 2 / \mathrm{s}\right)$.

\section{Output Format}

Each modeling group must provide their output in the standard OCMIP-2 format. Model output that does not follow these formatting conventions cannot be included for analysis during OCMIP-2. Model groups must use the standard routines that we have developed specifically for writing output in standard form for OCMIP-2.

If this is the first OCMIP-2 simulation you have made, you will need to recuperate the routine write_nc_MaskAreaBathy.f to write out characteristics of your model grid, mask, and bathymetry using the standard OCMIP-2 format. Use of this routine is detailed in the CFC HOWTO (section 5.1).

Otherwise if you have submitted OCMIP-2 model output previously, you will only need to resubmit the output file produced by write_nc_MaskAreaBathy.f under two conditions:

1. either your model's grid, mask, or bathymetry have changed; or

2. you have been notified by the OCMIP-2 analysis center at IPSL that your output file from this subroutine did not pass the routine integrity tests.

\subsection{Biotic-run output routines}

For the Biotic simulation, each modeling group will need to store both their active and passive tracer output in OCMIP-2 standard format. Thus modelers need to call two additional routines. They should be called just once each. Those output routines and the fields which are passed as arguments are detailed in the following table. 


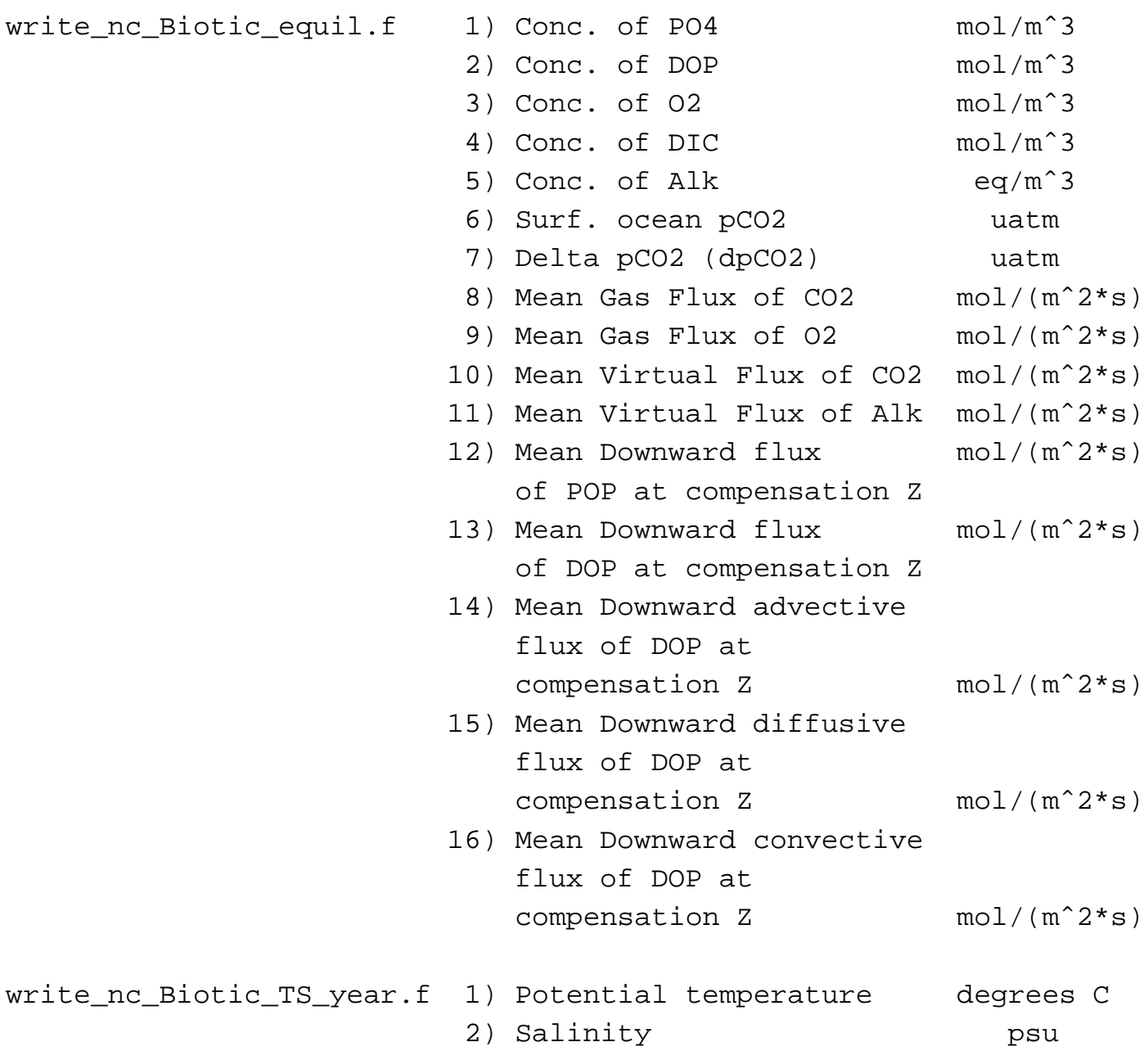

15) Mean Downward diffusive flux of DOP at compensation Z

16) Mean Downward convective flux of DOP at compensation $\mathrm{Z}$ 
- write_nc_Biotic_TS_year.f

You will also need to transfer the subroutine handle_errors.f to properly deal with errors while you are writing your netCDF files.

\subsection{Compiling the output routines}

Here is a an example of how you would compile one of the Biotic run output routines:

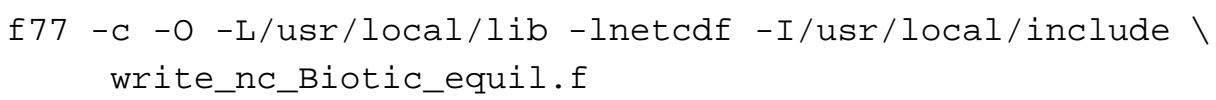

Because we have made the OCMIP-2 output routines F77 compatible, you may need a function len_trim.f (from F90), which we also provide and which returns the length of a character string (after neglecting trailing blanks).

\subsection{Using the output routines}

The Biotic-run output routines store your model results following the naming and output conventions (netCDF, GDT version 1.2) chosen for OCMIP-2. The output filename is constructed automatically within each routine from three of the arguments: the tracer name, the year, and the standard model code

<http://www.ipsl.jussieu.fr/OCMIP/phase2/\#modgroups> used during OCMIP-2 to identify your group.

For example, after compiling and linking the OCMIP-2 output routines, we add the following code to the IPSL routines to store output in standard OCMIP-2 form

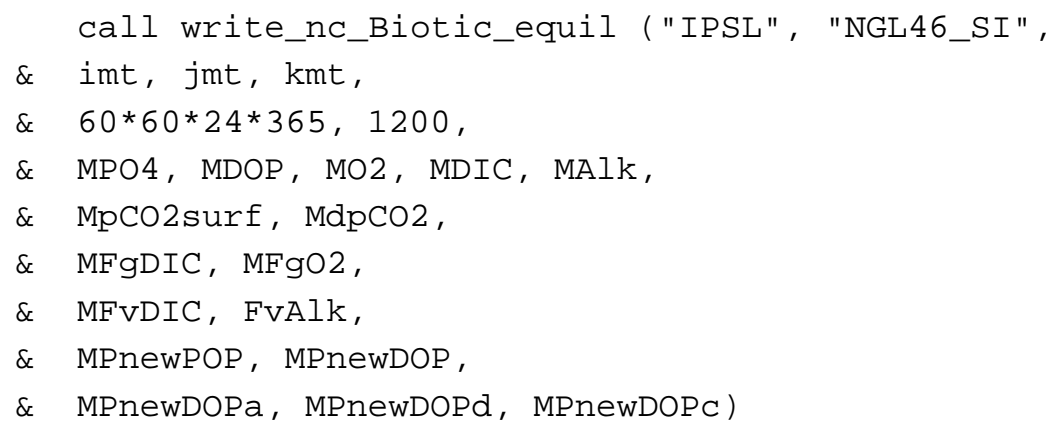

By line, the arguments to write_nc_Biotic_equil include

1. the OCMIP-2 model code AND your own model version indicator (in GDT 1.2 terminology, these 2 variables refer to the institution and production, respectively);

2. dimensions;

3. the number of seconds per year (in your model), and the number of timesteps per year; 
4. the 12 monthly means for the 3-D tracer arrays for passive tracers PO4, DOP, O2, DIC, and Alk;

5. the 12 monthly means for the 2-D arrays for surface ocean $\mathrm{pCO} 2$ (pCO2surf) and the sea-air pCO2 difference (dpCO2).

6. the 12 monthly means for the 2-D arrays for the air-sea fluxes for $\mathrm{CO} 2$ and $\mathrm{O} 2$;

7. the 12 monthly means for the 2-D arrays for the surface "virtual" fluxes for DIC and Alk;

8. the 12 monthly means for the 2-D arrays for the total downward fluxes of POP and DOP (at the compensation depth); and

9. the 12 monthly means for the 2-D arrays for the advective, diffusive, and convective components of the downward flux of DOP (at the compensation depth).

All arguments are input. The only output is the final netCDF file ("IPSL_Biotic_equil.nc") which contains the information for analyzing the IPSL monthly results for the steady-state climatological solution.

Furthermore, we need monthly 3-D data for potential temperature $\mathrm{T}$ and salinity $\mathrm{S}$ from each model. Again as an example, we add the following code to the IPSL routines to store output in standard OCMIP-2 form.

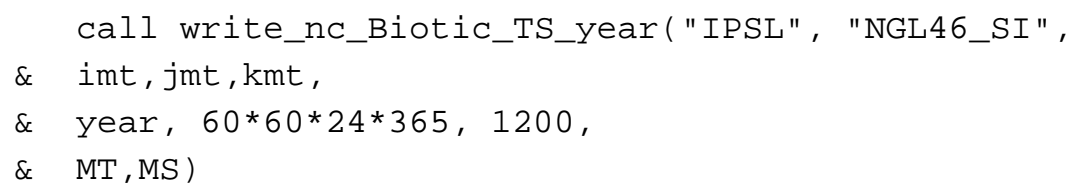

where the arguments include

1. the OCMIP-2 model code AND your own model version indicator (in GDT 1.2 terminology, these 2 variables refer to the institution and production, respectively);

2. dimensions;

3. the year, the number of seconds per year (in your model), and the number of timesteps per year;

4. the 12 monthly means for the 3-D tracer arrays for potential temperature $\mathrm{T}$ and salinity $\mathrm{S}$;

The only output is the final netCDF file ("IPSL_Biotic_TS_year.nc") which contains the information for analyzing the IPSL monthly results for the steady-state climatological solution.

Both "IPSL_Biotic_equil.nc" and "IPSL_Biotic_TS_year.nc" should be 6. Filenames should NOT be changed. Subsequently at IPSL, files will be (1) tested for consistency, (2) included in the OCMIP-2 data base, and (3) processed for base analysis.

\subsection{Need more details?}

See <http: / /www.ipsl.jussieu.fr/OCMIP/tech> for additional information about the format netCDF and other conventions (COARDS, GDT) chosen for storing OCMIP-2 model output.

If you have other questions, please contact Patrick.Brockmann@ipsl.jussieu.fr or orr@cea.fr 


\section{Transfer of output}

Both IPSL_Biotic_equil.nc and IPSL_Biotic_TS_year.nc should first be compressed

gzip IPSL_Biotic_equil.nc IPSL_Biotic_TS_year.nc

If gzip is not available on your machine, the alternative is to use compress. After compression, you should send your files to LSCE for processing and analysis. However, model output could be quite large depending upon model resolution. If output is larger than $300 \mathrm{Mb}$, you may wish to try to send it by ftp, but you should first send us e-mail to verify that enough disk space is available. If not, you'll need to write your output to tape (DDS, DDS2, Exabyte, or DLT) and mail it to

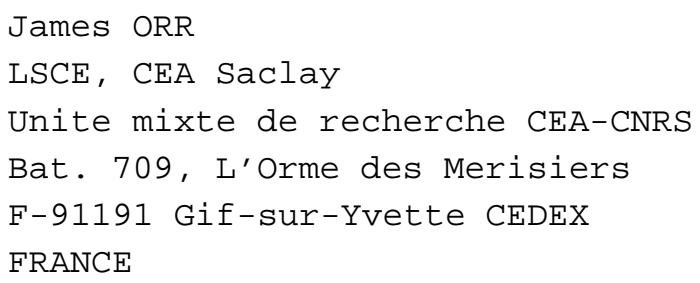

If smaller than $300 \mathrm{Mb}$, please first attempt to send this output via ftp:

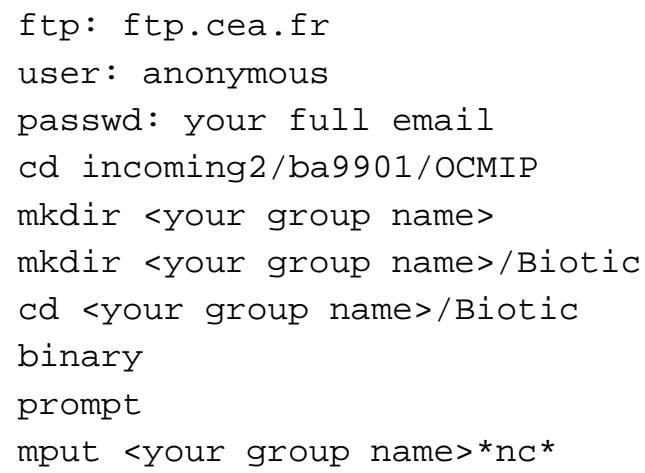

Then e-mail us (Patrick.Brockmann@ipsl.jussieu.fr and orr@cea.fr) that your transfer is complete.

\section{Who has submitted what?}

For a record of who has submitted what model output, see

<http://www.ipsl.jussieu.fr/OCMIP/phase2/progress/>. 


\section{References}

Broecker, W.S., J. R. Ledwell, T. Takahashi, R. Weiss, L. Merlivat, L. Memery, T.-H. Peng, B. Jahne, and K. O. Munnich, 1986. Isotopic versus micrometeorlogic ocean CO2 fluxes, J. Geophys. Res., 91, 10517-10527.

Bryan, K., 1984. Accelerating the convergence to equilibrium of ocean-climate models, J. Phys. Oceanogr. 14, 666-673.

Garcia, H. E. and L. I. Gordon. 1992. Oxygen solubility in seawater: Better fitting equations. Limnol. Oceanogr. 37, 1307-1312.

Levitus, S., 1982. Climatological atlas of the World Ocean, NOAA Prof. Pap. 13, U.S. GPO., Washington, D.C., 173 pp.

Walsh, J. 1978. A data set on northern hemisphere sea ice extent, 1953-1976. Glaciological Data, World Data Center for Glaciology (Snow and Ice), Report GD-2, 49-51.

Wanninkhof, R., 1992. Relationship between wind speed and gas exchange over the ocean, J. Geophys. Res., 97, 7373-7382.

Weiss, R. F., 1974. Carbon dioxide in water and seawater: the solubility of a non-ideal gas, Marine Chem., 2, 203-215.

Weiss, R. F. and B. A. Price. 1980. Nitrous oxide solubility in water and seawater. Mar. Chem., 8, 347-359.

Zwally, H. J., J. Comiso, C. Parkinson, W. Campbell, F. Carsey, and P. Gloerson, 1983. Antarctic Sea Ice, 1973-1976: Satellite Passive Microwave Observations, NASA, 206 pp.

\section{Contacts}

najjar@essc.psu.edu,orr@cea.fr, brock@1sce.saclay.cea.fr

\section{Same document, another format?}

This document is available in different formats:

- HTML ( <HOWTO-Biotic.html>)

- Postscript ( <HOWTO-Biotic.ps >)

- ASCII ( <HOWTO-Biotic.txt $>$ )

- $\operatorname{LaTeX}(<$ HOWTO-Biotic.tex $>$ )

- DVI (<HOWTO-Biotic.dvi>) 


\section{Injection-HOWTO}

O. Aumont and J. C. Orr

Revision: 1.14, Date: 2000/04/04 22:34:34

This document provides step-by-step guidelines to make simulations of deep-ocean $\mathrm{CO} 2$ sequestration according to standard protocols from OCMIP-2 and GOSAC. Simulations are made abiotically without $\mathrm{CaCO} 3$ sediments. Thus tracers are carried only as DIC. Each model run carries ten tracers, thereby simultaneously simulating the control, "permanent sequestration", the anthropogenic invasion of $\mathrm{CO} 2$, and injection at 7 different sites. In GOSAC's REQUIRED Standard scenario, atmospheric pCO2 is prescribed and $\mathrm{CO} 2$ is injected at $1500 \mathrm{~m}$ (Run C1500). An analogous simulation is STRONGLY ENCOURAGED where injection occurs instead at $3000 \mathrm{~m}$ (Run C3000). Additionally, we include two OPTIONAL simulations: (1) an analogous run with injection at 800 m (Run C800) and (2) an Emissions case where fossil emissions to the atmosphere are prescribed and injection is made at $1500 \mathrm{~m}$ (Run E1500).

\section{Contents}

1 Introduction

2 Recuperation of files by ftp: 3

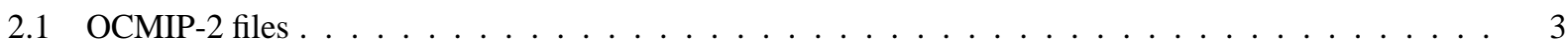

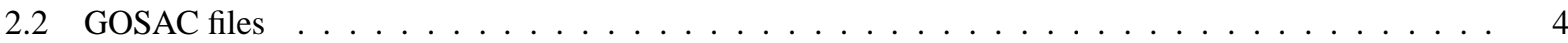

3 Model runs $\quad 5$

3.1 Injection sites $\ldots \ldots \ldots \ldots \ldots \ldots \ldots$

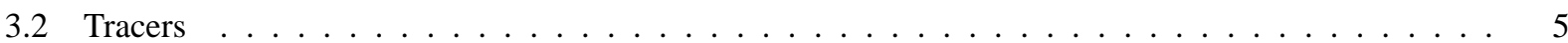

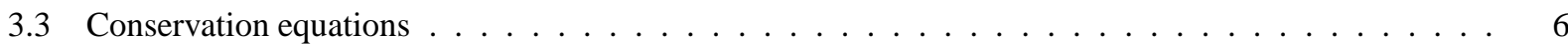

3.4 Air-sea gas exchange fluxes $(\mathrm{F}) \ldots \ldots \ldots \ldots \ldots \ldots$

3.5 Oceanic Component . . . . . . . . . . . . . . . . . . . . 7

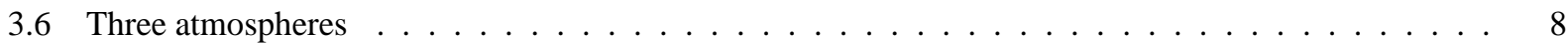

3.6 .1 Atmosphere description $\ldots \ldots \ldots \ldots \ldots$

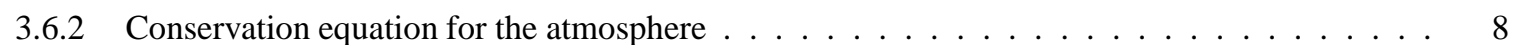

3.6.3 E and $\mathrm{d}(\mathrm{MCO} 2 \mathrm{~atm}) / \mathrm{dt} \ldots \ldots \ldots \ldots \ldots \ldots \ldots$

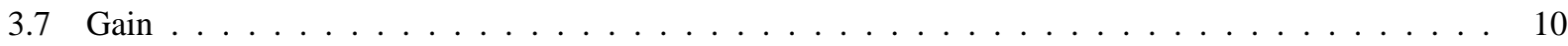

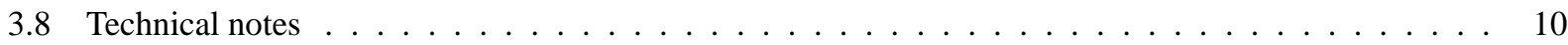

4 Description of the simulations $\quad 11$

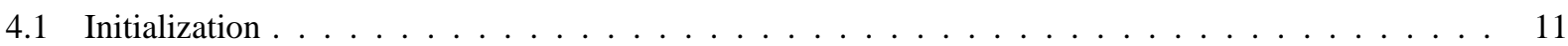




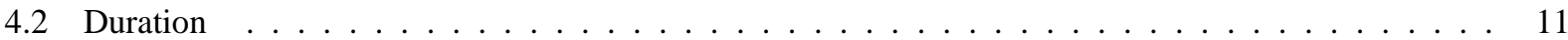

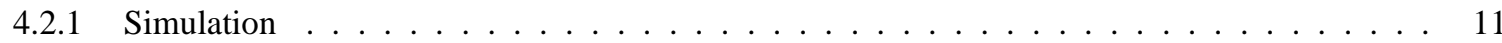

4.2 .2 Injection Period $\ldots \ldots \ldots \ldots \ldots \ldots \ldots \ldots \ldots \ldots \ldots$

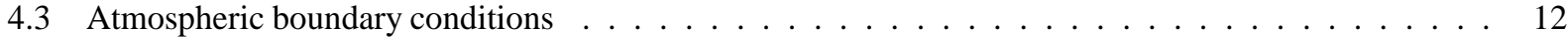

5 Output type and frequency 12

6 Output Format $\quad 13$

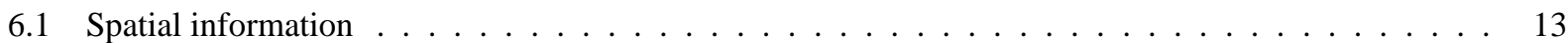

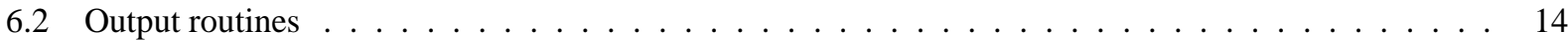

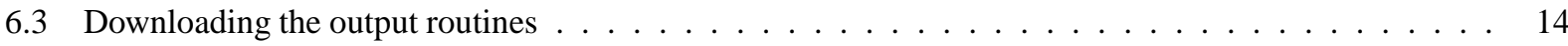

6.4 Compiling the output routines $\ldots \ldots \ldots \ldots \ldots \ldots$

6.5 Using the output routines . . . . . . . . . . . . . . . . . . . 15

6.6 Need more details? . . . . . . . . . . . . . . . . . . . . . . . . . . . . . 17

7 Transfer of output $\quad 18$

8 References $\quad 18$

9 Contacts

10 Same document, another format? 19 


\section{Introduction}

To help reduce the rate of increase of atmospheric $\mathrm{CO} 2$, one could in principle divert $\mathrm{CO} 2$ emissions from coastal power plants to the deep ocean and thereby short-circuit the naturally slow air-sea exchange of CO2 (Marchetti, 1977). However two key scientific questions remain to be answered before such a practice could ever be implemented. Accurate answers to these questions are needed in order to fully address other crucial concerns - socioeconomic, political, legal, and technological—all of which must play a role in future decisions that governments must make concerning possible mitigation strategies. The first of these scientific questions is, "how extensively would deep-ocean injection affect the marine biota in the vicinity of the injection site?" The second question is, "if fossil CO2 is to be injected into the ocean, how long might it stay isolated from the atmosphere?"

Our focus is on the second question, using the only means available, simulations in global-scale ocean models. Previous studies have addressed this same question, first with relatively simplistic box models and subsequently with one ocean general circulation model (OGCM) from MPI. A good summary of previous work is provided by Dewey et al. (1996). OGCM's describe ocean circulation in three dimensions. Thus they can be used to make assessments concerning the dependence of injection site location and depth upon the effectiveness of the ocean to retain sequestered CO2. Unfortunately, model estimates can be biased due to model simplifications, omissions, and uncertainties. Substantial effort is usually required in regards to model validation and comparison before one can be sure of predicted results.

Here we provide the necessary protocols, boundary conditions, and code so that different groups using different OGCM's can make ocean CO2 injection simulations in a consistent manner. Our objective is to begin to estimate the effect of uncertainties in model-predicted ocean circulation patterns on model-based estimates of the long term retention of $\mathrm{CO} 2$ injected in the ocean. This work is carried out under the framework of GOSAC (Global Ocean Storage of Anthropogenic Carbon), an international effort during 1998 to 2000, which is jointly funded by the EC Environment and Climate Programme and the IEA Greenhouse Gas R\& D Programme. GOSAC also provides support for European modeling groups to participate in the Ocean Carbon-Cycle Model Intercomparison Project (OCMIP), a project of the Global, Anlysis, Interpretation, and Modeling Task Force (GAIM) of the International Geosphere-Biosphere Programme (IGBP). Simulations described here are required for the seven GOSAC modeling groups. Non-european modeling groups (those not funded by GOSAC) are also strongly encouraged to make the simulations described in this document and to submit results for common analysis.

The protocols stipulated in this document are nearly the same as those tested in one of the GOSAC models, i.e., that from IPSL. Orr and Aumont (1999) discuss those preliminary tests and compare results to previous work.

\section{Recuperation of files by ftp:}

\subsection{OCMIP-2 files}

All injection simulations are to be made with an abiotic ocean. They must comply with previous OCMIP-2 guidelines, namely the abiotic simulation for DIC. Thus modelers should refer to the Abiotic HOWTO available on this Web site. The standard OCMIP-2 files necessary for the injection simulations are listed below. They can be retrieved directly from this Web page (you can save a file to disk by clicking a link while holding down the Shift key).

- rgasx_ocmip2.f 
- gasx_ocmip2.nc.gz

- vgasx_ocmip2.jnl

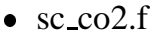

- sol_co2.f

After transferring the file gasx_ocmip2.nc.gz (binary mode), one must then uncompress it:

gunzip gasx_ocmip2.nc

Other files are text and need no special treatment after transfer. Use of these files is described below.

\subsection{GOSAC files}

In addition to following the guidelines described in the Abiotic HOWTO of OCMIP-2, all modelers must also follow the GOSAC guidelines given here to make the injection simulations. The appropriate files are listed below. They are used to read the prescribed boundary conditions, to perform the injection, and to provide some basic diagnostics. Just like the previous OCMIP-2 files, the files below can be retrieved directly from this Web page.

- pco2.s650.dat

- emissions.dat

- sitepos.dat

- initnl.f

- initgos.f

- gosac.f

- concent.f

- emit.f

- writegos.f

- gosac.h

- gosac.nl

All the files are text and need no special treatment after transfer. Use of these files is described below; comments within each file provide further details. 


\section{Model runs}

Since the injection simulations are based on the abiotic DIC runs, modelers must have read the related Abiotic HOWTO, also on this Web site. In the rest of this Injection-HOWTO, we describe only the sequestration of $\mathrm{CO} 2$ within the ocean and its effects on atmospheric $\mathrm{CO} 2$ and oceanic DIC.

\subsection{Injection sites}

Seven injection sites have been designated by GOSAC participants:

1. Bay of Biscay

2. New York

3. Rio de Janeiro

4. San Francisco

5. Tokyo

6. Jakarta

7. Bombay

Exact locations of these sites are shown in Fig. 1. They are also listed in the ASCII file sitepos.dat. All sites are located along coastlines near populated areas where large amounts of $\mathrm{CO} 2$ are emitted to the atmosphere. Only two of these sites are in the Southern Hemisphere. Protocols call for each model to make injections at all sites simultaneously. Models will make separate simulations for up to three injection depths: $800 \mathrm{~m}, 1500 \mathrm{~m}, 3000 \mathrm{~m}$.

To determine the 7 grid cells in your model where $\mathrm{CO} 2$ is to be injected, we use a simple algorithm (see initgos.f) to find each site's nearest grid cell that has a water column of at least $3000 \mathrm{~m}$ and is within $1000 \mathrm{~km}$ of the nearest coastline. These constraints are considered, roughly, as the current technical and economical limits of feasibility.

\subsection{Tracers}

Ten tracers are necessary to perform an injection simulation. Each of the ten tracers is carried simply as total dissolved inorganic carbon (DIC). These oceanic tracers exchange CO2 with three different atmospheric boxes, all of which are defined in section "Atmosphere description". The ten oceanic tracers are defined as follows:

\section{Tracer 1}

Control scenario: no effect of the anthropogenic perturbation on atmospheric $\mathrm{CO} 2$ is included. This tracer is used to remove the drift of the model.

\section{Tracer 2}

Future scenario: The effect of the anthropogenic perturbation on atmospheric $\mathrm{CO} 2$ is included, as is the resulting invasion of anthropogenic $\mathrm{CO} 2$ into the ocean; however, no injection is performed. Reference to this tracer allows us to determine, by difference, the total effect of ocean injection on atmospheric pCO2 and oceanic DIC. 


\section{Tracer 3}

Injection scenario ("Permanent sequestration"): Like Tracer 2 but in addition it includes the effect due to the reduction of atmospheric $\mathrm{CO} 2$ caused by the diversion of fossil carbon into the deep ocean (sequestration) instead of the atmosphere. However, Tracer 3 ignores the impact of direct injection of $\mathrm{CO} 2$ within the deep ocean on the oceanic DIC. Tracer 3 differs from Tracer 2 when atmospheric CO2 is computed (i.e., in the Emission case E1500), but not when atmospheric $\mathrm{CO} 2$ is prescribed (scenarios $\mathbf{C 8 0 0 ,} \mathbf{C 1 5 0 0}$, and $\mathbf{C 3 0 0 0}$ ). For the Emission case, Tracer 3 is used to compute atmospheric $\mathrm{CO} 2$, air-sea $\mathrm{CO} 2$ fluxes, and the distribution of oceanic DIC when CO2 sequestration is made in an ideal permanent reservoir that allows no leakage back to the atmosphere.

\section{Tracers 4-10}

These seven tracers simulate, individually for each injection site, the effects of injected CO2 on oceanic DIC. The impact of $\mathrm{CO} 2$ sequestration on atmospheric pCO2 is also considered, just as with Tracer 3. Tracers 4-10 are summed along with Tracer 3 to determine the loss of sequestered $\mathrm{CO} 2$ to the atmosphere and to evaluate the direct effect of the injection on the DIC distribution. These seven tracers are necessary to determine the efficiency of each site in retaining injected $\mathrm{CO} 2$.

\subsection{Conservation equations}

Each of the ten tracers is carried as dissolved inorganic carbon (DIC) and has the following conservation equation

(1) $\mathbf{d}[\mathrm{DIC}] / \mathrm{dt}=\mathbf{L}([\mathrm{DIC}])+\mathbf{J v}+\mathbf{J}+\mathbf{J i}$

where

- [DIC] is the model's concentration (moles/m3) of tracer representing total dissolved inorganic carbon;

- $\mathbf{L}$ is the 3-D transport operator, which represents effects due to advection, diffusion, and convection;

- Jv is the "virtual" source-sink term representing the changes in surface [DIC] due to evaporation and precipitation;

- $\mathbf{J}$ is the source-sink term due to air-sea exchange of $\mathrm{CO} 2$; and

- Ji is the source term due to the injection of anthropogenic CO2 within the deep ocean.

The source-sink terms $\mathbf{J v}$ and $\mathbf{J}$ are added only as surface boundary conditions. That is, they are equal to zero in all subsurface layers. These two source-sink terms are equivalent to the corresponding fluxes (described in the Abiotic-HOWTO) divided by the surface layer thickness dz1.

$$
\begin{aligned}
& J v=F v / d z 1 \\
& J=F / d z 1
\end{aligned}
$$

The virtual flux Fv is described in the Abiotic-HOWTO (Section 2.2).

For the last seven tracers (4-10), which are used to study the injection efficiency, each source term $\mathbf{J i}$ is added only to the grid cell of the model located nearest the corresponding injection site. Conversely, Ji is set to zero for the first 
three tracers. The $\mathbf{J i}$ source is equivalent to the quantity of $\mathrm{CO} 2$ injected at each site $(\mathbf{Q})$ divided by the volume $\mathbf{d V}$ of the corresponding grid cell of the model.

$$
\mathbf{J i}=\mathbf{Q} / \mathbf{d V}
$$

\subsection{Air-sea gas exchange fluxes (F)}

For simulations of $\mathrm{CO} 2$ sequestration, air-sea fluxes $\mathbf{F}$ for each tracer must be modeled according the OCMIP-2 guidelines described in the related Abiotic-HOWTO,

(2) $\mathbf{F}=\mathbf{K w}($ Csat - Csurf)

with

(3) Csat $=$ alphaC $*$ pCO2atm $* \mathbf{P} / \mathbf{P o}$

where

- Kw is the $\mathrm{CO} 2$ gas transfer (piston) velocity $[\mathrm{m} / \mathrm{s}]$;

- Csurf is the surface aqueous [CO2] concentration [mol/m^3], which is computed from the model's surface [DIC], T, S, and [Alk];

- alphaC is the $\mathrm{C}$ solubility for water-vapor saturated air $[\mathrm{mol} /(\mathrm{m} \wedge 3 *$ uatm $)]$;

- pCO2atm is the partial pressure of $\mathrm{CO} 2$ in dry air at one atmosphere total pressure [in microatm], which is the same as the dry air mixing ratio of $\mathrm{CO} 2$ multiplied by $10^{\wedge} 6$;

- $\mathbf{P}$ is the total air pressure at sea level [atm], locally; and

- Po is $1 \mathrm{~atm}$.

The three terms $\mathbf{P}, \mathbf{K w}$, and alphaC are identical for all the ten tracers. They are described in the Abiotic-HOWTO. Conversely, Csurf depends on which of the 10 tracers is considered. Furthermore, pCO2atm depends on which oceanic tracer is considered for the Emissions run $(\mathbf{E 1 5 0 0})$ but not for the other simulations. The dependencies of both terms are described below.

\subsection{Oceanic Component}

The oceanic term Csurf is not carried as a tracer. Thus to determine gas exchange, it must be computed each timestep for each of the ten tracers.

Csurf is the surface [CO2] concentration [mol/m^3], which is computed from the model's surface [DIC], T, $\mathbf{S}$, and [Alk] through the equations and constants found in the subroutine co2calc.f. We inject anthropogenic carbon as $\mathrm{CO}$, which does not affect Alkalinity. Thus Alkalinity is identical for all ten tracers. It is determined as a normalized linear function of salinity:

(4) $[$ Alk $]=$ Alkbar $*$ S/Sbar

where [Alkbar] is 2310 microeq $/ \mathrm{kg}$ and Sbar is the model's annual mean surface salinity, integrated globally (horizontally). 
IMPORTANT: The carbonate chemistry subroutine co2calc.f was originally designed to require tracer input ( $D I C$, $A l k, P O 4$, and $\mathrm{SiO} 2$ ) on a per mass basis (umol/kg); however, for OCMIP-2 co2calc.f has been modified to pass tracer concentrations on a per volume basis $\left(\mathrm{mol} / \mathrm{m}^{\wedge} 3\right)$, as carried in ocean models. To do so, we use the mean surface density of the ocean $\left(1024.5 \mathrm{~kg} / \mathrm{m}^{\wedge} 3\right)$ as a constant conversion factor; we do NOT use model-predicted densities. For example, OCMIP-2 modelers should used $\mathrm{SiO} 2=7.7 \mathrm{e}-03 \mathrm{~mol} / \mathrm{m} \wedge 3$ and $\mathrm{PO} 4=5.1 \mathrm{e}-04 \mathrm{~mol} / \mathrm{m} 3$ as input arguments; again both are constant for the abiotic simulation. The output arguments co2star (Csurf) and dco2star (Csat - Csurf) are also returned in $\mathrm{mol} / \mathrm{m}^{\wedge} 3$.

\subsection{Three atmospheres}

\subsubsection{Atmosphere description}

In the injection simulation, a set of three different atmospheric boxes, each which is global in nature, exchange $\mathrm{CO} 2$ with the ocean:

1. The first atmospheric box $\mathbf{B}(\mathbf{1})$ is related to the control scenario. In equation (2), Csurf is calculated from Tracer 1.

2. The second atmospheric box $\mathbf{B}(\mathbf{2})$ is related to the future scenario. Csurf is computed from Tracer 2 .

3. The third atmospheric box $\mathbf{B}(\mathbf{3})$ is related to the injection scenario. Csurf is computed from Tracers 3-10.

Each of the three atmospheres is defined as an homogeneous box $\mathbf{B}(\mathbf{i})$ (with $\mathrm{i}=1,2,3$ ), with global coverage, having a uniform atmospheric concentration of $\mathrm{CO} 2$ pCO2atm(i) (in uatm). To this concentration corresponds an atmospheric content of $\mathrm{CO} 2$ (in GtC) MCO2atm(i). The two variables are related by the following equation:

(5) $\operatorname{MCO2atm}(\mathbf{i})=\operatorname{Matm} *($ WCO2/Watm $) *($ CCO2atm $(i) * 1.0 e-06)$

where

- Matm is the total mass of this atmosphere $($ Matm = 5.119e+06 GT);

- Watm is the molecular weight, i.e., mass of 1 mole $(22.4 \mathrm{~L}$ at STP) of air (Watm = 28.964 g); and

- WCO2 is the molecular weight, i.e., the mass of 1 mole of carbon $(\mathbf{W C O 2}=\mathbf{1 2 . 0} \mathbf{~ g})$.

\subsubsection{Conservation equation for the atmosphere}

In each of the three atmospheric boxes B(i), the atmospheric mass of CO2 MCO2atm(i) depends on the following conservation equation:

(6) d MCO2atm(i) / dt = E(i) + S(i) - I(i)

where

- $\mathbf{E}(\mathbf{i})$ is the rate at which anthropogenic $\mathrm{CO} 2$ is added to atmospheric box $\mathbf{B}(\mathbf{i})$ due to fossil fuel combustion and deforestation (note: $\mathbf{E}(\mathbf{1})=\mathbf{0}$ ); 
- $\mathbf{S}(\mathbf{i})$ is the rate at which oceanic $\mathrm{CO} 2$ is added to atmospheric box $\mathbf{B}(\mathbf{i})$, i.e., due to the globally integrated total sea-to-air flux of $\mathrm{CO} 2$;

- I(i) is the rate at which atmospheric $\mathrm{CO} 2$ is reduced due to deep ocean sequestration, i.e., it is the atmospheric sink (reduction in emissions rate) due to the $\mathrm{CO} 2$ sequestration at all seven deep ocean injection sites (note: $\mathbf{I}(\mathbf{1})=\mathbf{0} ; \mathbf{I}(\mathbf{2})=\mathbf{0}$; conversely $\mathbf{I}(\mathbf{3})$ is nonzero, but only during the 100-year injection period).

The total sea-to-air flux of $\mathrm{CO} 2 \mathbf{S}(\mathbf{i})$ (for atmospheric boxes $\mathrm{i}=1,3$ ) is a global integral related to the air-to-sea $\mathrm{CO} 2$ flux $\mathbf{F}(\mathbf{n})$ at each surface grid box (for Tracers $\mathrm{n}=1,10$ ) — see definition of $\mathbf{F}$ in the sections Conservation equations and Air-sea gas exchange fluxes. The value of $\mathbf{S}(\mathbf{i})$ depends on the atmospheric box: $\mathbf{S}(\mathbf{1})$ is equivalent to the spatial integration over the whole surface ocean of the corresponding sea-to-air flux, i.e., -F(1); likewise, $\mathbf{S}(\mathbf{2})$ is the globally integrated sea-to-air flux -F(2); however, $\mathbf{S}(\mathbf{3})$ is more complicated. That is, for $\mathbf{S}(\mathbf{3})$, we must additionally account for the sea-to-air flux due to loss of injected CO2. For atmospheric box $\mathbf{B}(\mathbf{3})$, the sum of both air-to-sea fluxes at each grid box is then

(7) $\quad \mathbf{F}^{\prime}=\mathbf{F}(3)+\operatorname{sum}[\mathbf{F}(\mathbf{n})-\mathbf{F}(3)] \quad \mathbf{n}=[4-10]$

where

- $\mathbf{F}(3)$ is the air-to-sea flux of CO2 of Tracer 3;

- $\mathbf{F}(\mathbf{n})$ is the air-to-sea flux of Tracer n (For the injection tracers, $\mathrm{n}$ from 4 to 10); and

- sum represents the summation operator (Sigma); the sum is carried out over the indices from $n=4$ to $n=10$.

Thus, the global sea-to-air flux $\mathbf{S}(\mathbf{3})$ equals -F' integrated horizontally over the entire surface of the global ocean.

Regarding the injection rate, $\mathbf{I}(\mathbf{1})$ and $\mathbf{I}(\mathbf{2})$ are always zero. Conversely, $\mathbf{I}(\mathbf{3})$ is non-zero, but only during the 100 -year injection period. The reason is that unlike $\mathbf{B}(\mathbf{1})$ and $\mathbf{B}(2)$, atmospheric box $\mathbf{B}(\mathbf{3})$ accounts for the effect of $\mathrm{CO} 2$ injection. Furthermore, $\mathbf{I}(\mathbf{3})$ is not exactly equivalent to the total amount of $\mathrm{CO} 2$ that is injected into the deep ocean. In fact, $\mathbf{I}(3)$ is a little less because it requires energy to separate, transport, and pump CO2 to the deep ocean. Thus we remove less $\mathrm{CO} 2$ from the atmosphere than is added to the ocean. We assume a $14 \%$ energy penalty, based on removing $\mathrm{CO} 2$ from gas-fired plants or advanced technology coal-fired plants. Thus

(8) $\mathbf{I}(3)=\mathbf{N} * \mathbf{Q} / \mathbf{1 . 1 4}$

where

- $\mathbf{N}$ is the total number of injection sites (7); and

- $\mathbf{Q}$ is the amount of $\mathrm{CO} 2$ that is injected at each site (see section Conservation equations).

\subsubsection{E and d(MCO2atm)/ dt}

To close equation (6), either $\mathbf{E}$ or $\mathbf{d}(\mathbf{M C O 2 a t m}) / \mathbf{d t}$ must be specified a priori; the remaining term is calculated based on the computed air-sea $\mathrm{CO} 2$ flux. The specified term determines the type of run.

\section{Standard case - Required}


For the "C" runs, we specify the time evolution of the atmospheric $\mathrm{CO} 2 \mathbf{d}(\mathbf{M C O 2 a t m}) / \mathbf{d t}$ and the injection scenario; then with modeled air-sea $\mathrm{CO} 2$ exchange, each model computes the corresponding time evolution of anthropogenic carbon emissions $\mathbf{E}$ to each atmospheric box B(1)-B(3).

\section{Emissions case - Optional}

For the "E" run, we specify the history of the anthropogenic emissions $\mathbf{E}$ and the history of injected $\mathrm{CO} 2$; then with modeled air-sea $\mathrm{CO} 2$ exchange, each model computes its corresponding time evolution of atmospheric pCO2atm for each atmospheric box $\mathrm{B}(1)-\mathrm{B}(3)$.

When specified, pCO2atm and $\mathbf{E}$ should be interpolated temporally to each time step of the model.

\subsection{Gain}

The primary emphasis of these runs is to determine the efficiency of the ocean to retain artificially injected CO2. For each injection site $\mathbf{m}$, we define a Gain $\mathbf{G}(\mathbf{m})$ equal to the amount of $\mathrm{CO} 2$ injected at that site which remains in the ocean. The more efficient the injection site $\mathbf{m}$, the greater is its $\mathbf{G}(\mathbf{m})$. Thus

\section{(9) $\mathbf{d ~ G ( m )} / \mathbf{d t}=\mathbf{Q}-\mathbf{R}(\mathbf{m})$}

where

- $\mathbf{Q}$ is the rate at which $\mathrm{CO} 2$ injected is at each site;

- $\mathbf{R}(\mathbf{m})$ is the rate at which $\mathrm{CO} 2$ injected at site $\mathbf{m}$ is lost from the ocean to the atmosphere.

$\mathbf{R}(\mathbf{m})$ is the integral of $\mathbf{- (} \mathbf{F}(\mathbf{m}+\mathbf{3})-\mathbf{F}(\mathbf{3}))$ with respect to the global surface area of the ocean. We use the $\mathbf{m}+\mathbf{3}$ index because the seven injection sites $(\mathbf{m = 1 , 7})$ correspond to the last seven of the ten ocean tracers $(\mathbf{n = 4 , 1 0})$.

\subsection{Technical notes}

The following routines are used in the IPSL ocean model to perform the injection simulations. There are provided as templates that modelers may adapt and use in their own models. All the routines are coded in FORTRAN 77.

- initgos.f initializes the variables used in the injection simulations. In particular, this routine reads the location of the injection sites, and the atmospheric pCO2 or the fossil fuel emissions depending on the chosen case.

- initnl.f reads input parameters of the simulation from the namelist file (gosac.nl).

- gosac.f performs the injection in the ocean.

- concent.f and emit.f are the routines which determine the "allowable" fossil fuel emissions (Standard case) or atmospheric pCO2 (Emissions case).

- writegos.f writes out some basic diagnostics.

- gosac.h is a COMMON file in which the main variables are defined. 
- gosac.nl is a namelist file in which the characteristics of the simulation are defined: the first and last years of the injection (gabsyr0, gabsyr1), the type of the simulation (standard case or emissions case, fname), the amount of $\mathrm{CO} 2$ injected at each site (PUMPGOS), the amount of CO2 removed from the emissions (FAGOS), and the start date of the simulation (zan).

\section{Description of the simulations}

\subsection{Initialization}

- Standard case $(\mathbf{C 1 5 0 0})$ and other "C" runs $(\mathbf{C 3 0 0 0}, \mathbf{C 8 0 0})$

- Tracer 1

* Tracer - Initialize with 3-D DIC field from from year 2000.0 of the Abiotic Control Run;

* Cumulative flux (Tracer 1) - Initialize to 2-D cumulative flux field from year 2000.0 of the Abiotic Control Run;

* Atmospheric pCO2 - Initialize atmopsheric Box B(1) to 278 ppm, and hold it constant.

- Tracers 2-10

* Tracers - initialize all nine 3-D tracer fields to the DIC field from the end of the Abiotic Historical Run (year=2000.0);

* Cumulative fluxes - initialize all nine 2-D arrays to to the cumulative flux of DIC at the end of the Historical run (year=2000.0);

* Atmospheric pCO2 - atmospheric boxes B(1) and B(2) follow IPCC scenario S650.

- Emissions case (E1500)

- Tracers 1-10

* Tracers - Initialize all ten 3-D tracer fields to the DIC field from the end of the Abiotic Equilibrium Run (equivalent to year 1765.0);

* Cumulative fluxes - Initialize all ten 2-D fields to zero;

* Atmospheric pCO2 - Initialize atmospheric boxes B(1)-B(3) to 278 ppm.

\subsection{Duration}

\subsubsection{Simulation}

All "C" injection simulations (C800, C1500, C3000) begin at year=2000.0 and will be continued until year 2500.0. Thus, the duration of the $\mathbf{C}$ simulations is 500 years. Conversely, the "E" simulation $(\mathbf{E 1 5 0 0})$ begins in year=1765.0 and ends in year=2500.0; thus its duration is 735 years. 


\subsubsection{Injection Period}

In all simulations, artificial sequestration of anthropogenic CO2 will occur for 100 years, beginning on the first timestep of the year 2000 (Jan. 1) and continuing until the last timestep of the year 2099 (Dec. 31). Each year during the 100-yr injection period, $0.1 \mathrm{Gt} \mathrm{C}$ is injected at each site, for a total of $0.7 \mathrm{Gt} \mathrm{C} / \mathrm{yr}$ for the global ocean (seven sites). This amount corresponds to the emissions necessary to produce $350 \mathrm{GW}$ by coal-fired plants or $700 \mathrm{GW}$ by gas-fired plants. Meanwhile, $0.6 \mathrm{Gt} \mathrm{C} / \mathrm{yr}$ should be removed from the fossil fuel emissions to the atmosphere. The difference between the injection and the removal from fossil fuel emissions is due to the $14 \%$ cost penalty (see section Conservation equation for the atmosphere)

\subsection{Atmospheric boundary conditions}

The atmospheric boundary conditions depend on the chosen scenario:

\section{Standard scenario (C1500) and other C runs (C3000 and C800)}

Atmospheric pCO2 follows the IPCC S650 stabilization scenario. Atmospheric pCO2 stabilizes to 650 uatm at year 2200 .

The ASCII file pco2.s650.dat (Fig. 2) provides mid-year values of the atmospheric pCO2 that must be prescribed in the IPCC S650 cases $(\mathbf{C 8 0 0 ,} \mathbf{C 1 5 0 0}$, and C3000). See concent.f and related technical notes in Model runs). Concentrations from pco2.s650.dat are to be imposed only in the second and third atmospheric boxes $\mathbf{B}(\mathbf{2})$ and $\mathbf{B}(\mathbf{3})$. Conversely, in the first atmospheric box $\mathbf{B}(\mathbf{1})$, atmospheric pCO2 must be held to its preindustrial value 278 uatm.

\section{Emissions scenario (E1500)}

We require a smooth emissions scenario to avoid needlessly complicating analysis. Thus we avoid using historical emissions and IPCC future scenarios. Instead we rely on total emissions deduced from an IPCC S650 "concentration" run in one model. The choice of the model is not critical for our objectives of model comparison. We have chosen to use deduced emissions from the S650 concentration run with the HILDA model because (1) HILDA's deduced emissions are already available from 1765 to 2500, (2) its emissions will produce smooth atmospheric CO2 (and time deriviatives) in the other OCMIP models, and (3) HILDA has been used as the IPCC reference model. For further information about the HILDA model, see http://www.climate.unibe.ch/ joos/model_description/model_description.html.

The ASCII file emissions.dat (Fig.3) provides values of the total emissions every half year that must be prescribed in the Emissions scenario (E1500). These values should be interpolated at each time step of the model. See emit.f and related technical notes in Model runs. This emission scenario is prescribed in the second and third atmospheric boxes $\mathbf{B}(\mathbf{2})$ and $\mathbf{B}(\mathbf{3})$. Conversely, in the first atmospheric box $\mathbf{B}(\mathbf{1})$, there are no anthropogenic emissions.

\section{Output type and frequency}

1. [0-D] spatial fields ([1-D] in time):

- Frequency: annual averages every year (from 2000 through 2499) 
- Type:

- Annual average pCO2atm of each atmospheric box [uatm]

- Annual average Gain $\mathbf{G}$ for each injection site [mol/m^2]

- Globally and annually averaged air-to-sea fluxes $\mathbf{F}$ for Tracers 1-10 $\left(\mathrm{mol} /\left(\mathrm{m}^{\wedge} 2 * \mathrm{~s}\right)\right.$

- Globally and annually averaged virtual fluxes Fv for Tracers 1-10 (mol/(m^2* s)

- Globally and annually averaged whole-ocean concentrations for Tracers 1-10 [mol/m^3]

- Globally and annually averaged surface concentrations for Tracers 1-10 [mol/m^3]

- Globally and annually averaged pCO2surf (uatm) and dpCO2 (uatm) for Tracers 1-10

- Globally averaged cumulative air-to-sea fluxes (end-of-year) for $\mathrm{F}\left(\mathrm{mol} / \mathrm{m}^{\wedge} 2\right)$ and virtual fluxes $\mathrm{Fv}$ $\left(\mathrm{mol} / \mathrm{m}^{\wedge} 2\right)$ for Tracers 1-10;

- Global anthropogenic emissions of carbon $\mathbf{E}$ for each of the 3 atmospheric boxes [GT C/yr]

\section{2. [2-D] and [3-D] spatial fields:}

- Frequency: annual averages for years 2000, 2010, 2020, 2040, 2060, 2080, 2099, 2120, 2140, 2160 , 2180, 2200, 2300, 2400, 2499.

- Type: same as for Abiotic Future Run (see Abiotic HOWTO)

Convention for the direction of the air-sea fluxes: positive from the atmosphere to the ocean, except for $\mathbf{S}$, which must be given in the opposite sense.

\section{Output Format}

Each modeling group must provide their output in the standard OCMIP-2 format which is the same as that chosen for GOSAC. Model output that does not follow these formatting conventions cannot be included for analysis during GOSAC. Model groups must use the standard routines that we have developed specifically for writing output in standard form for GOSAC.

\subsection{Spatial information}

If this is the first OCMIP-2 simulation you have made, you will need to recuperate the routine write_nc_MaskAreaBathy.f to write out characteristics of your model grid, mask, and bathymetry using the standard OCMIP-2 format. Use of this routine is detailed in the CFC HOWTO (section 5.1).

Otherwise if you have submitted OCMIP-2 model output previously, you will only need to resubmit the output file produced by write_nc_MaskAreaBathy.f under two conditions:

1. either your model's grid, mask, or bathymetry have changed; or

2. you have been notified by the OCMIP-2 analysis center at IPSL that your output file from this subroutine did not pass the routine integrity tests. 


\subsection{Output routines}

Each modeling group must use the routines listed in the following table to store results in standard OCMIP-2 format for the $[2-D]$ and $[3-D]$ spatial fields.

Input to these routines consists of your model's output and characteristics. The routines (write_nc_Inject_year_3D.f write_nc_Inject_year_2D . f) must be called for the appropriate output years of the runs (see previous section Output type and frequency); conversely the routine write_nc_In ject_year_0D . $f$ is called only once, after builiding a 1-D time series of global mean information. The fourth and final routine write_nc_In ject_TS_year.f should be called only once for offline models; for online models, it should also be called a second time, in the year 2499.

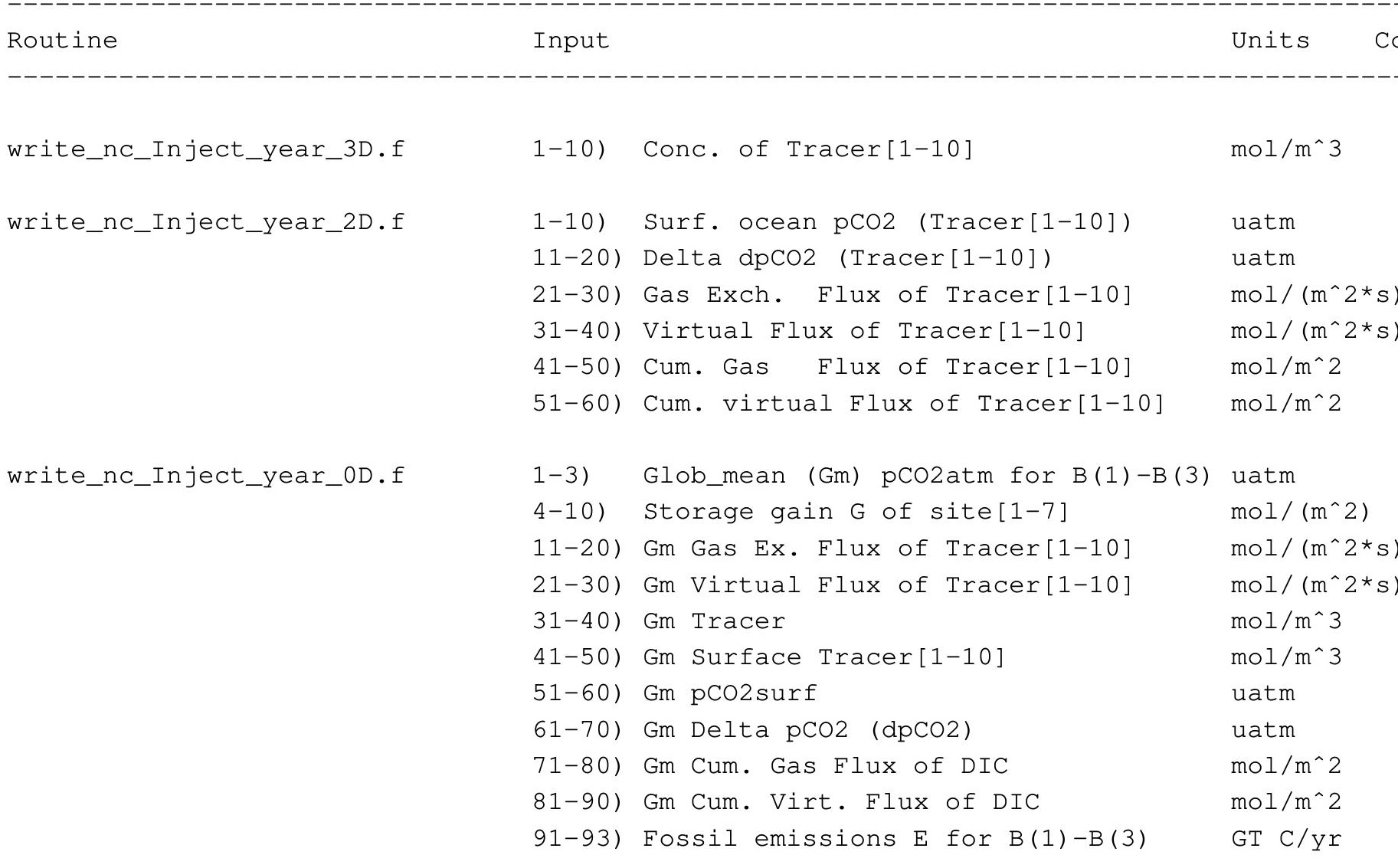

\subsection{Downloading the output routines}

The output routines can be transferred to your machine by clicking on the links below, while holding down the Shift key.

- write_nc_MaskAreaBathy.f (This routine is the same as linked to the CFC HOWTO; thus, there is no need to recuperate it if you have already contributed OCMIP-2 CFC results). 
- write_nc_Inject_year_3D.f

- write_nc_Inject_year_2D.f

- write_nc_Inject_year_0D.f

- write_nc_Inject_TS_year.f

You will also need to transfer the subroutine handle_errors.f to properly deal with errors while you are writing your netCDF files.

\subsection{Compiling the output routines}

Here is a an example of how you would compile one of the output routines:

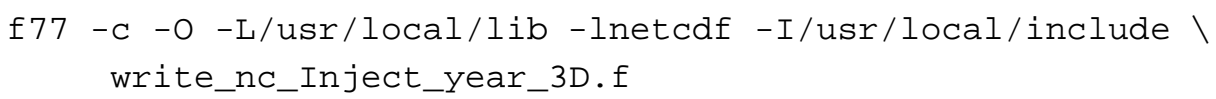

Because we have made these routines F77 compatible, you may need a function len_trim.f (from F90), which we also provide and which returns the length of a character string (after neglecting trailing blanks).

\subsection{Using the output routines}

The Injection-run output routines store your model results following the naming and output conventions (netCDF, GDT version 1.2) chosen for OCMIP-2. The output filename is constructed automatically within each routine from three of the arguments: the tracer name, the year, and the standard model code $<$ http://www.ipsl.jussieu.fr/OCMIP/phase2/\#modgroups $>$ used during OCMIP-2 to identify your group.

For compatibility with the Abiotic simulations, we separately store 3-D, 2-D, and 0-D data. For your 3-D model output for the Injection run, use:

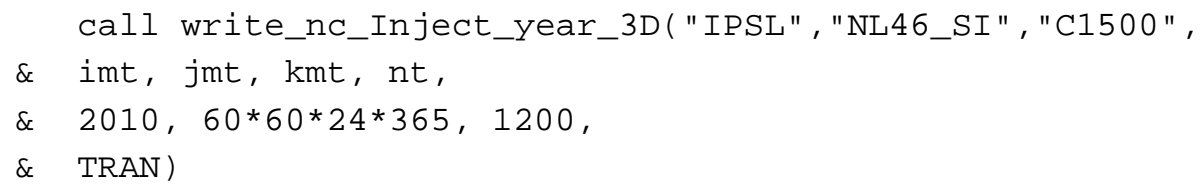

By line, the arguments include

1. the OCMIP-2 model code, your own model version indicator, AND the simulation indicator (C1500, C3000, $\mathrm{C} 800$, or E1500).

2. three spatial dimensions and one temporal dimension $n t$ (here, $n t=1$ for annual means);

3. the year, the number of seconds per year (in your model), and the number of timesteps per year; 
4. the annual mean concentrations of 3-D Tracers $1-10\left[\mathrm{~mol} / \mathrm{m}^{\wedge} 3\right]$.

For your 2-D output, use

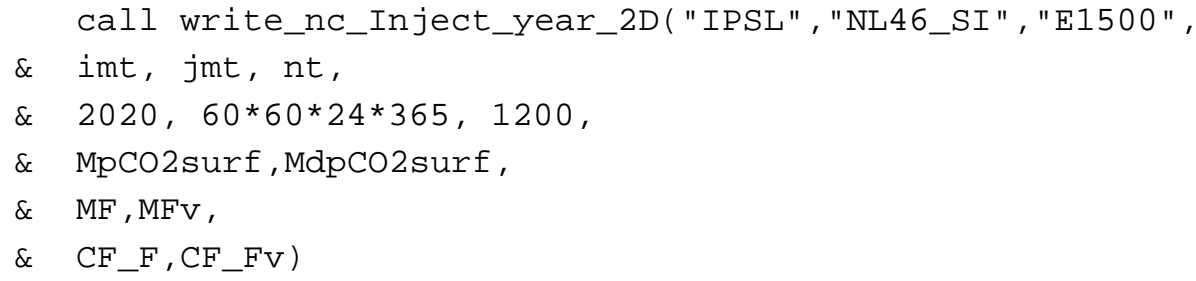

For 2-D output, we no longer need the dimension $k m t$, formerly in line 2. The 2-D Injection output also includes

- line 4: the annual mean surface pCO2 and Delta pCO2 for Tracer[1-10] (uatm);

- line 5: the annual mean 2-D air-to-sea and virtual fluxes of Tracer[1-10] (mol/m^2/s);

- line 6: the end-of-year 2-D cumulative air-to-sea fluxes and cumulative virtual fluxes (mol/m^2);

Cumulative fluxes (line 6 above) must be initialized as outlined in Section 4.1, and integrated with respect to time (i.e., each time step).

When do I call the above 2-D and 3-D Injection output routines? They should be called, with $\mathbf{n t = 1}$, at the end of each of the following years: 2010, 2020, 2040, 2060, 2080, 2099, 2120, 2140, 2160, 2180, 2200, 2300, $2400,2499$.

For 0-D (1-D with time) Injection output, use

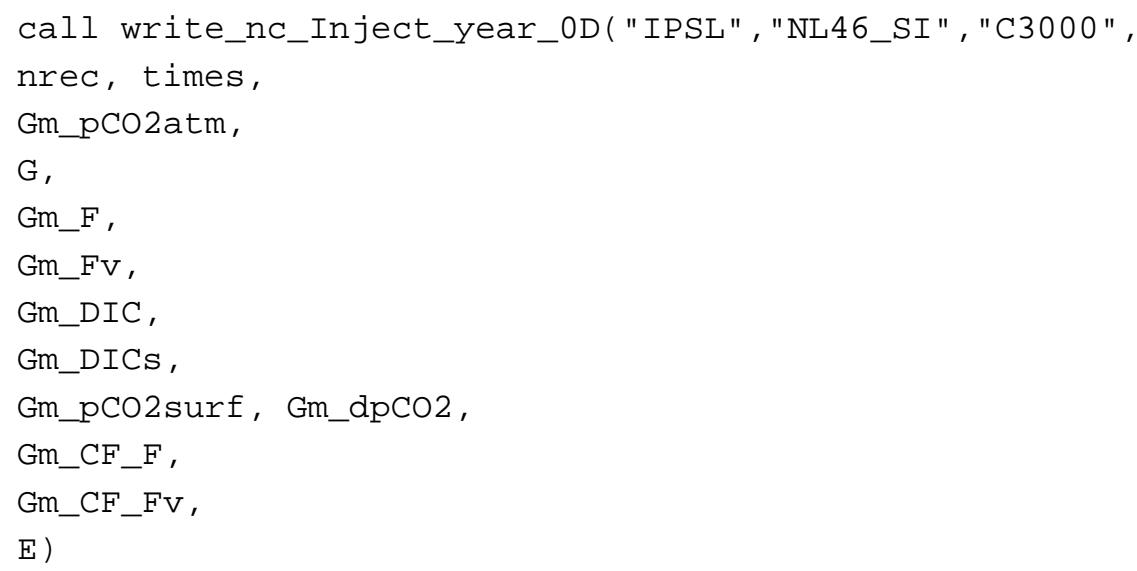

By line, the arguments include

1. the OCMIP-2 model code, your own model version indicator, AND the simulation indicator;

2. the number of records saved and the array of the times (in decimal years) at which they were saved; 
3. the history of the global mean atmospheric pCO2atm for 3 atmospheric boxes $\mathrm{B}(1), \mathrm{B}(2)$, and $\mathrm{B}(3)$ (in uatm). The pCO2atm(i) (i=1,2,3) is specified a priori for the $\mathbf{C}$ runs, but calculated for Run $\mathbf{E 1 5 0 0}$ via equation (6) - see subsection $E$ and $d($ MCO2atm $) / d t$;

4. the history of the Gain $\mathbf{G}$ for each of the seven injection sites ( $\left.\mathrm{mol} / \mathrm{m}^{\wedge} 2\right)$;

5. the history of the global sea-to-air flux $F$ for Tracers $1-10\left(\mathrm{~mol} /\left(\mathrm{m}^{\wedge} 2 * \mathrm{~s}\right)\right)$;

6. the history of the global mean virtual flux $F v$ for Tracers 1-10 (mol/m^2*s, see Abiotic HOWTO);

7. the history of the global mean concentrations of Tracers $1-10\left(\mathrm{~mol} / \mathrm{m}^{\wedge} 3\right)$

8. ;

9. the history of the global mean surface concentration of Tracers $1-10\left(\mathrm{~mol} / \mathrm{m}^{\wedge} 3\right)$;

10. the history of global mean surface ocean $\mathrm{pCO} 2$ (pCO2surf, in uatm), and the global mean sea-air pCO2 difference (dpCO2, in uatm) for Tracers 1-10;

11. the history of the global mean cumulative fluxes $\mathbf{F}$ for Tracers 1-10 (in $\mathrm{mol} / \mathrm{m}^{\wedge} 2$, integrated since 1765.0 ) at the end of each year, with each year indicated by its mid-year time given in line 2; and

12. the history of the global mean fossil fuel emissions $\mathbf{E}$ (in $\mathrm{GtC} / \mathrm{yr}$ ) for each atmospheric box B(1), B(2), and $\mathrm{B}(3)$. $\mathbf{E}(\mathbf{i})(\mathbf{i}=\mathbf{1 , 2 , 3})$ is specified a priori for Run $\mathbf{E 1 5 0 0}$, but it must be calculated for the $\mathbf{C}$ runs via equation (6) - see subsection $E$ and $d($ MCO2atm)/dt.

When do I call the above 0-D output routine? It should be called only once, after constructing 1-D (in time) arrays from all of your model output. The time storage frequency is regular: this routine should be called, using annuals means, for every year during the last 500 years of the run (i.e., all years 2000-2499, inclusive). Thus modelers must use $n r e c=500$, and fill the 1-D temporal array times with the appropriate values (i.e., 2000.5, 2001.5, 2002.5 ..., 2498.5, 2499.5).

All arguments of the Abiotic routines are input; none are output. With the arguments as listed in the nine routines above, the corresponding output netCDF files are

- "IPSL_Inject_C1500_2010_3D.nc",

- "IPSL_Inject_E1500_2020_2D.nc",

- "IPSL_Inject_C3000_global.nc";

These files along with all others produced by the Abiotic routines should be transferred to IPSL by ftp. Filenames should NOT be changed. Subsequently, at IPSL, files will be (1) tested for consistency, (2) included in the OCMIP-2 data base, and (3) processed for base analysis.

\subsection{Need more details?}

See <http://www.ipsl.jussieu.fr/OCMIP/tech>. for additional information about the format netCDF and other conventions (COARDS, GDT) chosen for storing OCMIP-2 model output.

If you have other questions, please contact aumont@1sce.saclay.cea.fr,or orr@cea.fr 


\section{Transfer of output}

The files including 0-D, 2-D, and 3-D fields should first be gzipped:

gzip *.nc

If gzip is not available on your machine, the alternative is to use compress. After compression, you should send your files to LSCE for processing and analysis. Your model output could be quite large depending upon model resolution. Disk space is not a problem - we have plenty to accommodate output from all OCMIP models. However, you should contact us if the ftp transfer rate is inadequate. In that case, you'll need to write your output to tape (DDS, DDS2, Exabyte, or DLT) and mail it to

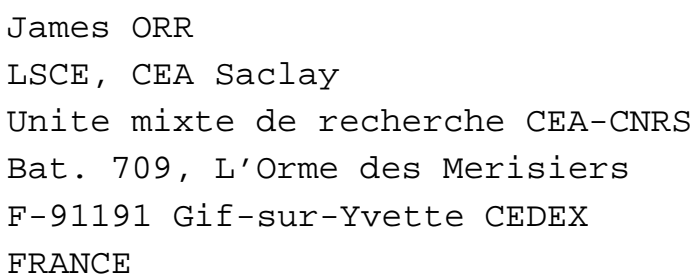

Here are the commands to transfer your output by ftp:

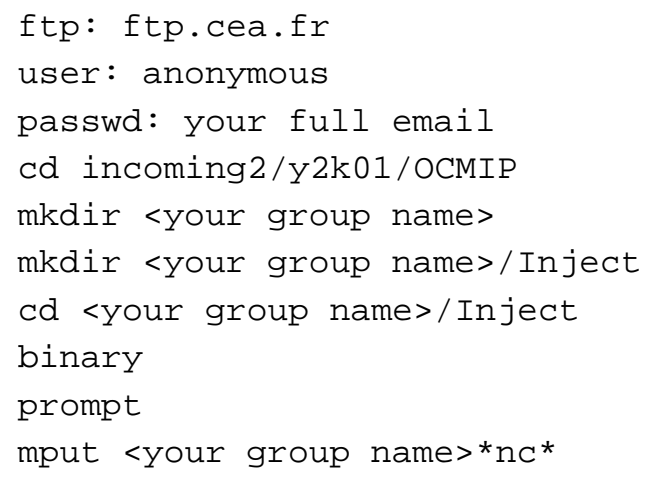

Then e-mail us (aumont@1sce.saclay.cea.fr and orr@cea.fr) that your transfer is complete.

The ftp archive is erased automatically every 8 days, so be sure to contact us as soon as you have completed transfer, and save your output files at least until we have notified you that they have been transferred to the OCMIP- 2 model output archive.

\section{References}

Dewey, R. K., G. R. Stegen, and R. Bacastow. 1996. Far-field environmental impacts associated with ocean disposal of CO2. in Enviromental Impacts of Ocean Disposal of CO2, Vol. 2 Topical Reports (eds. H. J. Herzog and E. E. Adams), MIT Energy Laboratory, MIT-EL 96-003, Cambridge, MA, USA. 
Orr, J. C. and O. Aumont, 1999. Exploring the capacity of the ocean to retain artificially sequestered CO2, in Greenhouse Gas Control Technologies (eds. B. Eliasson, P. Reimer, and A. Wokaun), Elsevier Science Ltd., 281-286.

Marchetti, C., 1977. On geoengineering and the CO2 problem, Clim. Change , 1, 59-68.

Wanninkhof, R., 1992. Relationship between wind speed and gas exchange over the ocean, J. Geophys. Res., 97 , 7373-7382.

\section{Contacts}

orr@cea.fr, brock@1sce.saclay.cea.fr

\section{Same document, another format?}

This document is available in other formats:

- HTML ( <HOWTO-In ject.html>)

- Postscript ( <HOWTO-Inject.ps $>$ )

- ASCII ( <HOWTO-Inject.txt $>$ )

- $\operatorname{LaTeX}(<$ HOWTO-Inject.tex $>$ )

- DVI (<HOWTO-Inject.dvi>) 


\section{Helium HOWTO}

J.-Cl. Dutay, M.-F. Weirig, P. Jean-Baptiste, E. Maier-Reimer, and J. Orr Revision: 1.8, Date: 2001/04/27 11:48:02

This document provides step-by-step guidelines to make a steady-state simulation for mantle Helium-3 and Helium-4 according to the standard OCMIP-2 protocols. This simulation has two boundary conditions: (1) a loss term due to the sea-to-air flux of mantle helium, and (2) a source term due to emission of rich ${ }^{3} \mathrm{He} /{ }^{4} \mathrm{He}$ water along ocean ridges on the seafloor. Globally integrated, the source term amounts to 1000 moles of ${ }^{3} \mathrm{He}$ per year; regionally, sources are partitioned as a function of ridge position, length, and spreading rate).

\section{Contents}

1 Introduction $\quad 3$

2 Recuperation of OCMIP-2 files by ftp: 3

3 Model runs $\quad 4$

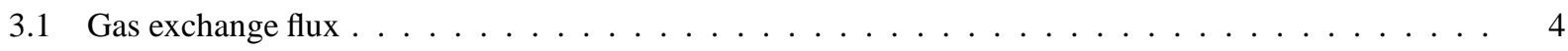

3.2 The Piston Velocity $\mathrm{Kw} \ldots \ldots \ldots \ldots \ldots \ldots$

3.3 Oceanic and Atmospheric Components . . . . . . . . . . . . . . . . . . . . . . 6

3.4 Helium mantle source . . . . . . . . . . . . . . . . . . . . . . . . . . 6

4 Initialization and duration of simulations $\quad 7$

5 Output type and frequency $\quad 7$

6 Output Format $\quad 7$

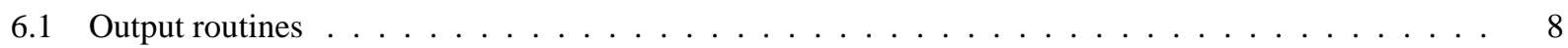

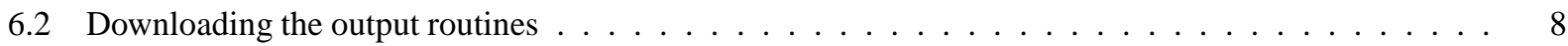

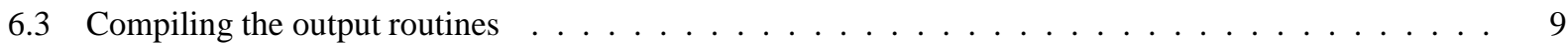

6.4 Using the output routine $\ldots \ldots \ldots \ldots \ldots \ldots \ldots$

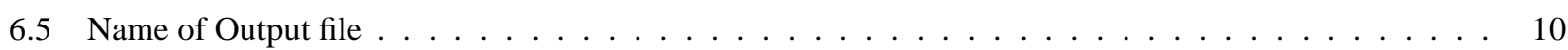

6.6 Need more details? . . . . . . . . . . . . . . . . . . . . . . . . . . . . . . . . . . . . 10

$\begin{array}{lll}7 & \text { Transfer of output } & 10\end{array}$

8 References $\quad 10$

9 Contacts $\quad 11$ 
10 Same document, another format? 


\section{Introduction}

As opposed to natural C-14/C-12 which enters the ocean through the air-sea interface, waters rich in primordial helium (high ${ }^{3} \mathrm{He} /{ }^{4} \mathrm{He}$ ratio) derive from mid-ocean ridges at the ocean floor. This unique boundary condition means that mantle helium can provide independant information concerning patterns of deep-ocean circulation. OCMIP modelers have already made simulations for natural C-14/C-12. Here we descibe protocols to make OCMIP simulations for mantle helium.

Primordial He, which also invades the deep sea from the earth's interior via mid-ocean ridges, has a distinctly different ${ }^{3} \mathrm{He} /{ }^{4} \mathrm{He}$ ratio than does atmospheric helium. Vent waters, along with their ${ }^{3} \mathrm{He} /{ }^{4} \mathrm{He}$ signature, enter the ocean at several hundred degrees centigrade and typically rise a few hundred meters in the water column, before coming to equilibrium and being transported along surfaces of constant density (isopycnals). When it was found that oceanographic circulation patterns deduced from ${ }^{3} \mathrm{He} /{ }^{4} \mathrm{He}$ data (Stommel, 1982) contradicted the simple, yet classic model of deep-ocean circulation (Stommel and Arons, 1960), it became obvious to many that the unique signature of ${ }^{3} \mathrm{He} /{ }^{4} \mathrm{He}$ could help shed light on the mysteries of deep-ocean circulation. Since then, many ${ }^{3} \mathrm{He} /{ }^{4} \mathrm{He}$ samples have been collected throughout the world ocean, largely during the WOCE sampling campaign. One ocean modeling study has been published that has focused on simulating ${ }^{3} \mathrm{He} /{ }^{4} \mathrm{He}$ in the LSG model (Farley et al., 1995). They assumed that the boundary condition for ${ }^{3} \mathrm{He} /{ }^{4} \mathrm{He}$ is proportional to the spreading rate of the mid-ocean ridges. Other groups have also begun making preliminary simulations for ${ }^{3} \mathrm{He} /{ }^{4} \mathrm{He}$.

For this comparison, all 3-D models will make one standard ${ }^{3} \mathrm{He} /{ }^{4} \mathrm{He}$ simulation, to near steady state. Following Farley et al. (1995), primordial ${ }^{3} \mathrm{He}$ and ${ }^{4} \mathrm{He}$ will be added to the ocean at mid-ocean ridges along the sea floor as a function of ridge positions and spreading rates. ${ }^{3} \mathrm{He}$ and ${ }^{4} \mathrm{He}$ will be carried as individual tracers. At the air-sea interface, all ocean models will exchange ${ }^{3} \mathrm{He}$ and ${ }^{4} \mathrm{He}$ with the atmosphere using sea-air flux boundary conditions that are analogous to those developed for $\mathrm{CO} 2$ during the first phase of OCMIP. Intercomparison of model results will focus on the ${ }^{3} \mathrm{He} /{ }^{4} \mathrm{He}$ distribution in the sea and to a lesser extent on helium fluxes from the ocean to atmosphere. Such comparison should provide unique insight, into the performance of each model's deep-ocean circulation, particularly in regard to evaluating the performance of OCMIP purposeful, deep-ocean CO2 injection simulations.

\section{Recuperation of OCMIP-2 files by ftp:}

To comply with OCMIP-2 guidelines, all modelers must make simulations according to OCMIP-2 standard boundary conditions. To do so, one must first recuperate the following files via this Web page (you can save a file to disk by clicking a link while holding down the Shift key).

- rgasx_ocmip $2 . f$

- gasx_ocmip2.nc

- vgasx_ocmip2.jnl

- sc_helium.f

- sol_helium.f

- $s r c \_h e l i u m . f$

- src_helium.nc

Use of these files is described below. 


\section{Model runs}

\subsection{Gas exchange flux}

For simulations of ${ }^{3} \mathrm{He}$ and ${ }^{4} \mathrm{He}$, we will directly model the finite air-sea flux $\mathbf{F}$. In other words, surface helium concentrations will NOT be set equal to temperature-derived equilibrium values determined from the solubility. Instead, modelers must use the formulation for the standard OCMIP-2 air-to-sea flux,

(1a) $\mathbf{F}=\mathbf{K w}$ (Csat - Csurf)

with

(1b) $\mathbf{C s a t}=\alpha * \mathbf{p H e}$

where

- Kw is the gas transfer (piston) velocity $[\mathrm{m} / \mathrm{s}]$;

- Csurf is the modeled surface ocean ${ }^{3} \mathrm{He}\left(\right.$ or $\left.{ }^{4} \mathrm{He}\right)$ concentration $\left[\mathrm{mol} \mathrm{m}^{-3}\right]$;

- $\alpha$ is the ${ }^{3} \mathrm{He}\left(\right.$ or ${ }^{4} \mathrm{He}$ ) solubility for water-vapor saturated air (in $\mathrm{mol} \mathrm{m} \mathrm{atm}^{-1}$ ). For ${ }^{4} \mathrm{He}$, $\alpha\left({ }^{4} \mathrm{He}\right)=\exp \left[\mathrm{A} 1+\mathrm{A} 2 * 100 / \mathrm{T}+\mathrm{A} 3 * \ln (\mathrm{T} / 100)+\mathrm{S} *\left(\mathrm{~B} 1+\mathrm{B} 2 * \mathbf{T} / 100+\mathrm{B} 3 *(\mathrm{~T} / 100){ }^{\wedge}\right)\right] / 22400$,

where $\mathrm{T}$ is the temperature (in Degrees Kelvin), $\mathrm{S}$ is the salinity (on the psu scale), and where the coefficients A1, A2, A3, B1, B2, and B3 are all taken from Wanninkhof (1992, Table A2).

- To check that you have correctly implemented this equation, the ${ }^{4} \mathrm{He}$ solubility should be $0.3299 \mathrm{~mol} /\left(\mathrm{m}^{\wedge} 3\right.$ * atm_He4) at a temperature of $10 \mathrm{C}(283.15 \mathrm{~K})$ and a salinity of 35 . Thus for this same $\mathrm{T}$ and $\mathrm{S}$, Csat would be $1.7288^{*} 10^{\wedge}-6 \mathrm{~mol} / \mathrm{m}^{\wedge} 3$, (from equation 1 (b) and the partial pressure of ${ }^{4} \mathrm{He}$ in the atmosphere, given below).

- The ${ }^{3} \mathrm{He}$ solubility $\left(\alpha\left[{ }^{3} \mathrm{He}\right]\right)$ is equal to ${ }^{4} \mathrm{He}$ solubility multiplied by the isotope fractionation factor $=0.984$ (Weiss, 1970; Top et al., 1987; Fuchs et al., 1987)

- $\mathbf{p H e}$ is the partial pressure of ${ }^{3} \mathrm{He}\left(\right.$ or ${ }^{4} \mathrm{He}$ ) in dry air at one atmosphere total pressure [in atm] Specifically, $\mathrm{p}^{4} \mathrm{He}$ $=5.24 * 10^{\wedge}-6$ and $\mathrm{p}^{3} \mathrm{He}=\mathrm{p}^{4} \mathrm{He}^{*} 1.38 * 10^{\wedge}-6$.

All right hand terms, in equations (1a) and (1b) are different for ${ }^{3} \mathrm{He}$ and ${ }^{4} \mathrm{He}$.

\subsection{The Piston Velocity Kw}

For simulations of ${ }^{3} \mathrm{He}$ and ${ }^{4} \mathrm{He}$, modelers must use the standard OCMIP-2 formulation for the piston velocity Kw. The monthly climatology of $\mathbf{K w}$, to be interpolated linearly in time by each modeling group, is computed with the following equation adapted from Wanninkhof (1992, eq. 3):

(2) $\mathrm{Kw}=(1-$ Fice $)[\mathrm{Xconv} * \mathbf{a} *(\mathbf{u} 2+\mathbf{v})](\mathrm{Sc} / 660) * *-1 / 2$

where

- Fice is the fraction of the sea surface covered with ice, which varies from 0.0 to 1.0 , and is given as monthly averages from the Walsh (1978) and Zwally et al. (1983) climatology (OCMIP-2 modelers must resest Fice values less than 0.2 to zero, after interpolation to their model grid) 
- $\mathbf{u} 2$ is the instantaneous SSMI wind speed, averaged for each month, then squared, and subsequently averaged over the same month of all years to give the monthly climatology. (see the OCMIP-1 README.satdat for further details);

- $\mathbf{v}$ is the variance of the instantaneous SSMI wind speed computed over one month temporal resolution and 2.5 degree spatial resolution, and subsequently averaged over the same month of all years to give the monthly climatology. Again, see the OCMIP-1 README.satdat for further details.

- $\mathbf{a}$ is the coefficient of 0.337 , consistent with a piston velocity in $\mathrm{cm} / \mathrm{hr}$. We adjusted the coefficient $\mathbf{a}$ for OCMIP2, in order to obtain Broecker et al.'s (1986) radiocarbon-calibrated, global CO2 gas exchange of $0.061 \mathrm{~mol} \mathrm{CO} 2$ $/\left(\mathrm{m}^{\wedge} 2 * \mathrm{yr} *\right.$ uatm $)$, when using the satellite SSMI wind information $(\mathbf{u} \mathbf{2}+\mathbf{v})$ from Boutin and Etcheto (pers. comm.). Our computed value for $\mathbf{a}$ is similar to that determined by Wanninkhof $(\mathbf{a}=0.31)$, who used a different wind speed data set and assumptions about wind speed variance; we use the observed variance.

- $\mathbf{X c o n v}=1 / 3.6 \mathrm{e}+05$, is a constant factor to convert the piston velocity from $[\mathrm{cm} / \mathrm{hr}]$ to $[\mathrm{m} / \mathrm{s}]$. This conversion factor is already included in the forcing field $\mathbf{x K w}$, provided below.

- Sc is the Schmidt number which is to be computed using modeled SST, using the formulation for ${ }^{4} \mathrm{He}$ given by Wanninkhof (1992, Table A1), derived from Jähne (1987a). For ${ }^{3} \mathrm{He}$, we reduce the Schmidt number (relative to $\left.{ }^{4} \mathrm{He}\right)$ by $15 \%\left(\mathrm{Sc}^{3} \mathrm{He}=\mathrm{Sc}^{4} \mathrm{He} / 1.15\right)$ based on the ratio of the reduced masses, which is consistent with helium isotopic fractionation measurements from Jähne (1987b). The function sc_helium.f computes the Sc's (unit-less) for both ${ }^{3} \mathrm{He}$ and ${ }^{4} \mathrm{He}$.

Practically speaking, to use equation (2), each group will interpolate the OCMIP-2 standard information to their own model grid. The standard information is provided by IPSL/LSCE as a monthly climatology on the $1 \mathrm{x} 1$ degree grid of Levitus (1982) in netCDF format (in file gasx_ocmip2.nc). Gridded variables in that file include

- the variable Fice,

- the second term, $[\mathbf{X c o n v} * \mathbf{a} *(\mathbf{u} \mathbf{2}+\mathbf{v})]$, denoted as $\mathbf{x K w}[\mathrm{m} / \mathrm{s}]$

- the mask Tmask (1 if ocean; 0 if land),

- the total atmospheric pressure at sea level $\mathbf{P}[\mathrm{atm}]$

- the longitude Lon at the center of each 1 x 1 degree grid box,

- the latitude Lat at the center of each 1 x 1 degree grid box.

For the variables Fice and $\mathbf{x K w}$, continents on the 1 x 1 degree standard grid have been flooded with adjacent ocean values. Such an approach avoids discontinuities at land-sea boundaries during interpolation. See the Fortran program rgasx_ocmip2.f for an example of how to read the 2-D gas exchange fields, written in netCDF format. After compilation, to link and use rgasx_ocmip2.f, one must have already installed netCDF.

<http: //www.unidata.ucar.edu/packages/netcdf/>

The file gasx_ocmip2.nc may also be inspected with software that uses netCDF format, such as ncdump or Ferret. Ferret is used for some of the analysis during OCMIP-2. We encourage OCMIP members to become familiar with Ferret.

<http://ferret.wrc.noaa.gov/Ferret/>

After installation, one can visualize maps of the standard information in gasx_ocmip2.nc, by using the Ferret script vgasx_ocmip2.jnl. 
After launching Ferret, simply issue the following command (at Ferret's "yes?" prompt)

yes? go vgasx_ocmip2.jnl

\subsection{Oceanic and Atmospheric Components}

Apart from Kw, there are two other terms in equation (1a). The ocean component Csurf [in mol/m^3] is computed by the model each timestep; the atmospheric component Csat is constant specified a priori via the three remaining terms:

1. $\alpha$ : The solubility $\alpha$, different for ${ }^{3} \mathrm{He}$ and ${ }^{4} \mathrm{He}$, will be computed using modeled SST and SSS, both of which vary in time at each grid point. For ${ }^{4} \mathrm{He}$ we use the solubility formulation provided by Wanninkhof (1992, Table A2), a temperature-dependant polynomial for He solubility, which was derived from measurements by Weiss (1971).The function sol_he.f determines $\alpha$ for both ${ }^{3} \mathrm{He}$ and ${ }^{4} \mathrm{He}$, but changes the units to [mol/(m^3* atm)] so that model helium concentrations can then be carried in SI units $\left[\mathrm{mol} / \mathrm{m}^{\wedge} 3\right]$.

2. pHe: For these simulations we set the partial pressure of atmospheric ${ }^{4} \mathrm{He}\left(\mathrm{p}^{4} \mathrm{He}\right)$ to $5.24 * 10^{\wedge}-6$ atm, constant in time and space; similarly, $\mathrm{p}^{3} \mathrm{He}=\mathrm{p}^{4} \mathrm{He}^{*} 1.38 * 10^{\wedge}-6 .=7.23 * 10^{\wedge}-12 \mathrm{~atm}$. ?

\subsection{Helium mantle source}

${ }^{3} \mathrm{He}$ is injected at the seafloor along ocean ridges at a global rate of around $1000 \mathrm{~mol} / \mathrm{yr}$ (Clarke et al., 1969; Craig et al., 1975; Jean-Baptiste, 1992; Farley et al., 1995). We hold the ${ }^{3} \mathrm{He} /{ }^{4} \mathrm{He}$ ratio of injected mantle helium to a constant value of 8 x 1.38. x 1.38*10^-6 (Farley et al., 1995). Thus the globally integrated source for ${ }^{4} \mathrm{He}$ is $1000 / 8 / 1.38 \mathrm{E}-6$ (i.e., $90.6 \times 10^{\wedge} 6$ ) $\mathrm{mol} / \mathrm{yr}$. The mass of mantle helium that is injected is partioned geographically as a function of ridge positions, lengths, and spreading rates (Farley et al., 1995).

For consistent simulations, we need to position mantle helium sources as a function of the REAL ocean's ridge positions, spreading rates, and depths. To facilitate making these simulations in any model, we have provided the mass/year of injection helium partitioned, as a SCALAR field, on the same 1 x 1 degree grid as used for the OCMIP-2 boundary condition for air-sea gas exchange. To derive that 1 x 1 degree field, we calculated length of the ridges falling within each grid box and multiplied each length by its corresponding spreading rate (i.e., see program src_helium.f). The injection points, which define the ridge lengths, and corresponding rates are those used by Farley et al. (1995) (MaierReimer, personal communication, 1998). However, that data set does not include known sites in the Western Pacific (Philippe: references?), which we have also included in this study. The complete list of sites and spreading rates is given in sitespread.dat.

To account for the mantle source, each modeling group will need to interpolate our standard 1 x 1 degree grid of helium sources and corresponding ridge depths to their model. Then, groups will need to adjust the vertical position of helium injection point, where necessary

- If the model bathymetry is deeper than the injection point, then NO Vertical adjustment

- If the model bathymetry is equal to or shallower than the injection point, then inject mantle helium into the deepest ocean box in the same water column.

Technical notes:

1. The $1 \times 1$ degree grid of sources and sinks is provided as a netCDF file src_helium.nc. 
2. Variables in that file are

- $z H e$ : the ridge depth already adjusted upward by $300 \mathrm{~m}$ (see following note)

- rateHe3flux: the rate of injection of ${ }^{3} \mathrm{He}(\mathrm{mol} / \mathrm{yr})$

- rateHe4flux: the rate of injection of ${ }^{4} \mathrm{He}(\mathrm{mol} / \mathrm{yr})$

3. Note that our "ridge depths" are already $300 \mathrm{~m}$ shallower than those actually observed, thereby accounting for the typical rise of the warm mantle source waters from the ridge up into the water column. Therefore, modelers should avoid additional coding to account for this effect.

4. Interpolation: When interpolating the mantle source (scalar) information from the $1 \mathrm{x} 1$ degree grid to your grid, please be sure that you conserve mass. Globally, the rate of injection of ${ }^{3} \mathrm{He}$ must be $1000 \mathrm{~mol} / \mathrm{year}$; that for ${ }^{4} \mathrm{He}$ should be around 90.6 x 10^ $6 \mathrm{~mol} / \mathrm{year}$. Groups should scale all local injection rates by a constant to exactly obtain those globally integrated rates.

\section{Initialization and duration of simulations}

- Initialization: Models are to be initialized so that initial concentrations for each grid box are equal to the solubilities of ${ }^{3} \mathrm{He}$ and ${ }^{4} \mathrm{He}$ that are in equilibrium with atmospheric partial pressures of ${ }^{3} \mathrm{He}$ and ${ }^{4} \mathrm{He}$, at the $\mathrm{T}=10^{\circ} \mathrm{C}$ and $\mathrm{S}=34 \%$. Thus initial model concentrations should be

- He-4 = $1.73 \times 10^{\wedge}-6$ molm^3

- He-3 = 2.35 x 10^-12 molm^3

- Duration: The mantle helium simulation should be continued until it reaches at least the following near steadystate criterion: the yearly drift of the globally integrated tracer inventories should be less than $4 \mathrm{~mol} / \mathrm{year}$ for ${ }^{3} \mathrm{He}$, and $1 \times 10^{\wedge} 6 \mathrm{~mol} / \mathrm{year}$ for ${ }^{4} \mathrm{He}$. Of course, this drift should be the same as the source (mantle flux at ridges) minus sink (loss due to the sea-to-air flux) terms. If you find if very difficult to reach this steady-state criterion, you should still submit output but please notify us: dutay@cea.fr AND orr@cea.fr. In this case, please send corresponding information about the drift in your model.

\section{Output type and frequency}

1. Frequency: monthly averages the final year of the simulation

2. Type:

- 3-D Fields: ${ }^{3} \mathrm{He}$ and ${ }^{4} \mathrm{He}$ tracer distributions [mol/m^3]

- 2-D Fields: Monthly mean air-to-sea flux of ${ }^{3} \mathrm{He}$ and ${ }^{4} \mathrm{He}\left[\mathrm{mol} /\left(\mathrm{m}^{\wedge} 2 * \mathrm{~s}\right)\right]$

\section{Output Format}

Each modeling group must provide their output in the standard OCMIP-2 format. Model output that does not follow these formatting conventions cannot be included for analysis during OCMIP-2. Model groups must use the standard routines that we have developed specifically for writing output in standard form for OCMIP-2. 
If this is the first OCMIP-2 simulation you have made, you will need to recuperate the routine write_nc_MaskAreaBathy. $f$ to write out characteristics of your model grid, mask, and bathymetry using the standard OCMIP-2 format. Use of this routine is detailed in the CFC HOWTO (section 5.1).

Otherwise if you have submitted OCMIP-2 model output previously, you will only need to resubmit the output file produced by write_nc_MaskAreaBathy.f under two conditions:

1. If your model's grid, mask, or bathymetry have changed; or

2. If you have been notified by the OCMIP-2 analysis center at IPSL that your output file from this subroutine did not pass the routine integrity tests.

\subsection{Output routines}

Each modeling group must use the output routine listed in the table below to store results in standard OCMIP-2 format for the 5 (Helium Output).

Input to this routine is simply your model's output for the concentrations and air-sea fluxes both tracers $\left({ }^{3} \mathrm{He}\right.$ and $\left.{ }^{4} \mathrm{He}\right)$. All groups will need to call the 1st output routine write_nc_Helium. f, but ONLY once, at the end of 4 (model spin-up). You may be able to skip calling the 2nd routine write_nc_Helium_TS.f (see 2nd footnote).

\begin{tabular}{|c|c|c|c|}
\hline Routine & Input & Units & Comments \\
\hline \multirow[t]{4}{*}{ write_nc_Helium.f } & Conc. of $\mathrm{He}-3$ & $\mathrm{~mol} / \mathrm{m}^{\wedge} 3$ & $(*)$ \\
\hline & Conc. of $\mathrm{He}-4$ & $\mathrm{~mol} / \mathrm{m}^{\wedge} 3$ & $(*)$ \\
\hline & Mean Flux of $\mathrm{He}-3$ & $\operatorname{mol} /\left(m^{\wedge} 2 * s\right)$ & $(*)$ \\
\hline & Mean Flux of $\mathrm{He}-4$ & $\mathrm{~mol} /\left(\mathrm{m}^{\wedge} 2 * \mathrm{~s}\right)$ & $(*)$ \\
\hline write_nc_Helium_TS.f & $\begin{array}{l}\text { Potential temperature } \\
\text { Salinity }\end{array}$ & $\begin{array}{c}\text { degrees } C \\
\text { psu }\end{array}$ & $(*)(+)$ \\
\hline
\end{tabular}

(*) This is an equilibrium run: All 2- and 3-D fields should be averaged for each month over the last year of the simulation.

(+) You only need to submit this output file if the year from the corresponding "dynamic" output differs from that from your Abiotic or Biotic runs. If the year is identical (same $T$ and $S$ fields), simply copy the Abiotic or Biotic output file, and rename it (e.g., changing "MODEL_Abiotic_TS_1765.nc" -> "MODEL_Helium_TS.nc").

\subsection{Downloading the output routines}

The output routines write_nc_Helium.f and write_nc_Helium_TS.f can be transferred to your machine by clicking on their link while holding down the Shift key. 
You will also need to transfer the subroutine handle_errors.f to properly deal with errors while you are writing your netCDF files.

\subsection{Compiling the output routines}

Here is a an example of how you would compile the output routine with the necessary link to the netCDF library:

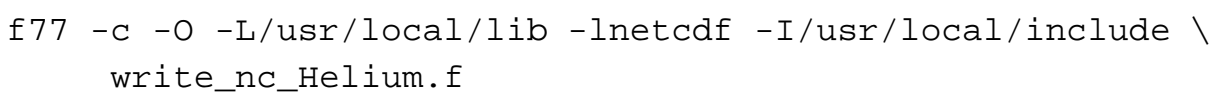

Because we have made this routine F77 compatible, you may need a function len_trim.f (from Fortran 90), which we also provide and which returns the length of a character string (after neglecting trailing blanks).

\subsection{Using the output routine}

The output routine write out your model results following the naming and output conventions (netCDF, COARDS, GDT) chosen for OCMIP-2. The output filename is constructed automatically the ouput routine from three of the arguments: the tracer name and the standard model code <http: //www. ipsl. jussieu.fr/OCMIP/phase2/ $\backslash$ \#modgroups $>$ used during OCMIP-2 to identify your group.

For example, after compiling and linking the OCMIP-2 output routine, we add the following code to the IPSL routines to store output in standard OCMIP-2 form

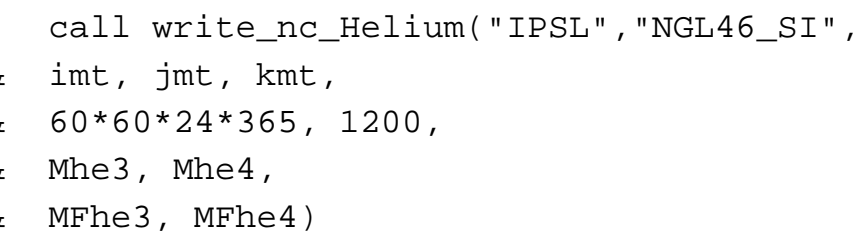

By line, the arguments include

1. the OCMIP-2 model code AND your own model version indicator (in GDT 1.2 terminology, these 2 variables refer to the institution and production, respectively);

2. dimensions;

3. the number of seconds per year (in your model), and the number of timesteps per year;

4. the 12 monthly means for the 3-D tracer arrays for ${ }^{3} \mathrm{He}$ and ${ }^{4} \mathrm{He}$ (both in $\mathrm{mol} / \mathrm{m}^{\wedge} 3$ ); and

5. the 12 monthly means for the 2-D air-sea flux for ${ }^{3} \mathrm{He}$ and ${ }^{4} \mathrm{He}$ (both in $\mathrm{mol} /\left(\mathrm{m}^{\wedge} 2^{*} \mathrm{~s}\right)$ ).

When do I call the above Equilibrium output routine? It should be called only once, at the end of the simulation after building monthly arrays (12 members) for both of the 2-D and 3-D spatial fields given as arguments. 


\subsection{Name of Output file}

All arguments of the Helium output routine are input; none are output. Using the arguments given above, the model output file (netCDF) would be ("IPSL_Helium.nc"), which contains the information for analyzing the IPSL results for 1985. This file should be 7 (transferred to IPSL). The filename should NOT be changed. At IPSL, files will subsequently be (1) tested for consistency, (2) included in the OCMIP-2 data base, and (3) processed for base analysis.

\subsection{Need more details?}

See <http://www.ipsl.jussieu.fr/OCMIP/tech>. for additional information about the format netCDF and other conventions (COARDS, GDT) chosen for storing OCMIP-2 model output.

If you have other questions, please contact orr@cea.fr or Patrick.Brockmann@ipsl.jussieu.fr.

\section{Transfer of output}

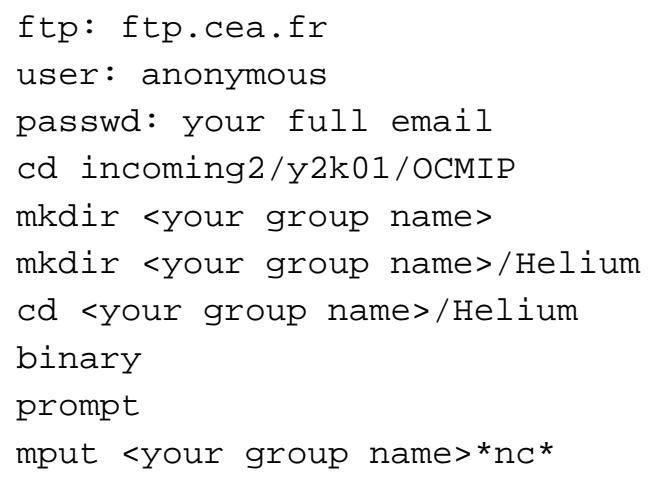

\section{References}

Broecker, W.S., J. R. Ledwell, T. Takahashi, R. Weiss, L. Merlivat, L. Memery, T.-H. Peng, B. Jahne, and K. O. Munnich, 1986. Isotopic versus micrometeorlogic ocean CO2 fluxes, J. Geophys. Res., 91, 10517-10527.

Clarke W.B., M.A. Beg and H. Craig (1969). Excess 3He in the sea: evidence for terrestrial primordial helium. Earth Planet. Sci. Lett., 6, 213-220.

Craig H., W.B. Clark and M.A. Beg (1975). Excess 3He in deep water on the east Pacific Rise. Earth Planet. Sci. Lett., 26, 125-132.

Fuchs G., W. Roether and P. Schlosser (1987). Excess 3He in the ocean surface layer. J. Geophys. Res., 92, 6559-6568.

Jean-Baptiste P. (1992). Helium-3 distribution in the deep world ocean, in "Isotopes of noble gases as tracers in environmental studies", IAEA Panel Proceedings Series, Vienna STI/PB/859, 219-240.

Top Z., W.C. Eismont and W.B. Clarke (1987). Helium isotope effect and solubility of helium and neon in distilled water and seawater. Deep-Sea Res., 34(7), 1139-1148.

Farley, K.A., E. Maier-Reimer, P. Schlosser, and W. S. Broecker, 1995. Constraints on mantle He-3 fluxes and deep-sea circulation from an ocean general circulation model, J. Geophys. Res., 100, 3829-3839. 
Jähne, B., K. O Münnich, R. Bösinger, A. Dutzi, W. Huber, and P. Libner\}, 1987a. On the Parameters Influencing Air-Water Gas Exchange, J. Geophys. Res., 92, 1937-1949.

Jähne, B., G. Heinz, W. Dietrich, 1987b. Measurement of the diffusion coefficients of sparingly soluble gases in water, J. Geophys. Res., 92, 10767-10776.

Levitus, S., 1982. Climatological atlas of the World Ocean, NOAA Prof. Pap. 13, U.S. GPO., Washington, D.C., 173 pp.

Stommel, H., 1982. Is the South Pacific helium3 plume dynamically active? Earth and Planet. Science Lett. , 61, $63-67$.

Stommel, H. and A. B. Arons, 1960. On the abyssal circulation of the world ocean-II. An idealized model of the circulation pattern and amplitude in oceanic basins, Deep-Sea Res., 6, 140-154.

Walsh, J. 1978. A data set on northern hemisphere sea ice extent, 1953-1976. Glaciological Data, World Data Center for Glaciology (Snow and Ice), Report GD-2, 49-51.

Wanninkhof, R., 1992. Relationship between wind speed and gas exchange over the ocean, J. Geophys. Res., 97, 7373-7382.

Weiss, R. F., 1971. Solubility of helium and neon in water and seawater, J. Chem. Eng. Data, 16, 235-241, 1971.

Weiss R.F. ,1971. Helium isotope effect in solution in water and seawater. Science, 168, 247-248.

Zwally, H. J., J. Comiso, C. Parkinson, W. Campbell, F. Carsey, and P. Gloerson, 1983. Antarctic Sea Ice, 1973-1976:

Satellite Passive Microwave Observations, NASA, 206 pp.

\section{Contacts}

dutay@lsce.saclay.cea.frorr@cea.fr,brock@lsce.saclay.cea.fr,

\section{Same document, another format?}

This document is available in other formats:

- $\operatorname{HTML}(<$ HOWTO-Helium.html>)

- $\operatorname{PDF}(<\mathrm{HOWTO}-\mathrm{Helium} \cdot \mathrm{pdf}>$ )

- Postscript ( <HOWTO-Helium.ps>)

- ASCII ( <HOWTO-Helium.txt >)

- $\operatorname{LaTeX}(<$ HOWTO-Helium.tex $>$ )

- DVI ( <HOWTO-Helium.dvi>) 